\title{
Revision of Aploparaksis Clerc, 1903 (Cestoda: Cyclophyllidea, Aploparaksidae), with keys to the species of the genus
}

\section{Svetlana Bondarenko*,}

\section{Vytautas Kontrimavichus}

Institute of Ecology,

Nature Research Centre,

Akademijos 2, Vilnius 08412,

Lithuania
This article reviews the primary results of a taxonomic revision of species of the genus Aploparaksis Clerc, 1903 (Cestoda: Cyclophyllidea: Aploparaksidae), which are widespread parasites of birds. We consolidate a deep, primarily Russian, literature that has not been easily accessible, including insights from the recent monograph of Bondarenko \& Kontrimavichus (2006a). A revision of Aploparaksis has been based on an extensive review of the literature and on the study of diverse specimens from the Palearctic (Lithuania, European and Asian parts of Russia) and the Nearctic (Alaska) regions assembled from our field collections. We also conducted the re-examination of type and voucher specimens from various museums and institutions in Russia, Europe, and the USA, and material from the personal collections of several scientists. Taxonomic conclusions in the revision combine observations of morphological characters for adults and data regarding metacestode ontogeny and life cycles of 36 species of Aploparaksis. The validity of 58 species of Aploparaksis among the 102 described is confirmed. Summaries for each valid species include: taxonomic synonyms, a range of both definitive and intermediate hosts (if known), site within the hosts, geographical distributions, morphological modifications of the cysticercoid, and a short specific diagnosis with illustrations of the principal characteristics. Collection numbers of specimens deposited in museums are provided for each species. Within the genus, two phylogenetic lineages differing in the topography of female gonads have been recognized: the nominotypical subgenus Aploparaksis (Aploparaksis) Clerc, 1903, with the female gonads arranged along the longitudinal axis of the proglottid, and Aploparaksis (Tanureria) Spassky et Yurpalova, 1968, with the female gonads disposed in a transverse row in the median field of the proglottid. Diagnoses of subgenera and identification keys to their species are presented. A list of invalid species with brief comments regarding each of them is also given. The taxonomic value of ontogenetic features and complex issues concerning the definition of Aploparaksis are discussed.

Keywords: Aploparaksis (Aploparaksis), Aploparaksis (Tanureria), synonyms, diagnosis, definitive host, intermediate host, modification of metacestode 


\section{INTRODUCTION}

Cestodes of the genus Aploparaksis Clerc, 1903 are the dominant group of cestodes occurring in Charadriiformes (shorebirds and gulls) and comprise a common but not numerous group of species among other avian orders including Galliformes, Anseriformes, and Passeriformes. The greatest species diversity has been observed in charadriiform birds of the northern regions of the Palearctic. The taxonomic history of the genus is over 230 years old, dating back to when the species Taenia filum Goeze, 1782 (=A. filum) was described by Goeze (1782) based on an aggregation of approximately 200 specimens from a single woodcock Scolopax rusticola Linnaeus. Goeze's material has not survived and his brief original description contained only data on external morphology of the cestodes and provided no information concerning internal anatomy including the disposition of the male and female systems. However, the figure depicted a scolex with five aploparaksoid rostellar hooks on its visible surface that gave reason to believe that the total number of hooks could be ten. Building on this original observation, studies by Bondarenko $(1989,1990 a, b)$ revealed that one woodcock can be simultaneously parasitized by up to five Aploparaksis species. Consequently, we consider that there is every reason to believe the original description of T. filum could be a composite based on several discrete species.

Clerc (1902) was the first to propose allocation of hymenolepidids, which have a single testis, within the genus Monorchis Clerc, 1902, and chose T. filum as the type species of this genus. Since this was a nomen preocupatum, Clerc (1903) substituted this name for Aploparaksis. Neslobinsky (1911) changed the spelling of Aploparaksis to Haploparaksis and although the ICZN permits grammatical corrections, this proposal was not generally acknowledged. For some time, both names co-existed in the literature, but recently the name Aploparaksis has become broadly accepted. The number of species described within this genus has been steadily increasing. Significant contributions to the morphology and taxonomy of Aploparaksis were made by Spassky (1963) and preliminary results of these investigations were outlined in short reviews (Spassky and Frese, 1958, 1961). Prior to these proposals, restricted morphological features, e.g., the length or sometimes the shape of rostellar hooks, the size of the cirrus sac and, in rare cases, the length of the cirrus were used for species identification. These characters, however, overlap in many species and therefore posed obstacles for unequivocal determination. Spassky (1963) specified the range of reliable morphological criteria applicable at the species level of Aploparaksis. Besides criteria outlined previously, such characters as the morphology of rostellar hooks, topography and morphology of reproductive organs, and the shape - and especially armament of the cirrus - were proposed. Among the 55 nominal species of Aploparaksis that were known at that time, 28 were considered by Spassky as representatives of the genus. Inclusion of five new taxa described in shorebirds from Kamchatka at that time brought the total number of valid species recognized by Spassky to 34. With the inclusion of new data in the 1960s and the 1970s, the list of Aploparaksis expanded rapidly, and, according to Schmidt, (1986) contained 75 species in avian hosts.

Unequivocal identification of species within the genus Aploparaksis is notably difficult and a revision and revaluation of the species has been badly needed. The results of our longterm investigations of aploparaksid cestodes have now made it possible to complete a comprehensive taxonomic revision of the genus. This revision was based on a review of the literature and insights gained from our own field collections of birds and tapeworms from the Palearctic (Lithuania, European and Asian regions of Russia) and the Nearctic (Alaska) regions. When possible, we re-examined type and voucher specimens of species held in various museums and institutions in Russia, Europe, and the USA, and material from personal collections of several scientists. In addition to the data based on adult strobilate tapeworms, knowledge of the ontogeny of metacestodes and life cycles of Aploparaksis gained from field and experimental observations were applied for 
the revision. The latter had ascertained that oligochaetes are the exclusive intermediate hosts for all species of Aploparaksis that have been studied. Further, the patterns of metacestode development and the morphology of the mature cysticercoids indicated the presence of six morphological modifications that differ in some details.

The aim of the present paper is to briefly review and set out the main results of the taxonomic revision of Aploparaksis, and to address some aspects of the phylogenetic relationships within the family Aploparaksidae. We consolidate a considerable Russian literature which is vital in understanding the taxonomy and history of these tapeworms across the Holarctic region, including insights from the monograph by Bondarenko and Kontrimavichus (2006a) published by Nauka, Moscow.

\section{MATERIALS AND METHODS}

The current revision was based on an investigation of the fauna, morphology, and life cycles of aploparaksid cestodes from 1963 to 2006. The study includes: (1) original materials collected from the Palearctic (Chukotka, Kolyma, the Taimyr Peninsula, the lower reaches of the Yenisey and $\mathrm{Ob}$ ' rivers, Karelia, Lithuania) and the Nearctic (Alaska); (2) re-examination of type and voucher specimens from the parasitological collections of various institutions in Russia, Moldova, and Ukraine, and from the major museums of Western Europe and North America; (3) material and whole-mounted slides from the personal collections of several scientists (Professor Mariya M. Belopolskaya, Dr. Nikolay I. Demshin, Dr. Thomas Davies, Dr. Valentina G. Kulachkova, Mr. Stanislav A. Leonov, and Dr. Aleksandr A. Schigin). In the Palearctic, we and our colleagues from the Institute of Biological Problems of the North, Russian Academy of Science (Magadan), collected and examined tapeworms from more than 2000 birds of the orders Charadriiformes, Anseriformes, Galliformes and Passeriformes. In Alaska, we collected cestodes of 41 birds at Old Chevak on the delta of the Kuskokwim River during 1976. Additional specimens of Aploparaksis, representing 49 samples of shorebirds from other localities across Alaska, were collected and provided by Professor Robert L. Rausch. Slide-mounted specimens from collections conducted by Schmidt and Neiland (1968) in shorebirds from Bristol Bay were generously provided for our re-examination by Dr. Kenneth Neiland. In addition, the data and our investigations of ontogeny and life cycles of 36 species of Aploparaksis studied under natural and experimental conditions were used in this revision.

The re-investigation of collections revealed numerous inaccuracies in original descriptions and later redescriptions, and also mistaken identifications that are now corrected in this article. The papers in which identification errors have been found are indicated herein (designated as unconfirmed records). Unfortunately, a complete resolution of some prior and inaccurate reports lies beyond the scope of the current revision. Due to a great abundance of apparent mistakes discovered in the published literature, we were unable to use some of works because we had no opportunity to directly study the specimens attributed to other authors. Consequently, the data concerning host associations of tapeworms and their sites within the intestine are specified only in those cases when we were able to verify the accuracy of published records. Further, explanations outlining the evidence for each of the identifications considered to be in error have not generally been included due to the volume of information involved. As a compromise, we provide the published references in the "Remarks" section, in which these explanations are reported in detail. Most Aploparaksis species are parasites of the small intestines, but the site within the definitive host specified in the text is, in rare instances, another anatomical site.

Techniques for the study of strobilate tapeworms and life cycles were described previously (e.g., Bondarenko and Kontrimavichus 1999, 2005). Additionally, we note that, in order to avoid deformation in the shape of the cirrus in unfixed proglottids mounted in polyvinyl alcohol or resin, we usually propped the corners of the coverslip with small pieces of cover glass. Although 
descriptions of the cirrus are consistent with generally accepted nomenclature, we also used the term "foliaceous" where the cirrus strongly resembles a leaf of a plant (a distinctly narrow "leafstalk" at the base and a broad "lamina" gradually narrowing to the apex; i.e., in A. filum).

The validity of 58 of the 102 nominal Aploparaksis species described in this genus is confirmed. Within the genus, two phylogenetic lineages have been supported: the nominotypical subgenus Aploparaksis (Aploparaksis) Clerc, 1903, and Aploparaksis (Tanureria) Spassky \& Yurpalova, 1968. Diagnoses of both subgenera and identification keys to their species are presented. The keys to the valid species of subgenus Aploparaksis are given separately for 43 species that are parasitic in Charadriiformes (shorebirds and gulls) and for seven species that are parasitic in Anseriformes (ducks) because these cestodes are very specific to these hosts. For each valid species we include: (1) a list of synonyms, (2) definitive and intermediate hosts (if known); (3) data on the site of infection within the hosts; (4) structure and modification of the cysticercoids, and (5) geographical distribution. We determined the minimum number of characters we believe to be necessary for species differentiation. This set included the description of the following characters: shape, total length and length of the constituents of rostellar hooks; size of cirrus sac; shape, total length, structure and armament of the cirrus; method of the extraction of eggs from the uterus; the morphology of the embryophore and the length of embryonic hooks. All figures are attributed to the monograph of Bondarenko and Kontrimavichus (2006).

The measurements are given in micrometres, unless otherwise stated. For each morphological character, both minimum and maximum dimensions observed in all studied specimens are indicated. The overwhelming majority of the species diagnoses are provided with original illustrations of the hook, cirrus, and egg or embryophore. Where established, identification errors in the published literature are clarified. Collection numbers of specimens deposited in museums are also given. Abbreviations: BMNH - Natu- ral History Museum, London; CPAR - Centre of Parasitology of the A. N. Severtsov Institute of Ecology and Evolution of the Russian Academy of Sciences, Moscow; HWML - Harold W. Manter Laboratory, University of Nebraska, Lincoln; IZU - Institute of Zoology of the National Academy of Sciences of Ukraine, Kiev; MHNG - Natural History Museum of Geneva; USNPC - United States National Parasite Collection, Beltsville, Maryland (now US Museum of Natural History, Smithsonian Institution); ZIN - Zoological Institute of the Russian Academy of Sciences, St. Petersburg.

The specimens Aploparaksis from the personal collection of Professor Robert L. Rausch and Virginia R. Rausch from North America, as well as those collected by us from shorebirds in Cooper Bay (Alaska) are presently stored at S. Bondarenko' collection. Ultimate disposition for these materials will be in the Parasitology Division, Museum of Southwestern Biology (MSB) University of New Mexico; holdings of the Robert and Virginia Rausch Helminthological Collections have been consolidated at the MSB.

\section{RESULTS}

\section{Genus Aploparaksis Clerc, 1903}

Syns: Monorchis Clerc, 1902, nec Monorchis Monticelli (Trematoda, Monorchidae); Haploporaksis Neslobinsky, 1911; Skorikowia Linstow, 1905; Linstowius Yamaguti, 1959; Globarilepis Bondarenko, 1966.

Diagnosis. Aploparaksidae Mayhew, 1925 (Cyclophyllidea). Strobila of moderate or large size, proglottids numerous. Suckers unarmed. Rostellum with single crown of 10 hooks. Hooks aploparaksoid or close to aploparaksoid with well-developed or reduced handle. Scolex attached by common or rarely permanent mode, as a result of formation of a calciferous capsule surrounding the holdfast. Genital pores dextral. Genital ducts situated dorsal to osmoregulatory canals. Osmoregulatory canals two pairs; transverse anastomoses irregular or absent. Inner longitudinal musclulature consists of numerous (up to 18) bundles (dorsal and ventral). Testis one, rarely appears as $2-3$ small primordia close 
together, which later unite to become a single, or rarely persists as a lobate structure in the mature proglottid; position relative to midline variable. Muscular cirrus sac of variable extent relative to osmoregulatory canals. External and internal seminal vesicles present. Cirrus of varying shape, armed. Position of female gonads variable: both ovarium and vitellarium arranged along the longitudinal axis of the proglottid, vitellarium under and ventral to the ovarium or disposed in transverse row in the median field of the proglottid, vitellarium antiporal to ovarium and ventral to testis. Ovary knobbed or lobate. Vitellarium compact, rounded, or slightly lobate. Seminal receptacle rounded or retort-shaped. Vagina tubular, rarely with sphincter between copulatory and conductive parts. Uterus sacciform. Eggs numerous, single or enclosed in packets containing different numbers of eggs. Embryophore varies in shape, with or without polar swellings. Oncosphere oriented perpendicular to the longitudinal axis of the embryophore or, rarely, along it. Embryonic hooks nearly equal length and shape. Diploid set of chromosomes $2 \mathrm{n}=12$. Parasitic in birds (mostly in Charadriiformes and Anseriformes, rarely in Galliformes and Passeriformes); intermediate hosts Annelida. Metacestode allocated to cysticercoid type, polymorphic.

Type species: A. filum (Goeze, 1782) Clerc, 1903.

Two subgenera: nominotypical Aploparaksis (Aploparaksis) Clerc, 1903 and Aploparaksis (Tanureria) Spassky et Yurpalova, 1968.

Key to the subgenera of genus Aploparaksis.

1a. Female gonads arranged along the longitudinal axis of proglottid, vittelarium under and ventral to the ovarium. Testis median or slightly antiporal (Fig. 3)... Aploparaksis (Aploparaksis)

1b. Female gonads disposed in a transverse row in median fields of proglottid, vittelarium antiporal or diagonal to ovarium and ventral to testis. Testis consistently antiporal (Fig. 159) Aploparaksis (Tanureria).

Keys to the species of subgenus Aploparaksis are presented separately for parasites of Charadriiformes and Anseriformes. Separation of keys relative to host higher taxonomy is consistent with considerable specificity demonstrated among these cestodes and their respective avian hosts and may facilitate identification.

\section{Subgenus Aploparaksis (Aploparaksis) Clerc, 1903}

Diagnosis. Aploparaksidae Mayhew, 1925 (Cyclophyllidea). Strobila of moderate or large size, proglottids numerous. Suckers unarmed. Rostellum with single crown of 10 hooks. Hooks aploparaksoid or close to aploparaksoid with well-developed or reduced handle. Scolex attached by common or rarely permanent mode, as a result of formation of a calciferous capsule surrounding the holdfast. Genital pores dextral. Genital ducts situated dorsal to osmoregulatory canals. Osmoregulatory canals two pairs; transverse anastomoses irregular or absent. Inner longitudinal muscle consists of numerous (up to 18) bundles (dorsal and ventral). Testis one, rarely appears as $2-3$ small primordia close together, which later unite to become a single, or rarely persists as a lobate structure in the mature proglottids; position relative to midline variable. Muscular cirrus sac of variable extent relative to osmoregulatory canals. External and internal seminal vesicles present. Cirrus of variable shape, armed. Female gonads arranged along the longitudinal axis of the proglottis, vitellarium under and ventral to the ovarium. Ovary knobbed or lobate. Vitellarium compact, rounded or slightly lobate. Seminal receptacle rounded or retort-shaped. Vagina tubular, rarely with sphincter between copulatory and conductive parts. Uterus sacciform. Eggs numerous, single or enclosed in packets containing different numbers of eggs. Embryophore varies in shape with or without polar swellings. Oncosphere oriented perpendicular to the longitudinal axis of the embryophore or, rarely, along it. Embryonic hooks nearly equal length and shape. Diploid set of chromosomes $2 \mathrm{n}=12$. Parasitic in birds (mostly in Charadriiformes and Anseriformes, rarely in Galliformes and Passeriformes); intermediate hosts Annelida. Metacestode allocated to cysticercoid type, polymorphic.

Type species: A. filum (Goeze, 1782) Clerc, 1903. 
Key to the species of Aploparaksis (Aploparaksis) parasitizing shorebirds and gulls (Charadriiformes)

Species with a cigar-shaped cirrus, embryophore without polar swellings, parasites of Scolopacinae (e.g., Figs. 37, 100)

1a. Scolex of adult attached permanently: hypertrophic, surrounded by calciferous capsule; hooks reduced, suckers positioned toward base of scolex. Scolex of immature the same size as that of metacestode, rostellar hooks 41-45 in length. Cirrus 70-82 × 25-29, evenly covered with small spines (Figs. 99, 100)... A. penetrans Clerc, 1903

$1 b$. Scolex of the usual shape and mode of attachment 2

2a. Cirrus $63-98 \times 14-18$, evenly covered with equal, miniscule spines (Fig. 37). Rostellar hooks 33-39 in length... A. crassirostris (Krabbe, 1869)

2b. Cirrus $62-90 \times 12-14$, basally covered with larger spines; spination sparse distally (Fig. 84). Rostellar hooks 29-34 in length... A. orientalis Spassky et Bobova, 1961

Species with a broad, irregular, foliaceous cirrus, embryophore with polar swellings, parasites of Scolopacinae (e.g. Figs. 4, 13, 106)

1a. "Leafstalk" and "lamina" of cirrus sharply defined (Figure 4). Total length of cirrus 110-135, maximal width $27-30$, "leafstalk" $21-25 \times 8-10$, only basal region covered with small spines arranged in several rows. Rostellar hooks 17-22 in length. Surface of embryophore smooth or tuberous in the middle part... A. filum (Goeze, 1782)

1b. "Leafstalk" of cirrus feebly marked... 2

2a. Cirrus 197-224 × 24-37; base of proximal part covered with fine, nearly uniform spines (Fig. 94). Rostellar hooks 22-25 in length... A. parafilum Gasowska, 1931

2b. Cirrus considerably shorter... 3

3a. Cirrus 27-42 × 12-16. Rostellar hooks 18-21 in length. Oncosphere oriented longitudinally in embryophore, embryonic hooks on one pole (Fig. 14). Surface of embryophore tuberous... A. australis Johnston, 1913

$3 b$. Oncosphere oriented ordinary (transversally) in embryophore. Surface of embryophore smooth... 4 4a. Rostellar hooks 16-18 in length. Cirrus 47-63 × 13-15 (Fig. 123)... A. sanjuanensis Tubangui et Masilungan, 1937

4b. Rostellar hooks 22-25 in length. Cirrus 33-61 × 11-29 (Fig. 107)... A. pseudofilum (Clerc, 1902)

Species with a cylindrical to conical cirrus, embryophore without polar swelling, parasite of shorebirds and gulls (e.g., Figs. 52, 64, 109)

1a. Cirrus short, 25-29 $\times 4-6$, distal part covered with spines (Fig. 74). Rostellar hooks 13-17 in length. Eggs in numerous, small packets. Parasite of Scolopacinae... A. microcirrus (Bondarenko, 1966)

1b. Cirrus longer, length of rostellar hooks not exceed 25, eggs single... 2

2a. Cirrus 55-61 long with maximum width in base 8-16, in distal part 6.5; sometimes with slight constriction in the middle part, covered with spines in proximal half (Fig. 64). Rostellar hooks 18-23 in length. Embryophore thick, about 2. Parasite of Calidritinae, rarely other shorebirds... A. leonovi Spassky, 1961

2b. Cirrus longer and wider... 3

3a. Cirrus 82-89 $\times 17-24.6$ without slight constriction in middle part, covered with spines in middle and distal parts (Fig. 87). Rostellar hooks 20-24 in length. Embryophore thin, notably thinner than 2. Parasite of Tringa, rarely of Philomachus pugnax... A. oschmarini Spassky, 1961

3b. Rostellar hooks larger, armament of cirrus different... 4

4a. Rostellar hooks $28-31$ in length. Proximal and medial parts of cirrus covered with fine spines (Fig. 146). Cirrus 75-105 $\times 8-$ Parasite of Calidris and Limicola falcinellus... A. stricta (Spassky, 1963)

4b. Rostellar hooks larger, cirrus narrower... 5

5a. Rostellar hooks 31-36 in length, cirrus $41-70 \times 5-8,2 / 3$ of cirrus length covered with small dense spines, distal region of cirrus unarmed (Fig. 109). Parasite of Calidritinae... A. rauschi Webster, 1955

$5 b$. Cirrus longer, armament of cirrus different... 6

6a. Rostellar hooks 29-31 in length. Cirrus 70-92 long, width of base 8-11, in distal part 
4-5, proximal half of cirrus covered with triangular spines (Fig. 34). Parasite of Calidris... A. crassipenis Deblock et Rausch, 1968

6b. Rostellar hooks and cirrus larger... 7

7a. Rostellar hooks 37-41 in length. Cirrus $127-139 \times 16-23$, with pipette - like distal end, covered with dense spines, except for distal end (Fig. 52). Specific parasite of ceca of Lymnocryptes minimus... A. hirsuta (Krabbe, 1882)

7 b. Cirrus slightly longer than 200, rostellar hooks smaller... 8

8a. Maximum cirrus length 209, maximum width in basal part 9-12, in distal part 3-4; only proximal part of cirrus covered with quite fine spines (Fig. 137). Rostellar hooks 16-20 in length. Parasite of Scolopacinae... A. spasskii Bondarenko, 1966

8b. Rostellar hooks slightly longer, cirrus wider... 9

9a. Rostellar hooks 17-25 in length. Cirrus 220-230 in length, maximum width in basal part 17-20, in distal part 7; most of cirrus covered with distinct spines (Fig. 152). Parasite of Gallinago gallinago... A. thomasi Bondarenko, 1990

9b. Cirrus longer than 400 and narrower, eggs single or in pockets... 10

10a. Cirrus conical, up to 413 in length, maximum width in basal part 8 (Figs. 115, 116). Eggs single or in packets containing 2-14 eggs in each. Rostellar hooks 18-21 in length. Parasite of Limnodromus, rarely of Arenaria, described from Rissa tridactyla... A. rissae Schiller, 1951

10b. Cirrus longer than $600 \ldots 11$

11. Cirrus cylindrical up to 697 in length, maximum width at base 25-37 (Fig. 67). Rostellar hooks 19 in length. Eggs single, possibly in packets. Parasite of Scolopacinae... A. mackoi Bondarenko et Hromada, 2004

Species with a spindle-shaped cirrus, often highly elongate, tapering distally, embryophore with or without polar swellings, parasites of shorebirds (e.g., Figs. 16, 40, 57)

1a. Embryophore without polar swellings. Rostellar hooks 25-29 in length. Cirrus 45-66 × 6-8; proximal two-thirds armed with small spines (Fig. 78). Parasite of Limnodromus, rarely of other shorebirds... A. occidentalis Prudhoe et Manger, 1966 1b. Embryophore with polar swellings, surface of middle region of embryophore tuberous... 2

2a. Rostellar hooks 37-40 in length. Cirrus $122-155 \times 8-10$. Surface of middle region of embryophore tuberous (Fig. 17). Parasite of Gallinago... A. belopolskajae Bondarenko, 1988

2b. Rostellar hooks and cirrus shorter... 3

3a. Rostellar hooks 27-31 in length, blade of hooks blunt, almost the same length as guard (Fig. 56). Cirrus 37-77 in length, middle of cirrus covered with spines. Embryophore with polar swellings, surface of middle region of embryophore tuberous. Parasite of Scolopax... A. kornyushini Bondarenko et Kontrimavichus, 2006

3b. Rostellar hooks another length and shape. Surface of middle region of embryophore smooth... 4

4. Rostellar hooks 20-25 in length, blade long and thin, significantly longer than guard (Fig. 39). Cirrus 83-151 long, proximal part covered with spines. Parasite of Scolopax... A. demschini Bondarenko et Kontrimavichus, 2005

\section{Species with a cirrus that has a prominent} bulbar swelling basally (e.g., Figs. 7, 25)

1a. Rostellar hooks 25-33 in length, blade and base of hook almost equal in length. Length of cirrus 50-55; embryophore of eggs without swellings (Figs. 154-156). Parasite of Calidris and Phalaropus, rarely of other shorebirds and gulls Xema sabini... A. xemae Schiller, 1951

1b. Rostellar hooks another shape... 2

2a. Rostellar hooks 32-33 in length, blade thin, longer than base. Length of cirrus 31; only middle region covered with spines. Embryophore without polar swellings. Parasite of Philomachus pugnax, rarely of other shorebirds (Figs. 149, 150)... A. taimyrensis Bondarenko, 1966

2b. Rostellar hooks another shape and length... 3

3a. Rostellar hooks 37-45 in length, blade slightly shorter than base. Length of cirrus 3139, (Figure 24-26). Embryophore without polar swellings. Parasite of Calidris and Phalaropus, rarely of other shorebirds... A. bulbocirrus Deblock et Rausch, 1968

3b. Embryophore of eggs with polar swellings, cirrus larger... 4 
4a. Rostellar hooks 18 in length, blade of hooks longer than base. Length of cirrus 62-69; basal swelling $12-21 \times 15-21$, covered with large needle-shaped spines; half of distal part of cirrus bears fine spines. Parasite of Gallinago and Scolopax (Figs. 6-8)... A. americanensis Bondarenko et Kontrimavichus, 2001

4b. Rostellar hooks largest... 5

5. Rostellar hooks 28-37 in length, blade and base of hook equal in length. Length of cirrus 28-49; swelling bears 4 transverse rows of spines; middle of distal part of cirrus armed with fine spines (Fig. 129). Embryophore with polar swellings and characteristic lateral projections. Parasite of Scolopax... A. scolopacis Yamaguti, 1935

\section{Species with a cirrus that has a prominent parabasal swelling (e.g., Figures 22, 131) parasites of shorebirds and gulls}

1a. Length of cirrus up to 188; parabasal swelling 17-20 × 13-18; cirrus covered with spines except distal part (Fig. 31). Rostellar hooks 16-18 in length; blade and guard nearly equal length. Parasite of Calidris, rarely of other shorebirds... A. clavata Spasskaja, 1966

$1 b$. Length of cirrus another (shorter)... 2

2a. Length of cirrus 49-54; basal part 12$16 \times 8$, distal part $29 \times 4$; parabasal swelling $12-13$ in diameter almost spherical; basal part and parabasal swelling covered with small spines (Fig. 22). Rostellar hooks 16 in length, blade slightly longer than guard (Fig. 21). Specific parasite of shorebirds, rarely in Laridae, intermediate host Lumbriculidae... A. brachyphallos (Krabbe, 1869)

2b. Parabasal swelling smaller in diameter, intermediate host another... 3

3a. Length of cirrus $37-52$, base $8 \times 4$, parabasal swelling 8 in diameter, distal part $16-27 \times 2-4$; armament of cirrus hardly visible (Fig. 46). Rostellar hooks 17-18 in length, blade of hook considerably longer than guard (Fig. 45). Eggs numerous, single. Parasite of Scolopacidae, intermediate host Enchytraeidae... A. gallinagii Bondarenko, 1979

3b. Cirrus larger, eggs enclosed in packets... 4

4a. Length of fully evaginated cirrus 104; parabasal swelling $12-16$ in diameter; spines larger on bulbous part of cirrus (Fig. 131). Eggs enclosed in a single packet. Parasite of gulls... A. shigini Bondarenko et Kontrimavichus, 2006

4b. Cirrus slightly larger, eggs enclosed in a few packets... 5

$5 a$. Length of fully evaginated cirrus 126 covered with large triangular spines; basal and distal regions bear smaller spines (Fig. 143), parabasal swelling 18-19 in diameter. Eggs in uterus enclosed in 6 packets. Parasite of Scolopacinae, rarely of other shorebirds... A. spinosus (Bondarenko, 1966)

5b. Parabasal swelling smaller, armament of cirrus other... 6

6a. Length of fully evaginated cirrus 73 , covered with fine uniform spines (Fig. 70), parabasal swelling 8-10 in diameter. Rostellar hooks 17 in length. Eggs in uterus enclosed in 4-6 packets. Parasite of Tringa and Erolia... A. mamaevi (Bondarenko, 1966)

6b. Length of rostellar hooks larger, eggs in uterus single, embryophore with polar swellings... 7

7a. Length of rostellar hooks 21-27, blade of hooks long and thin. Length of cirrus 22-31, parabasal swelling $8 \times 5-7$, covered with very fine spines (Figs. 133-135). Parasite of Scolopax... A. sinensis Tseng Shen, 1933

7b. Length of rostellar hooks larger... 8

8a. Length of rostellar hooks 25-29, length of pointed blade 16-17 (Fig. 111). Length of cirrus 16, maximum diameter 8. Embryophore thick, up to 4, knobbed. Parasite of Scolopacidae, rarely other shorebirds... A. retroversa Spassky et Gubanov, 1963 ("1961")

8b. Length of rostellar hooks larger, vagina with sphincter... 9

9a. Length of rostellar hooks $28-33$, blade blunt, 18-20 long (Fig. 80). Vagina with marked sphincter, 5-6.6 × 6.6-10, arranged between conductive and copulatory parts. Cirrus tiny, usually invaginated, 12-20 in length, evidently pipette-shaped, with maximum diameter in median part 3-5. Parasite of Calidris, rarely of other shorebirds... A. octacantha Spasskaja, 1966

$9 \mathrm{~b}$. Length of cirrus larger, parabasal swelling well-expressed... 10

10a. Length of cirrus 74-83, parabasal swelling 27-33 × 12-14; rather large spines cover only 
proximal part of cirrus and swelling (Fig. 10). Rostellar hooks 24-27 in length, blade thin. Parasite of Tringinae (one record in duck)... A. andrei Spassky, 1965

10b. Length of cirrus larger... 11

11a. Length of cirrus 90-95, parabasal swelling $21 \times 17$; swelling, proximal and 1/5 distal parts of cirrus covered with small spines (Fig. 125). Rostellar hooks 19-20 in length. Embryophore knobbed. Parasite of Calidritinae, rarely of other shorebirds... A. schilleri Webster, 1955

11b. Length of cirrus larger, parabasal swelling nearly globular... 12

12a. Length of cirrus 120 , parabasal swelling 25-29 × 25-33; covered with small, evenly distributed spines; end of distal part unarmed (Fig. 119). Rostellar hooks 20-24 in length, blade long and thin. Embryophore 3 thin, slightly tuberous. Parasite of Gallinago solitaria... A. sachalinensis Krotov, 1952

12b. Length of cirrus smaller, rostellar hooks larger, embryophore with polar swellings... 13

13. Length of cirrus $65-72$, basal region and parabasal swelling covered with spines. Length of rostellar hooks 31-35. Embryophore with polar swellings (Figs. 140, 141). Parasite of $\mathrm{Nu}$ menius... A. sphaerophora (Rudolphi, 1810)

\section{Species with a club-shaped cirrus or cirrus with a swelling in distal part (Figs. 90, 97)}

1a. Cirrus club-shaped, 130-140 long, diameter evenly enlarged toward distal region; covered with triangular spines, distal pipettelike part unarmed (Fig. 90). Rostellar hooks 30-35 in length. Eggs in uterus enclosed in a single packet. Parasite of Limnodromus... A. parabirulai Bonderenko, 1975

1b. Cirrus another shape, rostellar hooks smaller... 2

2. Cirrus with bulbous swelling in distal region $20 \times 12-21$; fully evaginated cirrus 180 in length, armed except swelling with fine spines (Fig. 97). Rostellar hooks 17-18 in length. Eggs in uterus enclosed in a few packets. Parasite of G. gallinago of the Nearctic... A. paraspinosus Bondarenko et Kontrimavichus, 2001
Key to the species of Aploparaksis (Aploparaksis) parasites of Anseriformes

1a. Cirrus short, fully evaginated not exceeding 25 in length, parabasal swelling well developed, $5 \times 9-12$; rostellar hooks $37-40$ in length. Eggs enclosed in a few packets, $3-51$ in each (Fig. 29)... A. clangulae Bondarenko et Kondratjeva, 1985

1b. Cirrus shorter, eggs single or enclosed in numerous packets... 2

2a. Cirrus very short, 14 in maximum length, parabasal swelling 7-12 in diameter. Rostellar hooks $34-42$ in length, eggs single or in small packets of a few eggs in each... A. polystictae Schiller, 1955

2b. Cirrus longer, rostellar hooks larger... 3

3a. Cirrus $18-25$ in length, parabasal swelling $7 \times 12-17$. Rostellar hooks $45-63$ in length... A. furcigera (Rudolphi, 1819)

3b. Cirrus longer, with bulbar basal and parabasal swelling... 4

4a. Cirrus 130-210 in length with poorly developed basal and parabasal swellings, both swellings covered by small spines. Rostellar hooks 31-42 in length; eggs single... A. groenlandica (Krabbe, 1869)

4b. Cirrus club-shaped... 5

5a. Cirrus thickened in distal part (Fig. 18), club-like, 57-84 in length; covered with triangular spines, distal pipette-like part unarmed. Rostellar hooks 30-35 in length, handle 10-12 long. Eggs enclosed in a single packet... A. brulai Linstow, 1905

5b. Cirrus cigar-shaped, eggs single... 6

6a. Rostellar hooks 61-62 in length. Cirrus $28-33$ in length, insignificant thickened in middle part to 5-8 maximum width; middle part of cirrus armed with small spines. Eggs single with an additional outer envelope... A. japonensis Jamaguti, 1935

6b. Rostellar hooks smaller, cirrus longer, eggs in packet... 7

7a. Rostellar hooks $47-53$ in length. Cirrus $38-56$ in length and 5-8 maximum width; covered with middle part with small spines. Eggs in packets, 1-6 in each... A. kulachkovae Bondarenko, 1987 


\section{Aploparaksis (A.) filum (Goeze, 1782) Clerc, 1903}

Objective synonyms: Taenia filum Goeze, 1782; Monorchis filum (Goeze, 1782) Clerc, 1902; Haploparaksis filum (Goeze, 1782) Neslobinsky, 1912; Monopylidium filum (Goeze, 1782) Parona, 1902.

Subjective synonyms: $A$. parafilum Gasowska, 1931 in part, A. parafilum Gasowska sensu Spasskaya $(1957,1964)$ in part, sensu Bondarenko (1966a) in part, sensu Ryjikov et al. (1974) in part.

Unconfirmed record: A. filum in Belopolskaya (1969) in part, Belopolskaya, Kulachkova (1970), Bondarenko (1966a) in part, 1969, 1975a), Clerc $(1903,1910)$ in part, Davies (1940) in part, Deblock and Rausch (1968), Dubinina (1953) in part; Gomez (1977), Huan (1962) in part, Krabbe (1869) in part, Lopez-Neyra (1944), Mamaev (1959) in part, Oshmarin (1963) in part, Parona $(1899,1902)$ in part; Ryzhikov et al. (1974) in part, Spasskaya $(1956,1964,1966)$ in part, Spasskaya and Spassky (1971) in part; Spassky (1963), Spassky and Yurpalova (1969).

Hosts: Scolopax rusticola L. (type host), Gallinago gallinago (L.), G. stenura (Bonaparte), G. media (Latham)
Life cycle: intermediate hosts: Lumbricidae (experimental infection): Eiseniella tetraedra (Savigny), Octolasium lacteum (Oerley); site: ventral nerve cord; metacestode: typical diplocyst

Localities: Germany (type locality), Lithuania, Ukraine, Russia (Karelia, the Urals, Tuva, the lower reaches of the Yenisey River, Yakutia, Primorskiy Kray, Chukotka).

Diagnostic characters (Figs. 1-5). Rostellar hooks 17-24.6 in length, blade long and thin; length of blade 13; length of base with guard 1415. Cirrus sac $259-381 \times 41-49$, in male proglottids reaches aporal osmoregulatory canals or crosses midline in hermaphroditic one. Cirrus foliaceous, "leafstalk" and "lamina" sharply defined. Total length of cirrus 110-135; "leafstalk" 21-25 × 8-10, "lamina" 90-110 × 27-30; only basal region of "leafstalk" covered with fine spines arranged in several transverse rows. Eggs single; embryophore with polar swellings, surface smooth or tuberous in middle part, embryonic hooks 15-18 long.

Remarks. A. filum had been selected by Clerc (1903) as the genotype of Aploparaksis. In view of lack of a type specimen in Goeze's

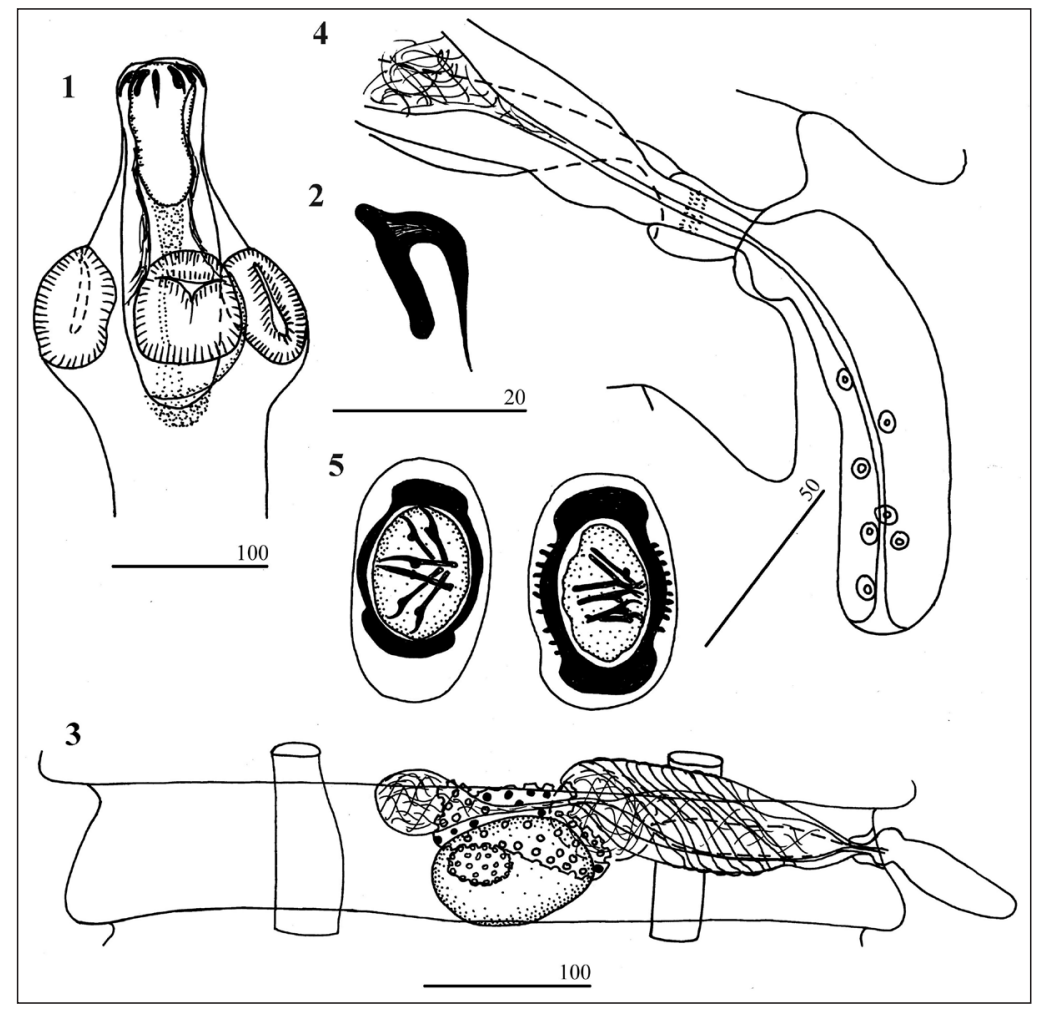

Figs. 1-5. Aploparaksis filum: 1 - scolex, 2 - hook, 3 - hermaphroditic proglottis, 4 - cirrus, 5 - eggs 
material, Clerc re-examined specimens of $A$. $f i$ lum from the collections of Krabbe, Wolfhhugel and Fuhrman, comparing them with specimens from his own collection in seven species of shorebirds from the Urals. He noticed that these individuals were most similar to those described by Krabbe (1869). However, the re-description of A. filum by Clerc (1903) also lacked information on the main diagnostic morphological features necessary for the identification of Aploparaksis species. Consequently, there had been difficulties in the comparison of this species with other congeners. As a result, $A$. $f i$ lum proved to be one of the most frequently recorded species of Aploparaksis in most faunistic investigations of the cestodes of charadriiform birds from the Holarctic. The host-range of A. filum has extended to 33 avian species from a variety different higher taxa (Spassky, 1963; Spasskaya, 1966). However, our first steps in the re-examination of the museum specimens of $A$. filum revealed a considerable number of misidentifications among the reports of previous authors (see Bondarenko, 1990a). A re-examination of a slide with multiple specimens prepared and identified as A. filum by Clerc (1903) in Scolopax rusticola from the Ural, deposited in MHNG (No. 13/78), revealed that the re-description was based on heterogeneous material. Three specimens on this slide represent A. filum (Goeze, 1782) sensu Clerc (1903), A. pseudofilum (Clerc, 1902) non Gasowska, 1932, and an unidentified specimen of Aploparaksis sp., which was later described by Bondarenko and Kontrimavichus (2005) as the new species $A$. demshini. Despite the absence of rostellar hooks, Clerc's specimens were differentiated by their strobilar morphology and by the structure of the copulatory apparatus. The missing morphological features characterizing each of the species were obtained by comparison with the data from Bondarenko's collection of Aploparaksis in woodcock assembled from various localities across Russia. Bondarenko (1990a) also revealed that A. filum is restricted to Scolopacinae. A detailed description of the neotype of A. filum, taxonomic comments, and life cycle was presented by
Bondarenko (1990a) and Bondarenko, Kontrimavichus (2006a).

Museum specimens: CPAR neotype 664, Scolopax rusticola, Primorskiy Kray, Russia; remaining specimens are in: CPAR 573 G. gallinago, Yakutia, Russia and 572 G. stenura, Tuva, Russia (collection of Spasskaya), 15 G. stenura, Chukotka, Russia (collection of Bondarenko), 7, 172 G. media, Ob' River (identified by Bondarenko (1990a); MNHG 13/78 S. rusticola the Urals (collection of Clerc), 19348 from S. rusticola, Lithuania (collection of Bondarenko); ZIN 285 G. media, the Urals (collection of Clerc); IZU 183-3, 200-5 S. rusticola, Ukraine (collection of Dr. V. Kornyushin). The remaining specimens are in the collection of Dr. S. K. Bondarenko.

\section{Aploparaksis (A.) americanensis Bonda- renko et Kontrimavichus, 2001}

Hosts: Scolopax minor Gmelin (type-host), Gallinago paraguaica (Vieillot).

Localities: North America USA (Michigan) (type locality), Canada (New Brunswick), South America (Argentina).

Diagnostic characters (Figs. 6-8). Rostellar hooks 18 in length, blade long and thin 12 in length; base with guard 13. Cirrus sac thickwalled, from 160 up to 348 long depending on the degree of maturation of proglottids, and 37-57 wide. Cirrus 62-69 long; basal swelling $12-21 \times 15-21$, asymmetrical, more convex surface covered with needle-shaped spines 3 long; median part of cirrus 20 in length bears of finest spines; distal part gradually decreases to 1 in diameter. Eggs single; embryophore with polar swellings; some oncospheres disposed along the longitudinal axis of embryophore; embryonic hooks 12-15 long.

Remarks. A. americanensis is known only from its original description (Bondarenko, Kontrimavichus, 2001).

Museum specimens: USNPC holotype 65761, Scolopax (=Philohela) minor, Michigan, USA; paratypes 10 slides in series 44165 and 65761, S. minor, New Brunswick, Canada; BMNH 203-212, Gallinago paraguaica, Patagonia, Argentina, designated as A. filum. 


\section{Aploparaksis (A.) andrei Spassky, 1965}

Subjective synonyms: Aploparaksis sp. Spassky, 1963 in part; A. acanthocirrus Deblock et Rausch, 1968

Unconfirmed records: $A$. andrei Spassky, 1963 in Belopolskaya (1969), in Belopolskaya, Kulachkova (1970).

Hosts: Heteroscelus incanus (Gmelin) (typehost), H. brevipes (Vieillot), Tringa nebularia (Gunnerus), Histrionicus histrionicus (L.).

Localities: Russia: (Kamchatka (type locality), Chukotka (Ugatkin), Magadanskaya oblast'), USA (Alaska).

Diagnostic characters (Figs. 9-11). Rostellar hooks 24-26.5 in length; length of blade 13-16; length of base with guard 18-20. Cirrus sac $170-348 \times 29-45$. Fully-evaginated cirrus conical with slightly enlarged median part. Total length of cirrus 74-83; median part 27$33 \times 12-14$; covered with relatively large spines arranged in 12-14 diagonal rows of 5-8 spines in each; basal part of cirrus (c. 8-15 long and 7 wide at base) and distal part 31-40 × 2-4, unarmed. Eggs single, embryophore smoothwalled; embryonic hooks 15-18 long.

Remarks. Among the specimens originally described by Spassky (1963) from Chukotka as Aploparaksis sp. and later (Spassky 1965) as a new species $A$. andrei, we found only one specimen in $H$. incanus in which the morphology corresponds with the original description. Three specimens collected by Dr. Kira Regel from a single Histrionicus histrionicus (L.) in Chukotka have been identified by us as $A$. andrei; however, we believe that the infection of ducks occurs only accidentally and therefore it has not been included in the key to the species parasitic in ducks. For a description and morphological variability of the species, see Bondarenko, Kontrimavichus (2006a).

Museum specimens: CPAR holotype 240, Heteroscelus incanus, Kamchatka, Russia; USNPC 71179, H. incanus, Alaska, USA (designated as a paratype of $A$. acanthocirrus).

\section{Aploparaksis (A.) australis Johnston, 1913}

Subjective synonyms: A. parafilum Gasowska, 1932 sensu Spasskaya (1964) in part; A. sanjuanensis Tubangui et Masilungan, 1937 sensu Spasskaya (1964) in part, sensu Spasskaya, Spassky (1971) in part; Hymenolepis recurvirostris (Krabbe, 1869) sensu Joyeux, Baer (1940).

Hosts: Gallinago megala Swinhoe (typehost), G. macrodactyla, G. media, G. stenura, Scolopax rusticola, Tringa glareola (?).

Life cycle: intermediate hosts: Lumbricidae (experimental infection): Nicodrilus roseus (Savigny), Eisenia foetida (Savigny), E. nordenskioldi Eisen, Eiseniella tetraedra, Dendrobaena octaedra Savigny, Enchytraeidae: Bryodrilus arctica (Bell), Henlea diverticulata (Cejka); site: mostly in the conjunctive tissue of ventral nerve cord, rarely in coelom; metacestode: typical diplocyst.

Localities: Australia (type locality), Madagascar, Sri Lanka, England, Lithuania, Russia (Karelia, Tuva, Primorskiy Kray).

Diagnostic characters (Figs. 12-14). Rostellar hooks 18-21 in length, blade long and thin 11.6-12 long; length of base with guard 13-15. Cirrus sac short, $104-155 \times 17-29$, does not reaches midline. Cirrus foliaceous, 27-42 long, 12-16 maximum wide; spines on basal part of cirrus small, coniform, in middle part thin and hair-like, distal part unarmed. Embryophore with polar swellings, surface in mid-region and rarely in polar swellings tuberous; oncosphere oriented along longitudinal axis of embryophore, and as a result embryonic hooks, 18-21 long, turn out in one pole.

Remarks. This species was known only from the original description (Johnston, 1913). The slide from Johnston's collection in the South Australian Museum available for our study contains only a juvenile strobila without a scolex. Specimens studied by us were identified as A. australis based on the length of the rostellar hooks and a characteristic property of the eggs represented on the figures that accompany the original description. The position of the oncosphere inside the embryophore allows differentiation of this species from other congeners. The statement by Johnston (1913) that A. australis has eight rostellar hooks was found to be erroneous. For a redescription, taxonomic comments, and life cycle, see Bondarenko (1989) and Bondarenko, Kontrimavichus 2006b. We considered the tapeworms attributed to Hymenolepis recurvirostris 


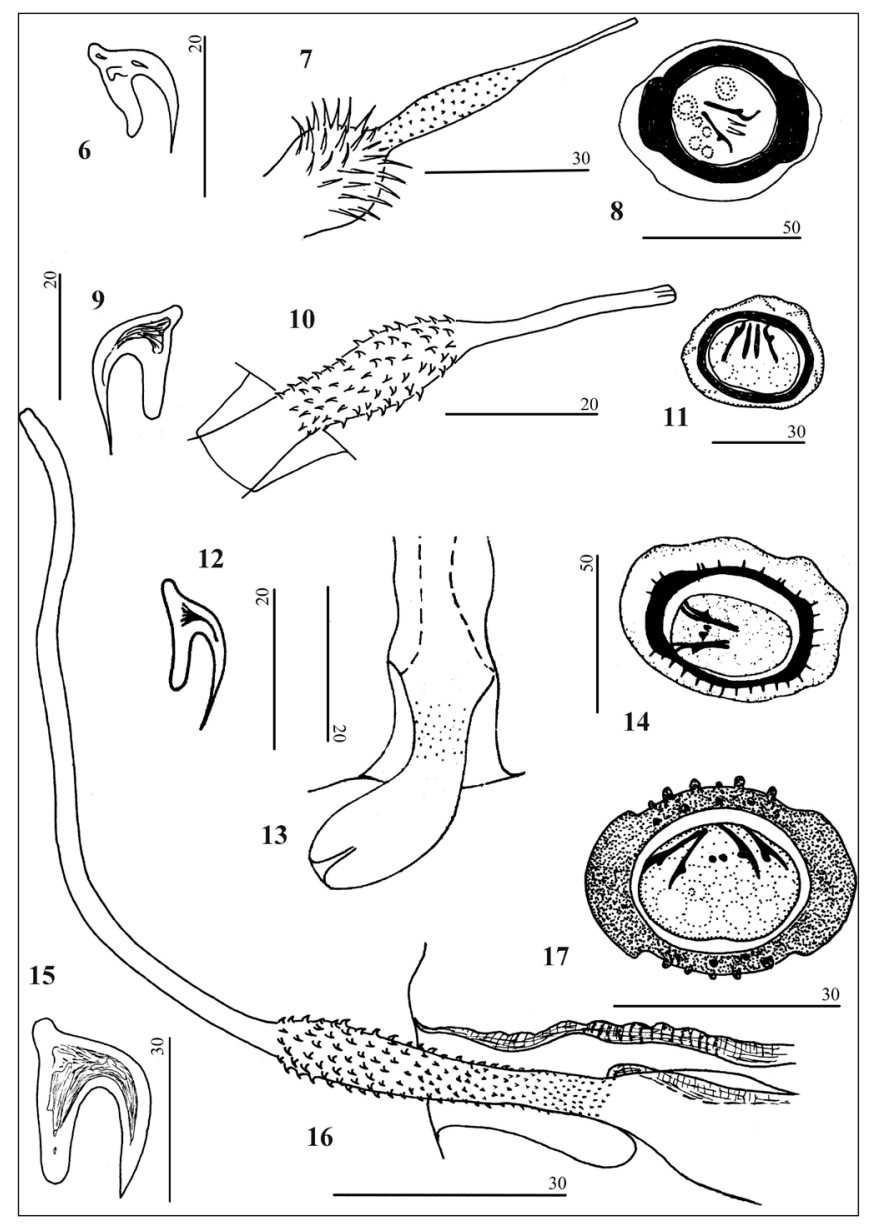

Figs. 6-8. Aploparaksis americanensis: 6 - hook, 7 - cirrus, 8 - egg. Figs. 9-11. Aploparaksis andrei: 9 - hook, 10 - cirrus, 11 - egg. Figs. 12-14. Aploparaksis australis: 12 - hook, 13 - cirrus, 14 - egg. Figs. 1517. Aploparaksis belopolskajae: 15 - hook, 16 - cirrus, 17 - egg by Joyeux, Baer (1940) a synonym of A. australis based on similar morphology of the eggs.

Museum specimens: South Australian Museum (AHC S 349), Gallinago megala; CPAR 27, 41, Galinago stenura, Yakutia, Russia and 596, G. media, Tuva, Russia (all designated as A. parafilum); № 268, G. media, Tuva, designated as A. sanjuanensis; MHNG 19349, Scolopax rusticola, Karelia, Russia; BMNH № 20-21 (collection of D.R.R. Burt), Tringa glareola, Sri Lanka.

\section{Aploparaksis (A.) belopolskajae Bondarenko, 1988}

Subjective synonyms: A. filum sensu Bondarenko (1966a).

Hosts: Gallinago media (type-host), G. gallinago.

Localities: Russia (the lower reaches of the Ob' (type locality) and Yenisey rivers), Slovak Republic.
Diagnostic characters (Figs. 15-17). Rostellar hooks 37-40 in length, blade wide and blunt 21-22 long approximately the same length as guard; length of base with guard 29-31, wide of hook 20-22. Cirrus sac 280-360 × 32-50, crosses midline. Cirrus spindle-shaped, 122$155 \times 8-10$; proximal part covered with spines (c. 7-8 spines in diagonal rows on each side of cirrus); spines smaller in base of cirrus. Eggs single; embryophore of mature with polar swellings, surface in middle region tuberous; embryonic hooks 10-12 long.

Remarks. For a detailed description, see Bondarenko (1988).

Museum specimens: CPAR 662 holotype, Gallinago gallinago, Ob' River, Russia; 663 paratype, G. media, Yenisey River, Russia.

\section{Aploparaksis (A.) birulai Linstow, 1905}

Hosts: Somateria spectabilis (L.) (type-host), S. fischeri (L.), S. molissima (L.), 
Aythia fuligula (L.), A. marila (L.), Clangula hyemalis (L.), Melanitta americana (Swainson).

Life cycle: intermediate hosts: Lumbriculidae: Lumbriculus variegatus (Müller), L. olgae Morev (?) (natural and experimental infections); site: coelom; metacestode: floricercus.

Localities: Russia (West Taimyr (type locality), Yakutia, Chukotka, Wrangel Island), North Kazakhstan, Iceland, Greenland.

Diagnostic characters (Figs. 18-20). Rostellar hooks 29-33 (30-34 in metacestodes) in length; length of blade and handle about equal, 14-16 and 10-12 accordingly. Cirrus sac 90-130 × 1215 , situated obliquely, in mature germaphroditic proglottids proximal part reaches or overlaps anterior margin of proglottis. Cirrus baseball batshape, 57-84 in length, diameter evenly enlarges toward distal region; covered with triangular spines differ in size; larger spines covered of middle part arranged in transverse rows of 3 in each; distal pipette-like part unarmed. Eggs enclosed in large, single packet; embryonic hooks 14 long.

Remarks. The description of Linstow (1905) was corrected by Baer (1956), who pointed out that, in fact, the length of the hooks of Linstow's specimen of A. birulai were larger, specifically, 3537 compared with the 32 indicated in the original description. Our investigation of Linstow's specimens confirmed that Baer was right. For a redescription and life cycle, see Bondarenko (1975), Bondarenko and Kontrimavichus (1976, 2006b), Bondarenko and Krasnoshchekov (1978).

Museum specimens: MHNG “Type" 24/87, 24/89 Somateria spectabilis, Taimyr, Russia.

\section{Aploparaksis (A.) brachyphallos (Krabbe, 1869) Fuhrmann, 1908}

Objective synonym: Taenia brachyphallos Krabbe, 1869.

Subjective synonyms: Aploparaksis diminuens Linstow, 1905, A. diminuens Linstow sensu Spasskaya and Spassky (1971); A. larina Fuhrmann, 1921; A. uelcal Spassky et Yurpalova 1969; Skorikowia clausa Linstow, 1905; Diorchis serpentata Linstow, 1905. A. hirsuta (Krabbe, 1882) sensu Belopolskaya (1969) in part; A. andrei sensu Spassky (1965) in part; A. clavata sensu Bondarenko (1966a), Spassky \& Yurpalova (1969 in part), Belopolskaya and Kulachkova (1970) in part; A. pseudofilum sensu Gynetsinskaya and Naumov (1958) in part; A. sachalinensis sensu Mamaev (1959) in part.

Unconfirmed records: $A$. brachyphallos in Bondarenko (1966a, 1975a), Davies (1940), Dubinina (1953), Hromada and Macko (1995), Huan (1962), Krotov (1952) in part, Kornyushin (1967) in part, Mamaev (1959) in part, Ryšavy and Sonin (1977), Ryšavy and Farkaš (1982), Spassky (1963) in part.

Hosts: Calidris alpine (L.) and C. maritima (Brunnich) were marked as type- hosts, C. bairdi (Coues), C. melanotos (Vieillot), Arenaria interpres (L.), Gallinago gallinago, Limnodromus griseus (Gmelin), L. scolopaceus, Phalaropus phulicarius (L.), Ph. lobatus (L.), Phylomachus pugnax, Pluvialis squatarola (L.), Tringa erythropus (Pallas), T. glareola L., T. nebularia (Gunnerus), T. tetanus (L.), Larus argentatus Vieillot, L. dominicanus Lichtenstein, Stercorarius longicaudus Vieillot, Xema sabini (Sabine).

Life cycle: intermediate hosts: Lumbriculidae: Stilodrilus sp., Lumbriculus sp. (olgae?); site: coelom; metacestode: caudate diplocyst.

Localities: Greenland, Faroe Islands (type locality), Russia (White Sea coast, Kaliningradskaya oblast', West Taimyr, the lower reaches of the Ob' and Yenisey rivers, Magadanskaya oblast', Kamchatka, Chukotka, Vrangel, Karaginskiy and Paramushir islands), Ukraine, Turkmenistan, Iceland, USA (Alaska), Canada, Antarctica.

Diagnostic characters (Figs. 21-23). Rostellar hooks 16 in length wth blade slightly longer than guard. Cirrus sac 184-291 crosses midline in hermaphroditic proglottids. Length of cirrus 49-54; basal part $12-16 \times 8$, distal part $29 \times 4$, parabasal swelling $12-13$ in diameter; basal part and parabasal swelling covered with small spines. Eggs single, embryophore of young eggs with smooth walls becoming knobbed in mature; embryonic hooks 12 long.

Remarks. The history of A. brachyphallos is rather confused. Both the wide host-range and several differences in the morphology of the male copulatory apparatus (the length of the cirrus sac and proportions of the parts of the cirrus) of specimens from different hosts and regions gave 
grounds to surmise the existence of intraspecific variability or that it possibly is a species complex. Further studies are needed to clarify the status of this species.

Museum specimens: CPAR voucher specimens 845, 1041, 1133, Limnodromus griseus, Chukotka, Russia; 750, 843, 850, 852, 944, 1144, 1146, Tringa glareola, Chukotka, Russia; MHNG 19346, Phalaropus fulicarius, Chukotka, Russia; 19347, Macrorhamphus griseus, Chukotka Russia; MSB: Para: 16808, Calidris melanotos, Alaska; \#48489, Limnodromus scolopaceus, Alaska (collection of R. L. Rausch).

\section{Aploparaksis (A.) bulbocirrus Deblock et Rausch, 1968}

Subjective synonyms: A. brachyphallos (Krabbe, 1869) sensu Mamaev (1959) in part; A. crassirostris (Krabbe, 1869) sensu Dubinina (1953) in part; A. clavata Spasskaya, 1966 sensu Belopolskaya and Kulachkova (1970); A. hirsuta (Krabbe, 1882) sensu Clerc (1903), sensu Belopolskaya (1969), sensu Bondarenko (1966a), sensu Mamaev (1959) in part, sensu Spasskaya (1956), sensu Spasskaya and Spassky (1971), sensu Spassky (1963), sensu Spassky and Yurpalova (1969); A. sachalinensis Krotov, 1952 sensu Ryzhikov et al. (1974).

Hosts: Actitis hypoleucos (L.), Arenaria interpres, Calidris mauri (Cabanis) (type-host), Calidris acuminate (Horsfield), C. alpina, C. ferruginea (Pontoppidan), C. melanotos, C. minuta (Leisler), C. subminuta, C. temminckii (Leisler), Gallinago gallinago, Limnodromus griseus, Phalaropus lobatus, Ph. fulicarius, Pluvialis squatarola, Tringa erythropus.

Life cycle: intermediate hosts: Lumbriculidae: Lumbriculus variegatus, Stylodrilus sp. (experimental and natural infections); site: coelom; metacestode: typical diplocyst.

Localities: USA (Alaska, type locality), Russia (the White Sea coast, West and East Siberia, Paramushir Island), Turkmenistan.

Diagnostic characters (Figs. 24-26). Rostellar hooks 37-45 in length; length of blade 21.5-25; length of base with guard 26-30; width of hook 18-21. Testes sometimes appear as $2-3$ small primordia close together, which later unite to become
1 (rarely their number persists in gravid proglottids). Cirrus sac 280-380 $\times 29-36$. Cirrus 31-39 in length, with basal bulbous swelling, 12-20 × 1115 covered with spines arranged in 5-6 transverse rows; distal part pipette-like, $17-19 \times 2-3$ unarmed. Eggs with additional outer envelope; single or enclosed in small packets with 2-6 (sometimes a little more) eggs in each; embryophore tuberous; embryonic hooks 16-17 long.

Remarks. The morphology of A. bulbocirrus is notably similar to that of $A$. xemae, and often concurrent infections can be observed in the intestine of the same bird. These two species, however, can be easily distinguished on the basis of the size of the rostellar hooks, which are smaller in the latter species. Among numerous samples of both species studied or re-studied by us during this investigation (materials from the lower reaches of the $\mathrm{Ob}^{\prime}$ River (Pelgunov, 1987), Chukotka and Alaska (our material)), we failed to discover specimens that had hook lengths with an intermediate value between their maximum length (33) in A. xemae and minimum length (37) in A. bulbocirrus. An intermediate value of the size of the hooks was not found among the metacestodes of A. bulbocirrus or A. xemae developed under experimental or natural conditions either. In spite of the fact that A. bulbocirrus appears to have low host specificity, we believe it is a common parasite of the shorebirds Calidris spp. and Phalaropus spp.

Museum specimens: USNPC holotype 71175, Calidris mauri, Alaska, USA and vaucher specimens under the field \# B-68-36 and B-68-37, Calidris alpina, from personal collection of R. L. Rausch, both from Point Barrow, Alaska, USA (at present stored in Bondarenko' collection); MHNG voucher specimen 19341, C. melanotos, Chukotka, Russia.

\section{Aploparaksis (A.) clangulae Bondarenko et Kondratyeva, 1985}

Host: Clangula hyemalis (L.)

Life cycle: intermediate hosts: Lumbriculidae: Lamprodrilus issosimovi Morev, Styloscolex sokolskajae Morev (experimental infection); site: coelom and dorsal blood vessels; metacestode: typical diplocyst.

Locality: Russia (Chukotka). 


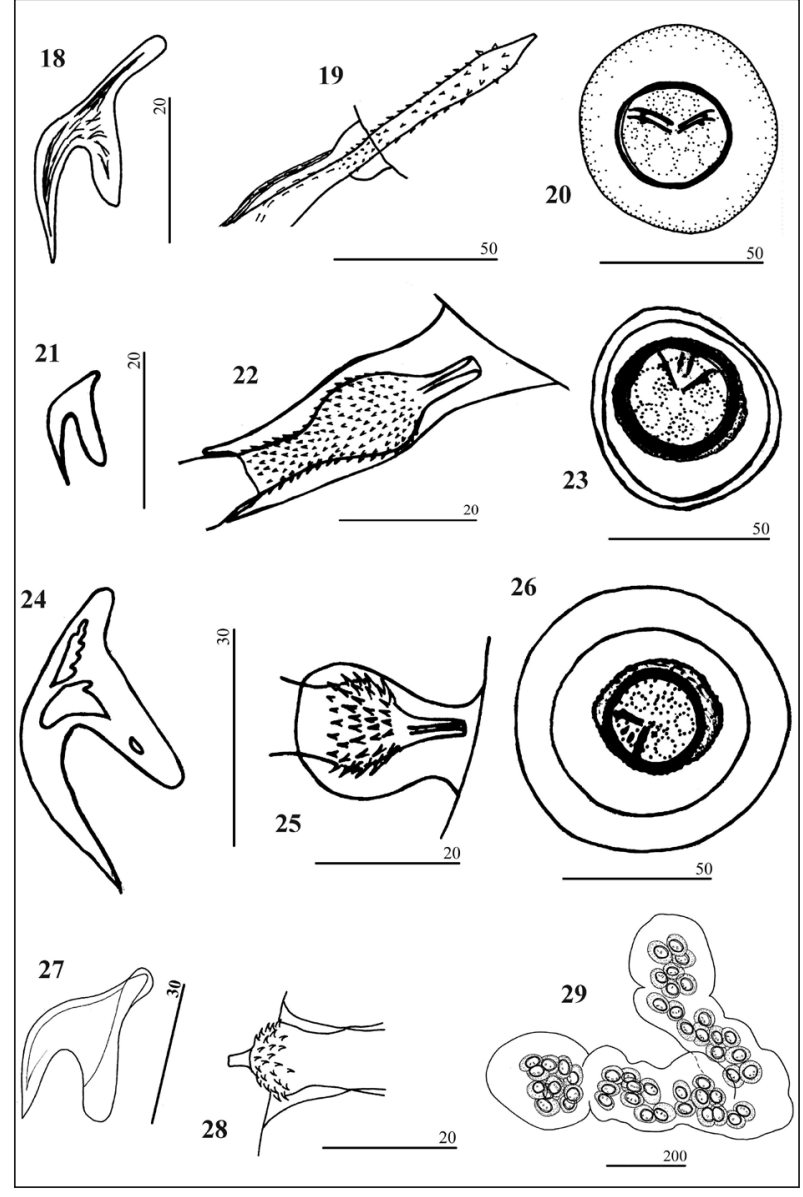

Diagnostic characters (Figs. 27-29). Rostellar hooks 37-40 long. Cirrus sac 240-280, reaches aporal osmoregulatory canals. Cirrus with parabasal swelling, very small, 24 in maximum length; swelling $5 \times 9-12$; covered with spines, slightly larger spines on ventral surface distributed in 3-4 transverse rows of 6-7 in each; smaller spines cover dorsal surface arranged in 4-5 transverse rows of 10-11 in each. Distal part of cirrus pipette-like, unarmed, in most cases invaginated. Eggs enclosed in several packets, 3-51 in each; embryophore with smooth wall; embryonic hooks 12 long.

Remarks. Details of the life cycle of A. clangulae confirmed its differentiation from the closely related species $A$. furcigera and $A$. polystictae, which are also parasitic in Anatinae. The distinctions apply to the species of intermediate hosts, the site within the hosts, and a difference in the metacestode morphology (for details, see Bondarenko and Kondratyeva, 1985). It has not
Figs. 18-20. Aploparaksis birulai: 18 - hook, 19 - cirrus, 20 - egg. Figs. 21-23. Aploparaksis brachyphallos: 21 - hook, 22 - cirrus, 23 - egg. Figs. 24-26. Aploparaksis bulbocirrus: 24 - hook, 25 - cirrus, 26 - egg. Figs. 27-29. Aploparaksis clangulae: 27 - hook, 28 - cirrus, 29 - egg packet

been ruled out that earlier A. clangulae could have been diagnosed under the one of these names.

Museum specimens: CPAR 666 holotype, 667 paratype, Clangula hyemalis, Chukotka, Russia.

\section{Aploparaksis (A.) clavata Spasskaya, 1966}

Subjective synonyms: A. brachyphallos (Krabbe, 1869) sensu Spassky $(1963,1965)$ in part; A. crassirostris (Krabbe, 1869) sensu Huan (1962) in part; A. filum (Goeze, 1782) sensu Huan (1962) in part; A. pseudofilum (Clerc, 1903) sensu Spassky (1965); A. strictae Spassky (1963) sensu Spassky and Yurpalova (1969) in part.

Unconfirmed records: A. clavata Spasskaya, 1966 in Belopolskaya (1969), Belopolskaya and Kulachkova (1970), Bondarenko (1966a)

Hosts: Limicola falcinellus (Pontoppidan) (type-host), Calidris alpina, C. maritima, C. melanotos, Arenaria interpres, Limnodromus griseus. 
Life cycle: intermediate hosts: Lumbriculidae: Styloscolex sokolskajae, Tubificidae: Rhyacodrilus coccineus (Vejdovsky), Enchytraeidae: Mesenchytraeus sp.; site: coelom; metacestode: caudate diplocyst.

Localities: Russia (Kamchatka, type locality), Chukotka, Khabarovskiy kray, Vrangel and Kuril islands), USA (Alaska).

Diagnostic characters (Figs. 30-32). Rostellar hooks 16.6-18 long; blade and guard nearly equal length. Cirrus sac 147-307 × 2137 crosses midline. Fully-evaginated cirrus with parabasal swelling, up to 188 in length; basal part 17-29 × 10-13; parabasal swelling 17-20 × 13-18; distal part 130-140 long gradually decreases in diameter from 6-8 to 3-4; basal part, parabasal swelling and $c .70$ length of distal part covered with numerous small spines. Eggs single; surface of mature embryophore knobbed; embryonic hooks 12 long.

Remarks. The distribution of A. clavata is limited to the eastern part of the Palearctic and Alaska and is not circumboreal, as Schmidt (1986) assumed. A. clavata is a specific parasite of $C$. alpina and is rarely recorded in other shorebirds.

Museum specimens: MHNG 19343, Calidris alpina, Chukotka, Russia.

\section{Aploparaksis (A.) crassipenis Deblock et Rausch, 1968}

Subjective synonyms: Aploparaksis sp. II Belopolskaya et Kulachkova, 1970.

Host: Calidris alpina.

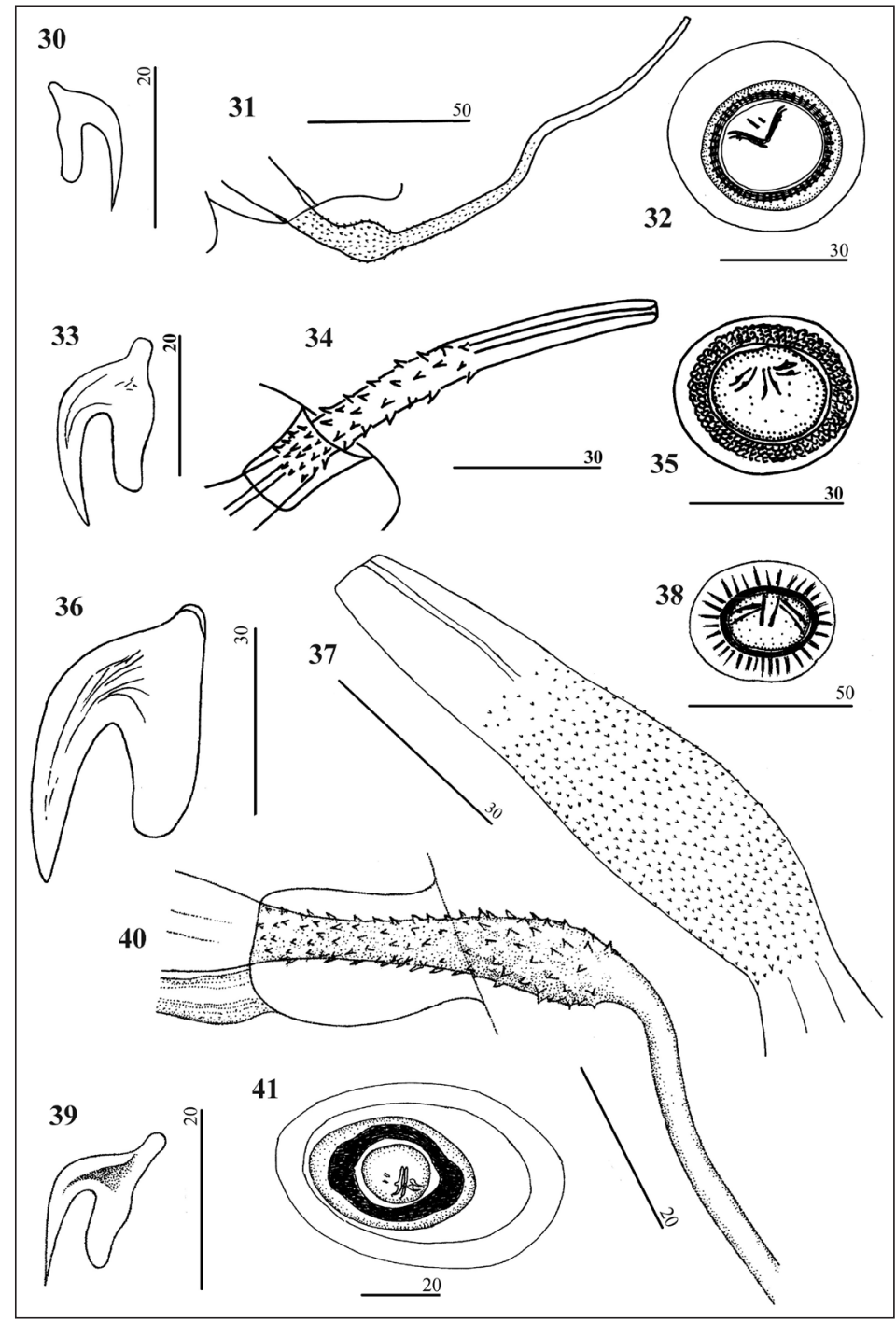

Figs. 30-32. Aploparaksis clavata: 30 - hook, 32 - cirrus, 33 - egg. Figs. 33-35. Aploparaksis crassipenis: 33 - hook, 34 - cirrus, 35 - egg. Figs. 36-38. Aploparaksis crassirostris: 36 - hook, 37 - cirrus, 38 - egg. Figs. 39-41. Aploparaksis demshini: 39 - hook, 40 - cirrus, 41 - egg 
Localities: France (type locality), Ukraine, Russia (White Sea coast).

Diagnostic characters (Figs. 33-35). Rostellar hooks 29-31 in length, blade of hook wide and sharp, slightly longer than guard. Testis large, occupies entire median field of proglottis. Cirrus sac $112-138 \times 28-32$, do not crosses median line. Evaginated cirrus conical, 70-114 long; width of base 8-11, width of distal part 4-5; basal and median parts covered with spines; smaller spines distributed in 5-6 longitudinal rows on basal part; largest triangular spines more sparsely distributed in middle of cirrus arranged in 3 longitudinal rows. Eggs single; surface of mature embryophore hardly knobbed; embryonic hooks 11 long.

Remarks. A. crassipenis corresponds closely with A. moensis, described by Oschmarin (1963) in Calidris tenuirostris (Horsfield) from Primorskiy Kray. According to the description, the only difference is in the armament of the cirrus. Oschmarin (1963) wrote that "surface of cirrus densely covered with spines, larger in its proximal part". Such a characterization, however, is subjective, and the description contains neither the number of rows nor the number of spines therein. We failed to find and study a type-specimen of A. moensis, and therefore we consider A. moensis Oschmarin, 1963 as species inquirenda.

Museum specimens: USNPC holotype 71184, Calidris alpina, France.

\section{Aploparaksis (A.) crassirostris (Krabbe, 1869) Clerc, 1903}

Objective synonyms: Taenia crassirostris Krabbe, 1869; Monorchis crassirostris (Krabbe, 1869) Clerc, 1902;

Subjective synonyms: Aploparaksis echinovatum Deblock et Rausch, 1968; A. moldavica Spasskaja et Shumilo, 1971; A. orientalis sensu Belopolskaya (1969) in parte; sensu Hromada and Macko 1995.

Unconfirmed records: A. crassirostris (Krabbe, 1869) in Clerc $(1903,1910)$, Bondarenko (1975a), Huan Shen I (1962), Mamaev (1959), Spasskaja (1957), Spassky (1963), Spassky and Jurpalova (1969), Spassky (1965), Dubinina (1953), Kornyushin (1967), Deblock and Rausch
(1968), Belopolskaya (1969), Belopolskaya and Kulachkova (1970), Petrova (1978) in part, Demshin (1984), Pelgunov (1986).

Host: Gallinago gallinago.

Localities: Germany (type locality), Moldova, Ukraine, Poland, Slovak Respublic, Russia (Kaliningradskaya oblast', Karelia, Kunashir Island), Iran, USA (Minnesota, Texas).

Diagnostic characters (Figs. 36-38). Rostellar hooks 33-39 in length; blade massive and blunt almost equal length as guard, 20-22 long; base with guard, 24-30 long; handle reduced; width of hook 19-21. Testis large sometime slightly lobed or divided on 2-3 parts; occupied whole middle field of proglottis. Cirrus sac $168-213 \times 33-41$. Cirrus cigar-shaped, 63-98 × 14-18 (20-21 in the specimen mounted in polyvinyl alcohol), evenly covered with equal miniscule spines with the exception of a small region in base and distal part. Eggs single; embryophore of mature eggs knobbed; embryonic hooks 12-14 long.

Remarks. The species was inadequately described by Krabbe (1869). Consequently, many cestodes were attributed to this taxon, and the reported host range of $A$. crassirostris exceeded 30 species of birds from different orders. Studies of type material and numerous collections showed that A. crassirostris, in fact, parasitizes a single host species. For the description of the lectotype of $A$. crassirostris and taxonomic comments, see Bondarenko et al. (2002). Interestingly, this species was never found by us in the snipes of Siberia.

Museum specimens: Zoological Museum of Kopenhagen lectotype 202 (specimen collected by Friis in Tønder), Gallinago gallinago; MNHG paralectotypes $62 / 23,62 / 26,62 / 28$, all from Gallinago gallinago, Germany.

\section{Aploparaksis (A.) demshini Bondarenko et Kontrimavichus, 2005}

Subjective synonyms: A. filum sensu Clerc (1903) in part, sensu Oshmarin (1963) in part.

Host: Scolopax rusticola.

Life cycle: intermediate hosts: Lumbricidae: Dendrobaena octaedra, Eisenia foetida, Eisenia nordenskieldi, Enchytraeidae: Bryadrilus arcticus (experimental infection); site: under 
the chlorogogenous tissue of the intestine of the earthworms and in the wall of the intestine of enchytraeids; metacestode: ovoid diplocyst.

Localities: Russia (Karelia, type locality), the Urals, Primorskiy Kray), Lithuania.

Diagnostic characters (Figs. 39-41). Rostellar hooks 20-25.4 in length; blade long and thin, longer than guard; length of blade 12-15; length of base with guard 15-17; length of guard 7.5; width of hooks 10. Cirrus sac 160-294, in male proglottids reaches and even crosses aporal osmoregulatory canals. Fully-evaginated cirrus spindle-shaped, 84-191 in length; basal part of cirrus 6-9 in length and distal part 59-102 in length, unarmed; parabasal swelling 33-43 × 8-11.6, covered with small, dense spines (c. 6-7 spines in diagonal rows on each side of cirrus). Eggs single; embryophore thinwalled with polar swellings; surface of swelling smooth; surface of middle region becomes slightly granular in most developed embryophores; embryonic hooks 12 long.

Remarks. Among the specimens from Prymorskiy Kray are those in which the cirrus, in a state of partial evagination, is claviform and has a more pronounced parabasal swelling when completely evaginated. We failed, however, to find any other morphological traits allowing the separation of these specimens at the specific or subspecific level (see Bondarenko and Kontrimavichus, 2005).

Museum specimens: BMNH holotype 2004.7.28.1 and paratypes 2004.7.28.2, Scolopax rusticola, Karelia, Russia; CPAR paratype 906, Scolopax rusticola, Karelia, Russia.

\section{Aploparaksis (A.) furcigera (Rudolphi, 1819) Fuhrmann, 1908}

Objective synonyms: Taenia furcigera $\mathrm{Ru}-$ dolphi, 1819; T. rhomboidea Dujardin, 1845; Dicranotaenia furcigera Stilles, 1896.

Subjective synonyms: $A$. pseudofurcigera Mathevosian in Skrjabin \& Mathevosian (1945).

Unconfirmed records: A. furcigera in Belopolskaya and Kulachkova (1970) in part, Spasskaya (1957) in part, Spassky and Yurpalova (1966) in part.
Hosts: Anas boschas ferra (type-host) and numerous Anatinae, mainly of the genus Anas, rarely in domesticated ducks.

Localities: type locality unknown, the geographical range includes Europe, Asia and North America.

Life cycle: intermediate hosts (natural and experimental infection): Lumbriculidae: Lumbriculus variegatus, Limnodrilus hoffmeisteri Claparede, Stylodrilus sp.; site: coelom; metacestode: typical diplocyst.

Diagnostic characters (Figs. 42-44). Rostellar hooks $45-63$ in length; blade wide and blunt, 17-31 in length; length of base with guard $40-44$, length of handle 10-16; width of hook 29-30. Cirrus sac 290-300 $\times 25-29$ reaches or overlaps of medline. Cirrus short, $18-25$ in length, with parabasal swelling, $7 \times 12-17$, covered with spines distributed in 4-5 transverse rows of 13-14 on each side of cirrus; distal part pipette-like, mostly invaginated. Eggs with additional outer envelope or joint in small packets; mature embryophore tuberous, embryonic hooks 14-16 long.

Remarks. A. furcigera is a well-known species, a parasite of wild and domesticated ducks of the Holarctic. According to the literature, the length of the rostellar hooks of $A$. furcigera varies within a wide range (from 47 to 63 ), which is rather unusual for Aploparaksis. In our collections, hook length in specimens from Chukotka are 47-53, 53-60 from Lithuania, and 55 from Karelia. Aploparaksis japonensis, which has hook lengths 59-62, as well as other species known from ducks, could be synonyms of $A$. furcigera. This species needs a detailed revision.

Museum specimens: The specimens in birds from Chukotka are currently held in collections of Bondarenko.

\section{Aploparaksis (A.) gallinagii Bondarenko, 1979}

Subjective synonyms: Monopylidium (=Aploparaksis) filum sensu Parona (1899) in part; A. brachyphallos sensu Davies (1940), sensu Bondarenko (1966a, 1975a); A. clavata Spasskaya, 1966 sensu Bondarenko (1966a) in part; A. crassirostris 
Mamaev (1959) in part); A. pseudofilum sensu Belopolskaya and Kulachkova (1970); A. secessivus sensu Huan (1962) in part; A. diminuens sensu Spasskaya and Spassky (1971).

Hosts: Gallinago gallinago (type-host), G. stenura, Limnocryptes minima.

Life cycle: intermediate hosts: Enchytraeidae: Mesenchytraeus penicillum Eisen (?) (experimental infection); site: coelom; metacestode: caudate diplocyst.

Localities: Russia (Chukotka, type locality), Kaliningradskaya oblast', the lower reaches of the Ob' and the Yenisey rivers, Tuva, the Kuriles), England, and Elba.

Diagnostic characters (Figs. 45-47). Rostellar hooks $17-18$ in length, blade considerably longer than guard, 12-13 long. Cirrus sac 270-360 × 16-33. Cirrus with parabasal swelling; total length $37-52$; basal part $8 \times 4$, swelling 8 in diameter, distal part up to 27 long and 4 wide at base; armament of cirrus hardly visible. Eggs single, with delicate additional outer envelope; surface of mature embryophore tuberous; embryonic hooks 14 long.

Remarks. A. gallinagii was at first described under the name $A$. brachyphallos by Davies (1940) in L. minima from England. Both A. gallinagii and $A$. brachyphallos differ not only morphologically but also with respect to their ontogeny and life cycles. For details of the morphology, taxonomic comments and life cycle, see Bondarenko (1979).

Museum specimens: CPAR 509 holotype, G. gallinago, Chukotka, Russia; MNHG 19334 paratype, G. gallinago, Chukotka, Russia.

\section{Aploparaksis (A.) groenlandica (Krabbe, 1869) Baer, 1956}

Objective synonyms: Taenia groenlandica Krabbe, 1869; Hymenolepis groenlandica (Krabbe, 1869) Railliet, 1899, Haploparaksis groenlandica Baer, 1962.

Subjective synonyms: $A$. polystictae sensu Leonov, Belogurov and Zueva (1970).

Hosts: Clangula hyemalis (type-host), Anas acuta L., Aythya marila (L.), Somateria fischeri, S. mollissima, S. spectabilis, Anser erythropus (L.).
Life cycle: intermediate hosts: Lumbriculidae: Stylodrilus sp. (experimental infection), Lumbriculus variegatus (natural infection); site: coelom; metacestode: tipical diplocyst.

Localities: Greenland (type locality), Iceland, Russia (White Sea coast, Yakutia, Kamchatka, Chukotka, Wrangel Island).

Diagnostic characters (Figs. 48-50). Rostellar hooks 31-42 in length, with well developed handle, 9-13 long. Cirrus sac 270-320, in mature proglottids crosses midline. Cirrus 130-210 long, with poorly developed basal $(14 \times 9)$ and parabasal $(38 \times 10)$ swellings; distal part sometimes coiled; basal swelling and proximal part of parabasal one covered with distinct spines; triangular spines covering parabasal swelling arranged in 14 transverse rows of 6 spines in each; small narrowed region between both swellings unarmed. Eggs single, embryonic hooks 14 long.

Remarks. The type material was not discovered. Baer (1962) considered A. polysticta as a synonym of $A$. groenlandica on the basis of almost equal length of hooks and cirrus sac, although the length and the form of cirrus were not considered. For details of the morphology, taxonomic comments and life cycle, see Bondarenko (1975b), Bondarenko and Kontrimavichus (2006a).

Museum specimens: MNHG 121/026-027 voucher specimens, Clangula hyemalis, Myvatn, Iceland.

\section{Aploparaksis (A.) hirsuta (Krabbe, 1882) Clerc, 1903}

Objective synonyms: Taenia hirsuta Krabbe, 1882; T. pubescens Krabbe, 1882; Monorchis hirsuta Clerc, 1902; Hymenolepis hirsuta (Krabbe, 1882) sensu Fuhrmann, 1908 lapsus (see Fuhrmann, 1932).

Subjective synonyms: A. lymnocrypti Bondarenko, 1966; A. crassirostris (Krabbe, 1869) sensu Petrova (1978).

Unconfirmed records: A. hirsuta in Belopolskaya (1969) in part, Bondarenko (1966a), Mamaev (1959) in part; Clerc (1903), Spasskaya (1956), Spassky (1963), Spassky and Spasskaya (1971), Spassky and Yurpalova (1969). 


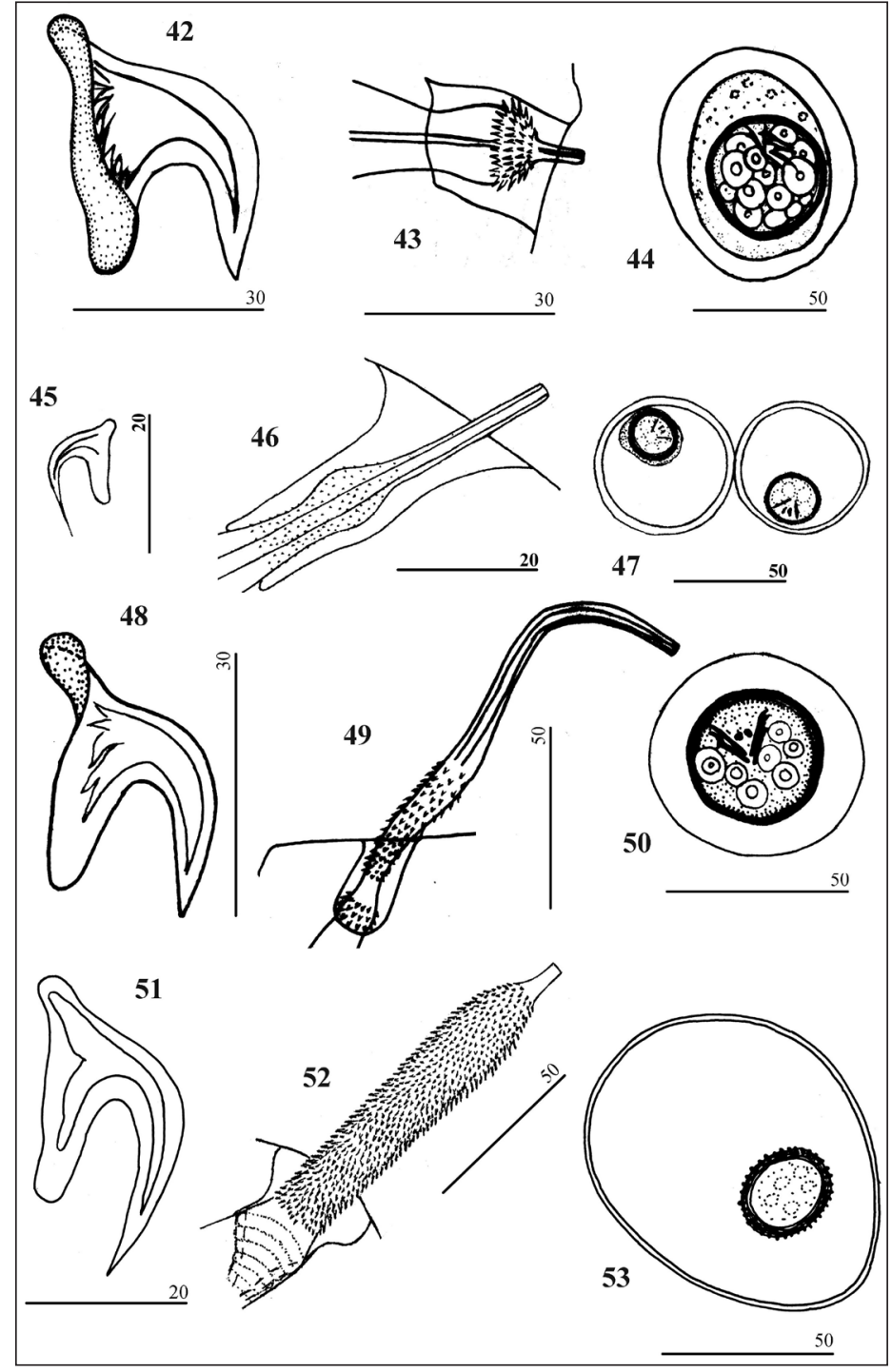

Figs. 42-44. Aploparaksis furcigera: 42 - hook, 43 - cirrus, 44 - egg. Figs. 4547. Aploparaksis gallinagii: 45 - hook, 46 - cirrus, 47 - eggs. Figs. 48-50. Aploparaksis groenlandica: 48 - hook, 49 - cirrus, 50 - egg. Figs. 51-53. Aploparaksis hirsuta: 51 - hook, 52 - cirrus, 53 - egg
Hosts: Lymnocryptes minimus (Brunnich) (type-host), Tringa ochropus L.

Localities: Germany (type locality), Bulgaria, Russia (White Sea coast, Kaliningradskaya and Novgorodskaya oblast', the lower reaches of the Ob' and the Yenisey rivers), Ukraine, Turkmenistan.

Diagnostic characters (Figs. 51-53). Rostellar hooks 37-41 in length, length of blade 22-23, length of base with guard 26-28. Cirrus sac $197-263 \times 35-49$, in gravid proglottids occupies $1 / 3$ of its wide. Cirrus cylindrical, $127-139 \times 16-23$; covered with evenly spaced and crowded spines, 2 in length, distributed in transverse rows (c. 15 spines in each); distal part pipette-like, mostly invaginated, unarmed.
Eggs single with additional outer envelope; embryophore without polar thickenings, tuberous; embryonic hooks 11-12 long.

Remarks. In the original description of Krabbe (1882), through a clerical error, this species appears concurrently under two species-names, T. hirsuta and T. pubiscens. Clerc $(1903,1910)$ corrected this error and transferred species within the genus Aploparaksis under the name A. hirsuta. Clerc did not, however, take into account the considerable differences in the shape and size of the cirrus of $A$. hirsuta and specimens in G. media and T. ochropus from the Urals, described by him under this name; he emphasized the length of rostellar hooks as the main specific characteristic. Spassky (1963) accepted Clerc's 
treatment and described as A. hirsuta a specimen in Tringa hypoleucos from Yakutia. Deblock and Rausch (1968) recognised A. hirsuta sensu Spassky (1963) as a synonym of A. bulbocirrus. At the same time, these authors supposed that A. lymnocrypti Bondarenko, 1966 in L. minimus from Central Siberia was a synonym of $A$. hirsuta. We support this opinion and show that A. hirsuta is a specific parasite of the jacksnipe and rarely the green sandpiper, and is only found in the ceca. We considered the data of Demshin (1981b) concerning the life cycle of $A$. hirsuta (studied experimentally) to be invalid because the description of tapeworms and information about a host are absent. The author probably described the life cycle of $A$. scolopacis.

Museum specimens: CPAR holotype 107 and paratypes 599, 600, Lymnocryptes minimus, Taimyr, Russia (all slides designated as type specimens of A. lymnocrypti).

\section{Aploparaksis (A.) japonensis Yamaguti, 1935}

Hosts: Anas platyrhynchos L. (type-host), A. crecca.

Localities: Japan (type locality), Russia (west coast of Sea of Okhotsk), Ukraine.

Diagnostic characters (Figs. 54, 55). Rostellar hooks 57-62 long, massive, with developed handle; length of blade 23-25; length of base with guard 49; length of handle 16-18. Cirrus sac relatively short, $140-200 \times 23-24$. Cirrus cigar-shaped, miniature, 28-65 long and 7-8 maximal wide in proximal part; diameter of distal part decreases to 3; middle of cirrus armed with numerous small spines which are absent on the distal end. Outer additional envelope of eggs intensively stained; embryophore smooth-walled; embryonic hooks 13 long.

Remarks. A. japonensis parasitizes the ceca and rectum of ducks. In the description of Yamaguti (1935), there is a certain inconsistency between the illustrations and descriptions of the cestode which gave Ablasov (1953) and Baer (1956) the basis to regard $A$. japonensis as a synonym of $A$. furcigera. This opinion was later approved by Spassky (1963). Yamaguti (1959) ignored the point of view of Baer and regarded A. japonensis to be a valid species. Yamaguti also included
Anas rubripes Brewster from America in its list of hosts with reference to USNPC; however, the catalogue of the museum does not contain the species mentioned. Bondarenko and Kondratyeva (1985) believed that one specimen described by them from A. crecca on the coast of the Sea of Okhotsk belonged to A. japonensis. The description of $A$. japonensis by Kornyushin and Greben (2000) in A crecca from Ukraine slightly differs from that published earlier. Yamaguti's type material was not available for our study.

Museum specimens: CPAR 697 voucher specimen, Anas crecca, west coast of the Okhotsk Sea, Russia.

\section{Aploparaksis (A.) kornyushini Bondaren- ko et Kontrimavichus, 2006}

Subjective synonyms: Aploparaksis scolopacis Kornyushin (1975) in part.

Life cycle: intermediate host: Lumbricidae: Dendrobaena octaedra (experimental infection); site: chlorogogenous tissue of intestine; metacestode: ovoid diplocyst.

Localities: Black Sea Reserve, Ukraine (type locality), Lithuania, Russia (Tver' Region, the Urals, Yakutia).

Diagnostic characters (Figs. 56-58). Rostellar hooks stout, 27-31 long, blade blunt, nearly as long as guard, 13-16 long; base 20-25 long; guard 14 long; handle 5-9 long. Cirrus sac 184-287 × 24-37 crosses median line. Fullyevaginated cirrus fusiform, 37-77 maximum length; maximum width in median region 5-9; width in distal part 2-3; basal region 8-10 long and distal region 12-42 long, unarmed; medial region 25-31 long, covered with small dense spines (c. 6-7 spines per diagonal row on each side of cirrus). Eggs single with additional outer envelope; embryophore 47-49 × 42-45, with wall up to eight thick, with polar swellings and two large or several smaller lateral projections; embryonic hooks 13-14 long.

Remarks. For details on morphology, the life cycle, and discussion, see Bondarenko and Kontrimavichus (2006c).

Museum specimens: IZU holotype 181-3, Scolopax rusticola, Ukraine; BMNH paratypes 2004.7.28.6 and 2004.7.28.7, S. rusticola, 
Lithuania; ZIN paratypes, S. rusticola, Russia, the Urals (collection of Clerc).

\section{Aploparaksis (A.) kulachkovae Bondarenko, 1987}

Subjective synonyms: $A$. furcigera sensu Spasskaya (1957) in part, Spassky and Yurpalova (1966) in part, Belopolskaya and Kulachkova (1970) in part.

Hosts: Anas crecca (type host), A. formosa Georgi, A. platyrhynchos, Aythya marila.

Site: ceca, rarely boundary between small intestine and rectum.

Life cycle: intermediate host: Lumbriculidae: Lumbriculus olgae (experimental infection), site: coelom; metacestode: typical diplocyst.
Localities: Russia: Tyumenskaya oblast' (type locality), Chukotka, Murmanskaya oblast', Komi Republic and Republic of Tuva.

Diagnostic characters (Figs. 59-62). Rostellar hooks 47-53 in length; blade 15-20 long, about the same length as guard; base with guard 37-45 long; handle 12-20 long. Cirrus sac 170$220 \times 20-30$. Cirrus cigar-shaped, 38-56 × 5-9; covered with middle part with small spines distributed in 11-15 transverse rows (c. 7-8 spines in each); diameter of distal part decreases to 2 . Eggs in packet, 1-6 eggs in each; embryophore smooth; embryonic hooks 13-14 long.

Remarks. A. kulachkovae is very similar to A. japonensis and differs only metrically; this species often occurs concurrently with

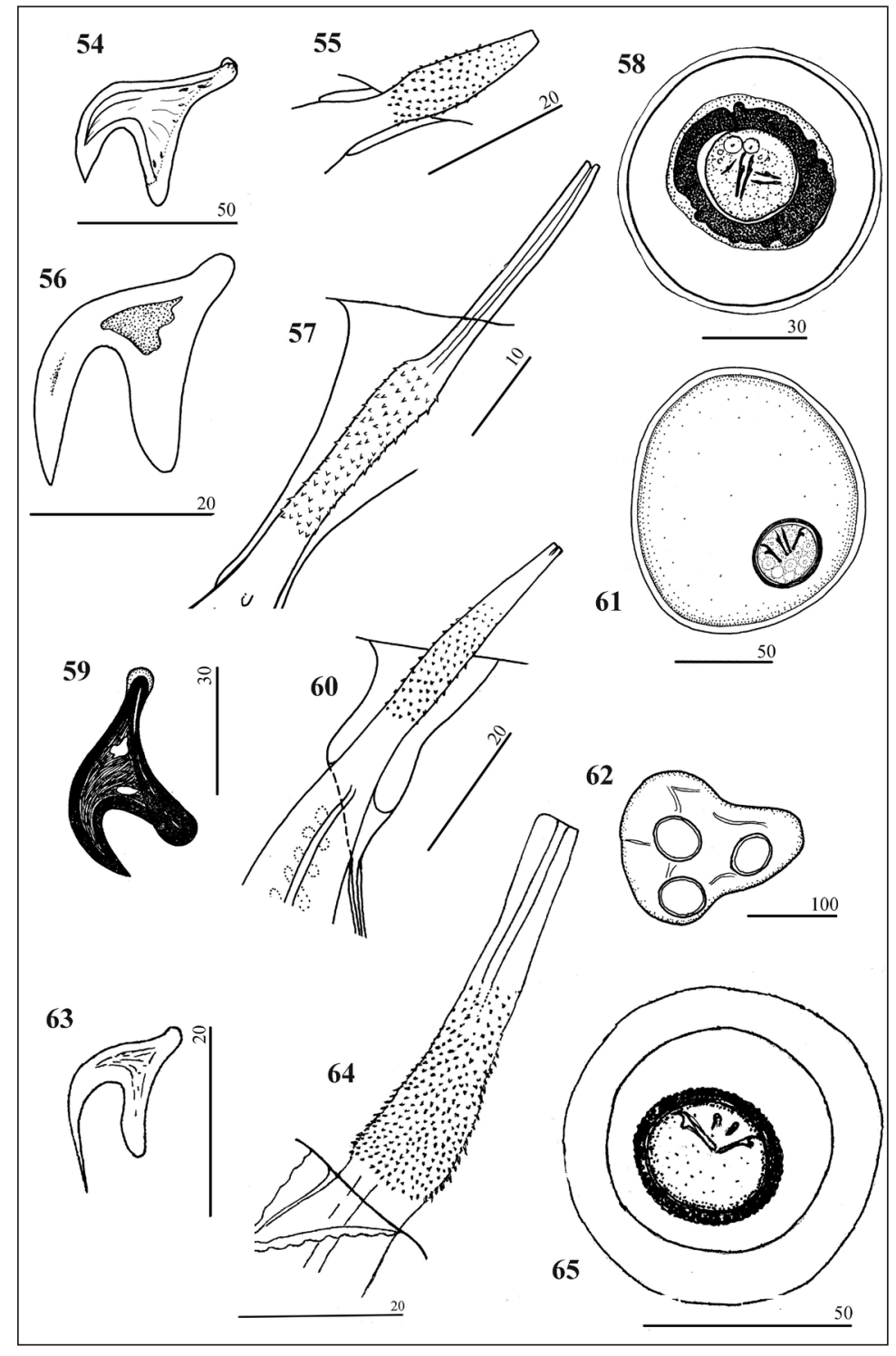

Figs. 54-55. Aploparaksis japonensis: 54 - hook, 55 - cirrus. Figs. 56-58. Aploparaksis kornyushini: 56 - hook, 57 - cirrus, 58 - egg. Figs. 59-62. Aploparaksis kulachkovae: 59 - hook, 60 - cirrus, 61 - egg, 62 - egg packet. Figs. 63-65. Aploparaksis leonovi: 63 - hook, 64 - cirrus, 65 - egg 
A. furcigera. For details of the morphology, taxonomic comments and the life cycle, see Bondarenko (1987).

Museum specimens: CPAR holotype 636, Anas crecca, lower reaches of the $\mathrm{Ob}$ ' river and paratypes 636a, 637, A. crecca, Komi, Russia.

\section{Aploparaksis (A.) leonovi Spassky, 1963}

Subjective synonyms: $A$. brachyphallus sensu Mamaev (1959); A. clavata sensu Spassky \& Yurpalova (1969) in part; A. filum sensu Dubinina (1953) in part.

Hosts: Calidris minuta (type host), C. alpina, C. mauri, C. melanotos, C. ruficollis (Pallas), C. temminckii, Calidris alba (Pallas), Arenaria melanocephala (Vigors), Eurynorhynchus pygmeus (Linnaeus), Limicola falcinellus, Limnodromus griseus, Numenius madagascariensis (Linnaeus), Phalaropus lobatus, Xenus cinereus (Guldenstadt), Tringa glareola, T. totanus.

Life cycle: intermediate host: Lumbriculidae: Styloskolex sokolskajae, Tubificidae: Ryacodrilus coccineus, Enchytraeidae: Mesenchytraeus sp.; site: coelom; metacestode: caudate diplocyst.

Localities: Russia (Kamchatka (type locality), Kaliningradskaya oblast', White Sea coast, the lower reaches of the Ob', Yenisey, and Lena rivers, Chany Lake, Chukotka, Bering and $\mathrm{Ku}-$ nashir islands), Ukraine, Alaska (USA).

Diagnostic characters (Figs. 63-65). Rostellar hooks 18-22.5 in length; blade thin, 13-14 long; base with guard 15-15.5 long; width of hook 10.5. Testis large, $80-90 \times 241-300$ can permit in next proglottis. Cirrus sac does not reach midline, $250 \times 33$. Cirrus cylindrical, 55-61 long, sometimes with slight constriction in middle part; maximum of cirrus width 8-16; covered with spines at proximal part; distal part 6.5 in diameter, unarmed. Eggs single with additional hyaline envelope; embryophore evenly thickened, tuberous; embryonic hooks 12-13 long.

Remarks. The name A. leonovi was first introduced by Spassky (1961) in the published key to the species of genus Aploparaksis; a full description of this species was published later (Spassky, 1963). A. leonovi is a widespread parasite of sandpipers and, rarely, other shorebirds of the Holarctic, especially in its northern region. For the details of the morphology and the life cycle, see Bondarenko et al. (2006a).

Museum specimens: CPAR syntypes 245254, 257, 258 Calidris minutus, 242-244 Limicola falcinellus, 255 Numenius madagascariensis, all from Kamchatka, Russia; MHNG 19339, Calidris melanotos and 19344, Phalaropus lobatus, Chukotka, Russia; USNPC voucher specimens 091865.00 and 091867.02, Phalaropus lobatus, both from Alaska; 71178, Calidris mauri, Napaskiak, Alaska (specimen from collection of R. Rausch).

\section{Aploparaksis (A.) mackoi Bondarenko et Hromada, 2004}

Subjective synonym: Aploparaksis sp. sensu Hromada \& Macko (1995)

Host: Gallinago gallinago

Localities: Slovak Republic (Carpathian Region)

Diagnostic characters (Figs. 66-68). Rostellar hooks 19 in length, blade long and thin, twice as long as guard, length of blade 15; length of base with guard 12; length of guard 8 ; handle reduced. Testes appear as three small primordia close together, which later unite to become single. Cirrus sac large, 246-533 $\times 45-61$, reaches or overlaps antiporal osmoregulatory canals; sometimes antiporal region of cirrus sac reaches opposite margin of hermaphroditic proglottis and forms S-shaped bend relative to its transverse axis. Fully-evaginated cirrus enormous, conical, up to 697 long and 25-37 wide at base; distal part of fully-evaginated cirrus often spirally coiled, decreases to 8 in diameter; basal part of cirrus (c. 40-80 in length) covered with very small spines in 12-16 transverse rows. Internal surface of uterus covered by layer of cells, which possibly secretes granular substance that surrounds eggs and links them together in packets. Embryophore without polar swellings, embryonic hooks 16-18 long.

Remarks. For a detailed description of A. mackoi, see Bondarenko and Hromada (2004).

Museum specimens: BMNH holotype 2001.7.16.1, G. gallinago, Carpathian Region; paratype 2001.7.16.2, G. gallinago, Carpathian Region; paratypes also are in the Museum of 


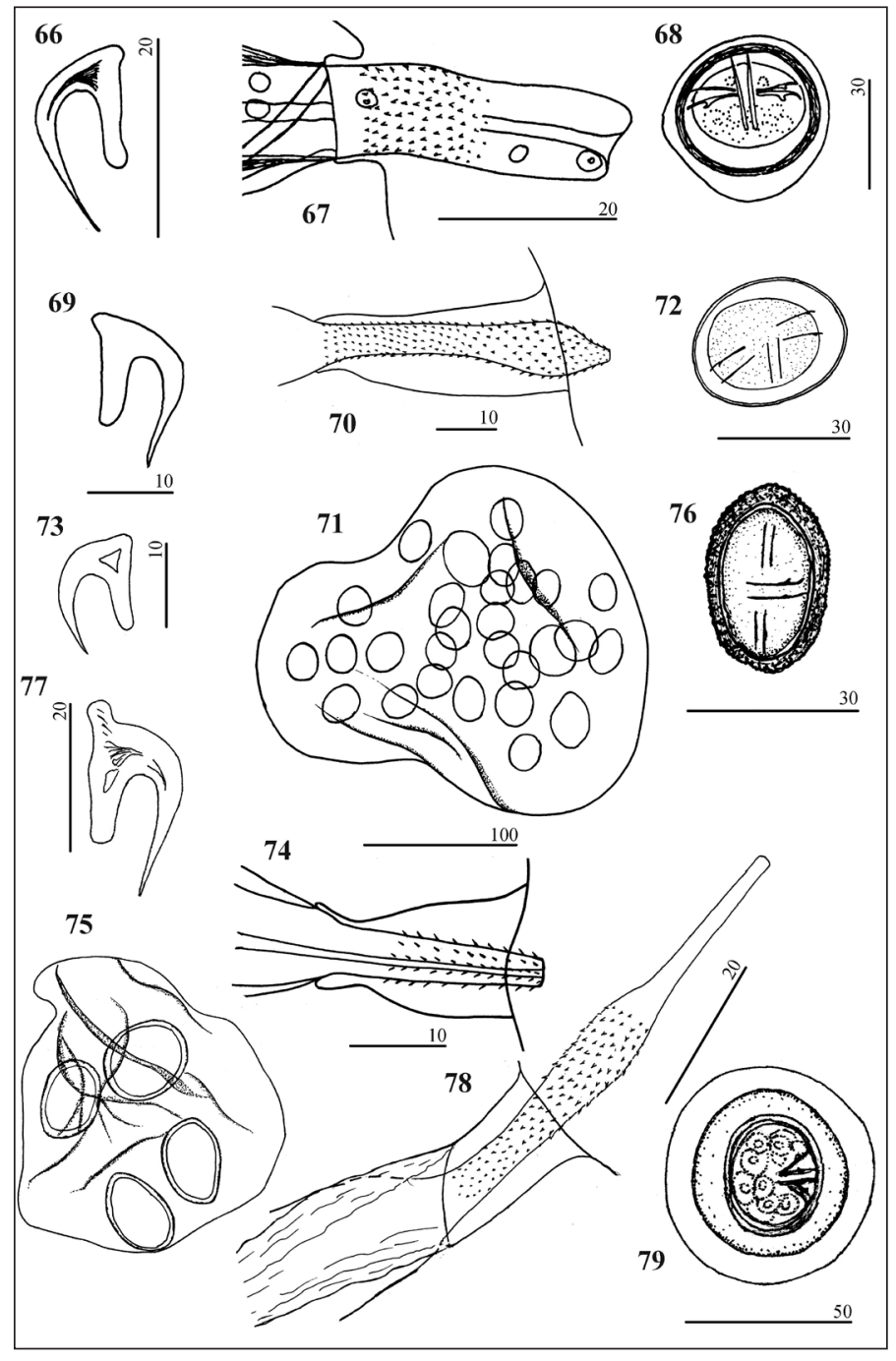

Figs. 66-68. Aploparaksis mackoi: 66 hook, 67 - cirrus, 68 - egg. Figs. 6972. Aploparaksis mamaevi: 69 - hook, 70 - cirrus, 71 - egg packet, 72 - egg. Figs. 73-76. Aploparaksis microcirrus: 73 - hook, 74 - cirrus, 75 - egg packet, 76 - egg. Figs. 77-79. Aploparaksis occidentalis: 77 - hook, 78 - cirrus, 79 - egg

the Parasitological Institute SAS, Košice, Slovak Republic.

23. Aploparaksis (A.) mamaevi (Bondarenko, 1966) Belopolskaya et Kulachkova, 1968

Objective synonym: Globarilepis mamaevi Bondarenko, 1966.

Subjective synonym: A. sachalinensis Krotov, 1952 sensu Mamaev (1959).

Host: Tringa glareola (type host), Calidris acuminata, Heteroscelus incanus.

Localities: Russia: Yakutia (type locality), the Baltic Sea coast, Taimyr.

Diagnostic characters (Figs. 69-72). Rostellar hooks 17 in length. Cirrus sac reaches, but not crosses median line, $235-252 \times 25-29$. Cirrus with parabasal swelling, total length of cirrus 73 ; length of base with guard 21 ; paraba- sal swelling of cirrus $15 \times 8-10$; length of distal part 37; base and parabasal swelling covered with small spines. Eggs enclosed within 4-6 large packets; embryophore smooth-walled; embryonic hooks 11-12 long.

Remarks. A. mamaevi was originally described as a member of Globarilepis (Bondarenko, 1966b), but Belopolskaya and Kulachkova (1968) reduced the status of Globarilepis to a subgenus. This decision was based on the histology of the uterine packets or "capsules" which have a secretory origin. Schmidt (1986) ignored their opinion and, moreover, replaced Globarilepis within the subfamily Pseudohymenolepidinae. Our later investigations (Bondarenko, 1975a,b; Bondarenko and Kontrimavichus, 1976; Bondarenko and Krasnoshchekov, 1978) show that the live eggs of most studied species 
of Aploparaksis have an additional external hyaline envelope, and when the envelopes of a few or all of the eggs join together, the eggs accordingly become enclosed in numerous or single packets. We reduced the genus Globarilepis as a synonym of the genus Aploparaksis based on this observation.

Museum specimens: CPAR syntypes 228, 232, 233 Tringa glareola, 239 T. nebularia, 231 Calidris acuminata, all from Yakutia, Russia.

\section{Aploparaksis (A.) microcirrus (Bondaren- ko, 1966) Belopolskaya et Kulachkova, 1968}

Objective synonym: Globarilepis microcirrus Bondarenko, 1966.

Subjective synonyms: A. filum sensu Parona (1902) in part; A. clavata Spasskaya, 1966 sensu Bondarenko (1966a); A. diminuens Linstow, 1905 sensu Spasskaya and Spassky (1971).

Hosts: Lymnocryptes minimus (type host), Gallinago gallinago.

Localities: Russia (Taimyr, type locality), the lower reaches of the Ob' River, Republic Tuva, coasts of the White and the Baltic seas), Elba, Turkmenistan, Slovak Republic (Carpathian Region.)

Diagnostic characters (Figs. 73-76). Rostellar hooks 13-17 (frequently 14-15) in length; length of blades 10-12; length of base with guard 12-13; length of guard 7-8; handle reduced. Young testis sometimes lobed or consists of 2-3 parts. Cirrus sac 190-230 × 21-31, do not cross median line. Cirrus very small, conical, $25-29 \times 4-6$; covered with very small spines (visible under immersion objective) distributed in 4-5 longitudinal row of 9-10 spines; basal part of cirrus about five long, unarmed. Eggs enclosed within numerous packets, each with 1 to 20 eggs; embryophore tuberous; embryonic hooks 11 long.

Remarks. This species was originally described as a member of Globarilepis (see Bondarenko, 1966b). The concurrent infection of A. microcirrus and A. mackoi in the intestine of G. gallinago was discovered by us in the material of Dr. Macko from the Carpathian Region in the Museum of the Parasitological Institute SAS, Košice, Slovak Republic (slide No. 1159/62). In $\mathrm{BMNH}$, we recorded A. microcirrus in L. minu- tus on slide No. 26 from Rees's collection, which was originally designated as A. brachyphallos from England, and on two slides from series 246-249 from Northern Ireland, 1938 (the author of the material is unknown), which were originally designated as A. filum.

Museum specimens: CPAR holotype 228, Lymnocryptes minimus, Taimyr, Russia; 431, 508 Gallinago gallinago, Tuva, Russia.

\section{Aploparaksis (A.) occidentalis Prudhoe et Manger, 1966}

Subjective synonyms: $A$. diagonalis Spassky et Bobova, 1961 sensu Deblock and Rausch (1968) in part; A. stricta Spassky, 1963 sensu Deblock and Rausch (1968) in part.

Unconfirmed records: A. occidentalis in Spassky and Yurpalova (1968) in part.

Hosts: Limnodromus scolopaceus (Say) (type host), L. griseus, Calidris alpina, C. melanotos, Philomachus pugnax, Phalaropus lobatus, Pluvialis squatarola.

Localities: North America: USA (Alaska, Montana, Texas (type locality), Mexico; Russia (Chukotka).

Life cycle: intermediate hosts (natural and experimental infection): Lumbriculidae: Styloscolex socolskajae, Tubificidae: Rhyacodrilus coccineus, Enchytraeidae: Bryodrilus arcticus, Mesenchytraeus sp. (=M. chaunus Piper et MacLean), Henlea perpusilla Friend, Marionina (?) sp.; site: coelom; metacestode: caudate diplocyst.

Diagnostic characters (Figs. 77-79). Rostellar hooks 25-29 in length; blade thin 14-18 long, longer than guard; base with guard 18-20 long; length of guard 10-12, width of hook 12-14. Cirrus sac $130-210 \times 15-20$ (in original description), 225-266 × 29-45 (concerning our data). Cirrus spindle-shaped, 40-66 × 6-8; proximal two-thirds armed with small spines arranged in diagonal rows of 7-8 in each; distal end 23 long unarmed. Live eggs with an additional outer envelope, single or sometimes paired; embryophore without polar swellings, slightly tuberous; embryonic hooks 12-15 long.

Remarks. Common and one of the dominant parasites of Limnodromus spp. from 
North America (Bondarenko and Kontrimavichus, 1999, Canaris et al., 2010) and Chukotka (Spassky and Yurpalova, 1969, Bondarenko, 1975a). For variability of morphological characters and the life cycle of $A$. occidentalis, which parasitizes birds of Chukotka, see Bondarenko and Kontrimavichus (2006a).

Museum specimens: BMNH holotype and paratypes 1966.8. 1. 69-80, Limnodromus griseus, USA, Texas; USNPC 71177, Arenaria interpres designated as $A$. diagonalis; 71181, Calidris melanotos designated as A. stricta, both from Alaska, USA; 19280, L. scolopaceus, Alaska in the collection of R. Rausch designated as $A$. diagonalis; USNPC among the voucher speciments 78881-78891, Limnodromus spp. from USA (Texas) and Mexico.

\section{Aploparaksis (A.) octacantha Spasskaya, 1950}

Subjective synonyms: A. brachyphallos Krabbe sensu Krotov (1952) in part; A. clavata Spasskaja, 1966 sensu Spassky and Yurpalova (1969) in part; A. crassirostris (Krabbe) sensu Mamaev (1959), sensu Huan (1962) in part, sensu Spassky and Yurpalova (1969) in part; A. rauschi Spassky sensu Schmidt and Neiland (1968) in part; A. retroversa Spassky et Gubanov sensu Spasskaya (1966) in part, sensu Deblock and Rausch (1968), sensu Belopolskaya (1969) in part, sensu Belopolskaya and Kulachkova (1970), sensu Bondarenko (1975a ) in part.

Hosts: Calidris temminckii (type host), C. alpina, C. ferruginea, C. maritima, C. minuta, C. ptilocnemis (Coues), C. ruficollis, C. temminckii, Philomachus pugnax, Arenaria interpres.

Site: ceca, rarely the margin between small intestine and rectum.

Life cycle: intermediate hosts: Tubificidae: Rhyacodrilus coccineus, Enchytraeidae: Mesenchytraeus sp. II (=M. penicillus?), Bryodrylus arctica; site: coelom; metacestode: caudate diplocyst.

Localities: Russia (West Siberia (type locality), coasts of the White, the Baltic, and the Okhotsk seas, Chukotka, the lower reaches of the Amur River, Wrangel, Kuril and Sakhalin islands), Ukraine, France, USA (Alaska).
Diagnostic characters (Figs. 80-82). Rostellar hooks 28-33 in length; blade blunt, slightly longer than guard, 18-20 long; length of base with guard 20-25; length of guard 8-12; handle rudimental; width of hook 17-21. Cirrus sac $184-225 \times 24-32$, whole places in lateral field or reaches, but not crosses median line. Cirrus short, mostly invaginated, 12-20 in length, maximum diameter in median part $3-5$, at distal end 2; covered with feebly marked spines, visible only when magnified $\times 1000$ in specimens placed in polyvinyl alcohol. Vagina with marked sphincter, 5-6.6 $\times 6.6-10$ located between conductive and copulatory parts. Eggs single; embryophore of mature eggs tuberous, embryonic hooks 12-13 long.

Remarks. This species is a common parasite of Calidris. In the original description of A. octacantha, Spasskaya (1950) mistakenly pointed out that the species was characterised by the presence of eight rostellar hooks, and, as a result, cestodes of this species, which actually have ten hooks, were reported under other names. See also comments for A. retroversa. The life cycle of this species was studied under natural and experimental conditions (Bondarenko and Kontrimavichus, 2006a).

Museum specimens: type specimens are lost; MNHG voucher specimen 19337, Calidris alpina, Chukotka, Russia; USNPC voucher specimen 71186 C. alpina, France, designated as $A$. retroversa; CPAR voucher specimens in Calidris spp. from different parts of Russia (collections determined by Huan, Mamaev, Spassky and Yurpalova), all allocated to A.crassirostris.

\section{Aploparaksis (A.) orientalis Spassky et Bobova, 1961}

Subjective synonyms: $A$. crassirostris (Krabbe) sensu Dubinina (1953) in part, sensu Mamaev (1959) in part, sensu Huan (1962) in part, sensu Spassky and Spasskaya (1971) in part, sensu Leyva et al. (1980), sensu Hromada and Macko (1995); A. filum (Krabbe) sensu Dubinina (1953) in part; A. sanjuanensis Tubangui et Masilungan sensu Mamaev (1959) in part; A. secessivus Gubanov et Mamaev sensu Huan (1962) in part. 
Unconfirmed records: A. orientalis Spassky et Bobova in Tolkacheva (1975) in part.

Hosts: Gallinago gallinago (type host), G. stenura.

Life cycle: intermediate hosts: Lumbriculidae: Lumbriculus variegatus, L. olgae (natural and experimental infection); site: coelom; metacestode: ramicercus.

Localities: Russia: Kamchatka (type locality), Kaliningradskaya oblast', Karelia, the lower reaches of the Yenisey River, Tuva, Yakutia and Chukotka; USA: Colorado; Ukraine.

Diagnostic characters (Figs. 83-85). Rostellar hooks 29-34 long; blade blunt and wide 16.4-20 long; length of base with guard 22-24.6; width of hook 18-21; handle entirely reduced. Cirrus sac $174-230 \times 30-40$. Cirrus sac cigar- shaped, 62-90 in length, maximum width 12-14 in central part; decreases to 4-6 in diameter in pipette-form distal part; middle part of cirrus covered with spines more sparse toward distal end. Eggs single; mature embryophore knobbed; embryonic hooks 13 long.

Remarks. The original description of Spassky and Bobova (1961) lacks information about the scolex, but the strobilar morphology and the structure of the copulatory apparatus were described in detail and prevented mistaken identifications. A. orientalis is very similar to $A$. crassirostris, and both species often coexist in the intestine of the same snipe. The geographical range of $A$. orientalis includes European and Asian parts of the Palearctic, but it is not improbable that tapeworms of this species have

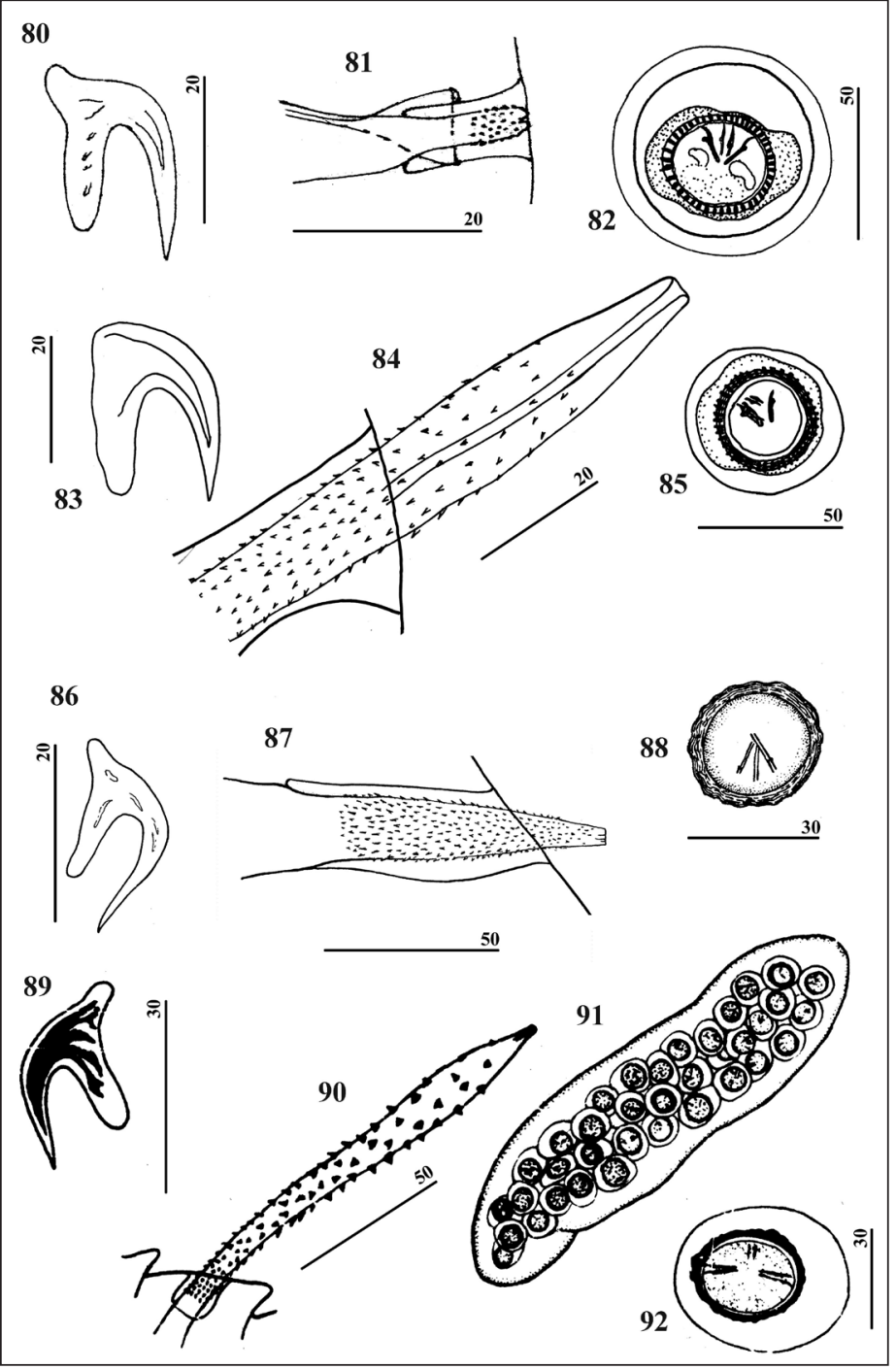

Figs. 80-82. Aploparaksis octacantha: 80 - hook, 81 - cirrus, 82 - egg. Figs. 8385. Aploparaksis orientalis: 83 - hook, 84 - cirrus, 85 - egg. Figs. 86-88. Aploparaksis oschmarini: 86 - hook, 87 - cirrus, 88 - egg. Figs. 89-92. Aploparaksis parabirulai: 89 - hook, 90 - cirrus, 91 - egg packet, 92 - egg 
been recorded under another species name (e.g., Leyva et al., 1980). The life cycle of this species in Chukotka was studied by Bondarenko (1993b).

Museum specimen: Type material is lost, MNHG voucher specimen 19338, Gallinago gallinago, Chukotka Russia.

\section{Aploparaksis (A.) oschmarini Spassky et Bobova, 1961}

Subjective synonyms: Aploparaksis filum (Goeze) sensu Mamaev (1959) in part; sensu Huan (1962) in part; sensu Spasskaya (1964) in part.

Hosts: Tringa glareola (type host), T. ochropus, T. nebularia, Actitis hypoleucos (Linnaeus), Heteroscelus incanus, Philomachus pugnax.

Localities: Russia (Kamchatka, type locality), Kaliningradskaya Oblast', the White Sea coast, Middle Siberia, Yakutia, Khabarovskiy Kray, Chukotka, and Kunashir Island).

Diagnostic characters (Figs. 86-88). Rostellar hooks 20-24 (26-27 in original description) long; blade sharp, longer than guard, 13 long; base with guard 15-17 long. Cirrus sac $270 \times 30-41$. Cirrus conical, 82-89 long, with maximum width in base 17-24.6, in distal part 5; covered with evenly distributed distinct spines except for base. Eggs single, embryophore without polar swellings, embryonic hooks 14 long.

Remarks. A. oshmarini is the usual parasite of Tringa. Morphologically, this species is similar to A. leonovi, a common parasite of Calidritinae, but there are certain small differences concerning the length of the rostellar hooks and morphology of the cirrus.

Museum specimens: CPAR holotype 239, Tringa glareola; paratype 259 Heteroscelus incanus, all from Kamchatka, Russia.

\section{Aploparaksis (A.) parabirulai Bonda- renko, 1975}

Hosts: Limnodromus griseus (type host), L. scolopaceus.

Locality: Russia (Chukotka), USA (Alaska and Montana).

Diagnostic characters (Figs. 89-92). Rostellar hooks 30-35 in length; length of blade 18-23; length of base with guard 21-24; length of feebly demarcated handle 6. Cirrus sac highly elongated, $170-200 \times 13-14$; in male proglottids crosses aporal osmoregulatory canals; in mature proglottids crosses only midline. Cirrus baseball bat-like, 130-140; diameter evenly enlarges from 8 at base up to 13 (without spine length) toward distal region; cirrus armed with spines of different size: small spines on base arranged in 6 transverse rows; sparse triangular spines distributed in three transverse rows on enlarged part; distal pipette like part unarmed. Eggs enclosed in large, single packet releases from uterus via break of lateral margin of proglottis; embryonic hooks 12 long.

Remarks. A. parabirulai is a specific but rare parasite of dowitchers. Originally, this species was described in a single $L$. griseus from Chukotka (Bondarenko, 1975a). It was first recorded by Kinsella et al. (2008) in two species of dowitchers from North America (Alaska and Montana). A. parabirulai shows strong morphological and metrical similarities with A. birulai, a parasite of ducks, but the shapes of their rostellar hooks differ completely, making the recognition of both species valid.

Museum specimens: CPAR holotype 459; paratypes 1027, 1028, Limnodromus griseus; MHNG paratype 19331, Limnodromus griseus, all from Chukotka, Russia; USNPC voucher specimens, under accession numbers 100290100300 and 100302-100306 in L. griseus and L. scolopaceus, Alaska, USA

\section{Aploparaksis (A.) parafilum Gasowska, 1931}

Subjective synonyms: A. filum (Krabbe) sensu Parona (1902), Lopez-Neyra (1944), Spasskaya (1956), Gomez (1977).

Unconfirmed records: $A$. parafilum in Bayanov (1977), Bondarenko (1966a) in part, Deblock and Rausch (1968), Kornyushin (1967) in part, Kornyushin et al. (1984), Mahon (1956), Ryjikov et al. (1974) in part, Spasskaya $(1957,1964)$ in part, Spasskaya and Spassky (1971) in part.

Hosts: Gallinago gallinago (type host), G. media, G. megala.

Life cycle: intermediate host: Enchytraeidae: Mesenchytraeus sp.; site: coelom; metacestode: typical diplocyst. 
Localities: Ukraine (type locality), Elba, Slovak Republic, Russia (the lower reaches of the $\mathrm{Ob}$ ' and the Yenisey rivers).

Diagnostic characters (Figs. 93-95). Rostellar hooks 22-24.9 in length; blade long and thin $15-16.6$ in length; base with guard 15-16.6 in length; width of hook 10-12. Cirrus sac thickwalled, 143-387 × 37-73. Cirrus foliaceous (lanceolate), 102-224 long in spite of range of evagination; diameter of base 8-13, maximum diameter 24-37 in middle part; evenly decreases to 10-16 in distal part; base of proximal part of cirrus covered with fine, nearly uniform spines. Eggs single; embryophore smooth-walled, with polar swellings, embryonic hooks 15-16 long.

Remarks. For the redescription, morphological variabilities, taxonomic comments and the life cycle, see Bondarenko and Kontrimavichus (2002b).

Museum specimens: MHNG neotype C-6850.19329, Gallinago media, Ob' River, Russia; voucher specimens 61/69 73-75 G. megala, Elba Island, designed as A. filum (collection of Parona).

\section{Aploparaksis (A.) paraspinosus Bonda-} renko et Kontrimavichus, 2001

Subjective synonym: Aploparaksis clerci Yamaguti, 1935 sensu Schmidt (1964) in part.

Host: Gallinago gallinago delicata (Ord).

Locality: Colorado, USA.

Diagnostic characters (Figs. 96-98). Rostellar hooks 17-18 in length; blade 12 long; base with guard 13-15 long. Cirrus sac in young

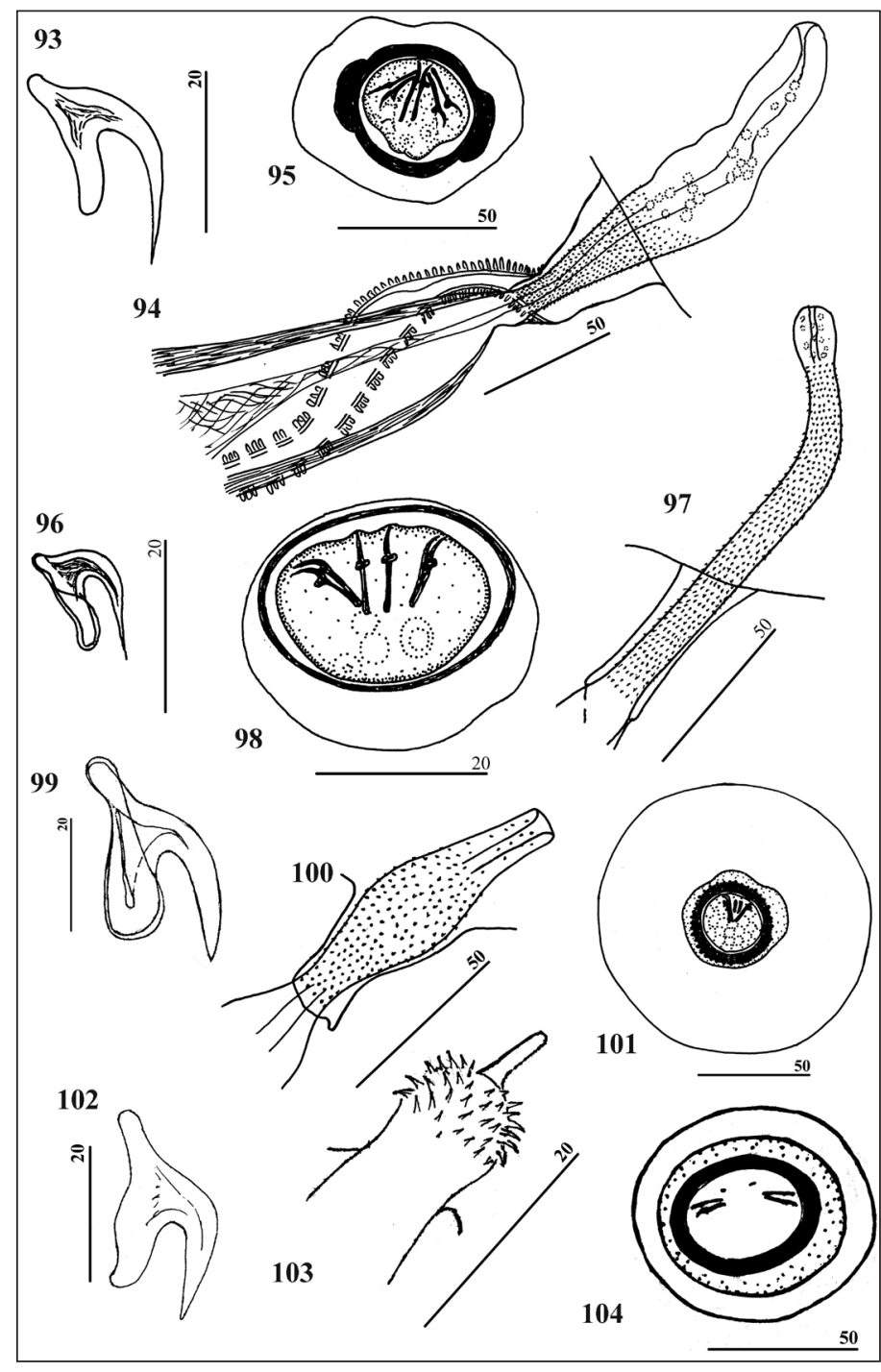

Figs. 93-95. Aploparaksis parafilum: 93 - hook, 94 - cirrus, 95 - egg. Figs. 9698. Aploparaksis paraspinosus: 96 - hook, 97 - cirrus, 98 - egg. Figs. 99-101. Aploparaksis penetrans: 99 - hook, 100 - cirrus, 101 - egg. Figs. 102-104. Aploparaksis polystictae: 102 - hook, 103 - cirrus, 104 - egg 
male proglottids reaches aporal osmoregulatory canals, in mature reaches but not crosses midline. Cirrus clavate when evaginated, when partly evaginated almost cylindrical with thickening in distal part. Length of fully-evaginated cirrus 115-172; base 90-120 long and 12 wide decreases slightly along length; distal swelling $20 \times 12-21$, distal end sharply narrowed, 20-30 long and 3-4 wide at base. Cirrus covered with small spines, distributed in numerous transverse rows approximately 10 in each on visible surface of base; bulbous swelling and distal filament unarmed. Eggs enclosed within few packets; both number of eggs in packets and number of packets variable; embryonic hooks 11-12 long.

Remarks. For details of the morphology of A. paraspinosus, see Bondarenko et al. (2001).

Museum specimens: HWML holotype 33809 A-80, paratype 33809 A-89, syntypes 33809 A-81, A-82, A-86, A-87, Gallinago gallinago, Colorado, USA.

\section{Aploparaksis (A.) penetrans (Clerc, 1902) Clerc, 1903}

Objective synonym: Monorchis penetrans Clerc, 1902.

Subjective synonym: Aploparaksis sobolevi Oschmarin et Morosov, 1948 in Spassky (1963).

Hosts: Gallinago gallinago (type host), G. media.

Site: duodenum, rarely anterior part of small intestine.

Life cycle: intermediate hosts (experimental and natural infection): Lumbriculidae: Lumbriculus variegatus, Styloscolex sokolskajae; site: coelom; metacestode: ramicercus.

Localities: Russia (Urals, type locality), Kaliningradskaya oblast', Karelia, Western and Eastern Siberia, Chukotka, Kunashir Island), Ukraine, Canada (Ontario), USA (California).

Diagnostic characters (Figs. 99-101). Scolex of adult hypertrophic, ten times larger than in metacestode, surrounded by calciferous capsule; rostellum discoidal, hooks reduced; suckers moved towards base of scolex. Scolex of juvenile and immature specimens the same size as in metacestode and usual mode of attachment. Rostellar hooks 41-45 in length; blade blunt 21-25 in length, base with guard 29-35 in length, handle reduced. Cirrus sac piriform 229-328 × 62-119; crosses poral osmoregulatory canals but not reaches middle line. Cirrus mostly invaginated, 127 long and 16 wide, spines covered 45-61 of it length. Cirrus sigar-shaped, fully-evaginated 70-82 long and 25-29 wide in mid-region; evenly covered with small spines. Eggs single, embryophore knobbed, embryonic hooks 12 long.

Remarks. A. penetrans is a specific but rare parasite of Gallinago. This species may coexist with $A$. crassirostris and A. orientalis but differs noticeably from both in the size of strobila, morphology of the adult scolex and the site in the intestine. In a description of A. penetrans, Clerc (1903) mistakenly indicated the size of strobila as being 6-8 $\mathrm{mm}$ long. For the details of morphology and the life cycle of this species, see Bondarenko (1993b) and Bondarenko and Kontrimavichus (2006a).

Museum specimens: Type material not discovered. HWML voucher specimen 33811, G. gallinago, Colorado (USA) designated as A. sobolevi. Additional voucher specimens are in collection of S. Bondarenko.

\section{Aploparaksis (A.) polystictae Schiller, 1955}

Unconfirmed records: A. polystictae in Leonov et al. (1970).

Hosts: Polysticta stelleri (Pallas) (type host), Somateria fischeri, S. spectabilis, Anas acuta, A. formosa, Aythia marilla, Clangula hyemalis.

Life cycle: intermediate host: Lumbriculidae: Stylodrilus sp. (experimental and natural infection); site: coelom; metacestode: typical diplocyst.

Localities: USA (Alaska, type locality), Russia (Chukotka).

Diagnostic characters (Figs. 102-104). Rostellar hooks 34-42 in length; length of blade 14-16; length of base with guard 30-36, length of handle 10-14. Cirrus sac long and thin, 280$310 \times 17-21$, crosses midline or sometimes overlaps aporal osmoregulator canals. Cirrus with parabasal swelling, very small, 14 in maximum length; swelling 7-12 in diameter; covered with spines distributed in four transverse rows of 7-9 
in each; distal part pipette-like, unarmed, invaginated in most cases. Eggs single, with an additional outer envelope or enclosed in packets of few eggs in each; embryophore smooth-walled, embryonic hooks 12 long.

Remarks. In the original description of Schiller (1955), the details of the copulatory system of A. polystictae are obscure. Therefore, Baer (1962) regarded A. polystictae as a synonym of $A$. groenlandica, whereas Ryzhikov (1960) proposed it to be a synonym of $A$. birulai. The life cycle of this species was studied under natural and experimental conditions in Chukotka (Bondarenko, 1975b; Bondarenko and Kontrimavichus, 2006a)

Museum specimen: USNPC holotype and paratype 49437, Polysticta stelleri, USA, Alaska.

\section{Aploparaksis (A.) pseudofilum (Clerc, 1902) Clerc, 1903}

Objective synonyms: Monorchis pseudofilum Clerc, 1902, A. filum var. pseudofilum (Goeze, 1782) Clerc, 1903 in part;

Subjective synonyms: A. filum sensu Krabbe (1869) in part, Clerc (1910) in part, Davies (1940) in part, Dubinina (1953) in part; A. clerci Yamaguti, 1935; A. parafilum sensu Kornyuschin (1967) in part; A. sanjuanensis sensu Mamaev (1959) in part, Bondarenko (1966a) in part, Belopolskaya (1969) in part, Belopolskaya and Kulachkova (1970), Ryzhikov et al. (1974) in part.

Unconfirmed records: A. pseudofilum in Gasowska (1931), Belopolskaya and Kulachkova (1970), Gynetsinskaya and Naumov (1958) in part, Hromada and Macko (1993), Mamaev (1959) in part.

Hosts: Scolopax rusticola (type host), Gallinago gallinago, G. media, G. solitaria, G. stenura.

Life cycle: intermediate hosts (experimental infection): Enchytraeidae: Bryodrilus arctica, Henlea diverticulata, Lumbricidae: Octolasium lacteum, Nicodrilus caliginosus, $N$. roseus, Eisenia foetida, E. nordenskioldi, Eiseniella tetraedra, Dendrobaena octaedra; site: coelom; metacestode: typical diplocyst.

Localities: Russia (Urals, type locality), the White Sea, Karelia, Western and Eastern Siberia, Chukotka, Primorskiy Kray), Ukraine,
Lithuania, England, Germany, Slovak Republic, USA (Colorado).

Diagnostic characters (Figs. 105-107). Rostellar hooks 21.5-24.9 in length; blade long and thin, 13-15 in length; base with guard 13-16 in length. Cirrus sac short, $60-180 \times 29-32$, crosses poral osmoregulator canals or rarely reaches mediam line. Cirrus foliaceous, small, 33-61 in maximal length; diameter of base 11-16; maximum diameter in middle part 18-29; distal part pipette-like, mostly invaginated; basal and medial parts covered with spines. Spines differ in size and shape: spines on basal part small and coniform, in middle part thin and hair-like. Eggs single, embryophore smooth-walled with polar swellings, embryonic hooks 18-21 long.

Remarks. For the details of the morphology and the life cycle of this species, see Bondarenko (1990b).

Museum specimens: Type material is lost. MHNG voucher specimen 19350, Scolopax rusticola, Russia, vicinity of Vladivostok; BMHN B-173 Gallinago gallinago, England (collection of Davies, designed as A. filum).

\section{Aploparaksis (A.) rauschi Webster, 1955}

Subjective synonyms: $A$. crassirostris sensu Mamaev (1959) in part, Spassky (1965) in part, Belopolskaya and Kulachkova (1970) in part, Spasskaya and Spassky (1971) in part; A. filum sensu Huan (1962); A. pseudofilum sensu Mamaev (1959) in part.

Unconfirmed records: $A$. rauschi in Schmidt and Neiland (1968) in part, Spassky (1965) in part.

Hosts: Calidris alpina (type host), C. minuta, C. ferruginea, C. ruficollis, C. temminckii, Eurynorhynchus pygmeus.

Site: ceca, rarely posterior part of small intestine or rectum (evidently due to postmortem movement).

Life cycle: intermediate host (experimental infection): Enchytraeidae: Mesenchytraeus penicillus; site: coelom; metacestode: caudate diplocyst.

Localities: USA (Alaska, type locality), Russia (the White Sea coast, Kamchatka, Chukotka, the Kuril Islands), Turkmenistan. 
Diagnostic characters (Figs. 108-110). Rostellar hooks with wide blade, 31-36 in length; blade 17-20 long, base with guard 22-27 long, guard 13 long, handle 3-5 long; wide of hook 16-19. Cirrus sac 160-180 $\times 16-20$. Fullyevaginated cirrus short, 41-70 in length, nearly cylindrical; maximum width in median region $5-8$, width in basal region 4 , width in distal part $4 ; 2 / 3$ of cirrus length covered with small dense spines (c. 6-7 spines per transversal row on each side of cirrus); distal region of cirrus unarmed. Live eggs single, with accessory external envelope; embryophore without polar swellings, embryonic hooks 12-14 long.

Remarks. A. rauschi appears to show high host specificity to sandpipers of the genus Calidris. When studying the type material in the USNPC, we found that the specimen designated as a 'Type' did not agree with the original description of $A$. rauschi (the real type-specimen prob- ably was left in the collection of the author), but that it corresponds well with that described later by Spassky (1963) as A. rauschi stricta, from the same host. In fact, Webster (1955) described and illustrated the specimen A. rauschi, which had been supported by multiple reports. For morphological variability and its life cycle, see Bondarenko and Kontrimavichus (2006a).

Museum specimens: USNPC holotype 49423, Calidris alpina pacifica, USA, Alaska; MHNG 19340, C. alpina, Russia, Chukotka; CPAR 506, C. testacea (=C. ferruginea), Russia, Tuva, 682 C. alpina, East Siberia, all designed as A. crassirostris.

\section{Aploparaksis (A.) retroversa Spassky et Gubanov, 1961}

Subjective syns: $A$. clavulus Deblock et Rausch, 1968; A. rauschi sensu Schmidt and Neiland (1968) in part.

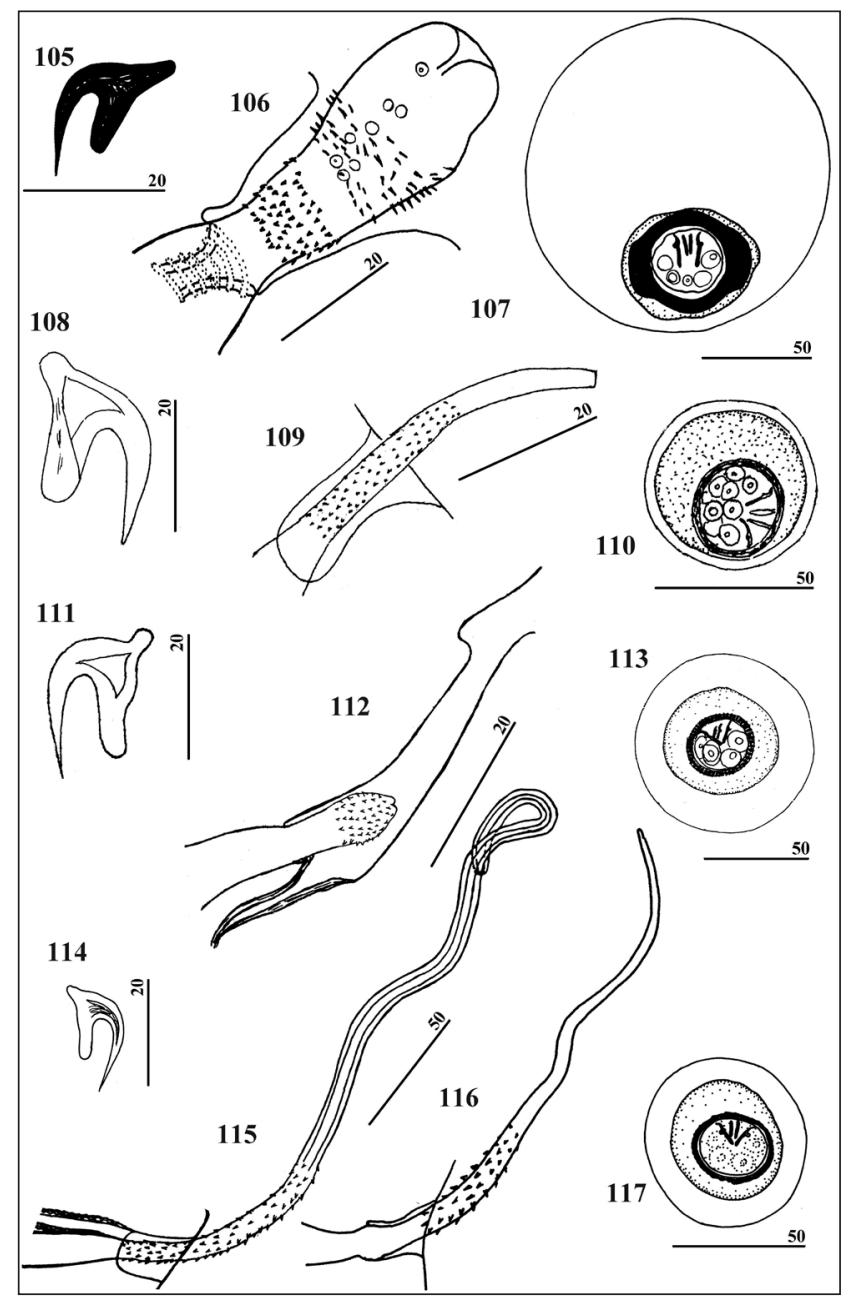

Figs. 105-107. Aploparaksis pseudofilum: 105 - hook, 106 - cirrus, 107 - egg. Figs. 108110. Aploparaksis rauschi: 108 - hook, 109 - cirrus, 110 - egg. Figs. 111-113. Aploparaksis retroversa: 111 - hook, 112 - cirrus, 113 - egg. Figs. 114-117. Aploparaksis rissae: 114 - hook, 115-116 - cirrus, 117 - egg 
Unconfirmed records: $A$. retroversa in Belopolskaya (1969) in part, Belopolskaya and Kulachkova (1970), Bondarenko (1975a) in part, Deblock and Rausch (1968), Spasskaya (1966) in part.

Hosts: Limnodromus griseus (type host), L. scolopaceus, rare Arenaria interpres, A. melanocephala, Calidris melanotos, Tringa glareola, Philomachus pugnax, Pluvialis squatarola.

Site: ceca, rarely posterior part of small intestine or rectum (evidently due to a postmortem movement).

Life cycle: intermediate hosts (experimental infection): Lumbriculidae: Styloscolex sokolskajae, Enchytraeidae: Bryodrilus arcticus, Henlea diverticulata, Mesenchytraeus penicillus (?), Mesenchytraeus sp., Marionina sp., Lumbricidae: Dendrobaena octaedra; site: coelom; metacestode: caudate diplocyst.

Localities: Russia (Yakutia, type locality), Chukotka, Kamchatka), USA (Alaska, Texas), Canada (Manitoba), Mexico.

Diagnostic characters (Figs. 111-113). Rostellar hooks 24.6-29 in length; blade pointed, 16-17 long; base with guard 21 long; guard 17 long; handle 3-5 long; wide of hook 16-17. Cirrus sac thin-walled, $140-200 \times 12-20$; in male proglottids do not reach midline; in mature and gravid proglottids put in lateral field, do not overlap poral osmoregulator canals. Cirrus very short, with small parabasal swelling; incompletely evaginated cirrus $13-16$ in length, entirely situated into genital atrium; wide in basal part 5; maximal wide in parabasal swelling 8; distal part invaginated; minute spines cover only parabasal swelling distributed in 7-8 transverse rows on each visible surface. Eggs single with an additional outer envelope; embryophore knobbed; embryonic hooks 13 long.

Remarks. A. retroversa is a common parasite of dowitchers (Limnodromus). Spasskaya (1966) regards A. octacantha, which is parasitic mainly in Calidris, to be a synonym of $A$. retroversa on the basis of morphological similarities in the sizes of their hooks and evaginated cirrus. Our study, however, showed that the shape of the rostellar hooks and the pres- ence of a sphincter on the vagina of A. octacantha clearly differentiate these cestodes. For the morphological variability and the life cycle of $A$. retroversa, see Bondarenko and Kontrimavichus (2006a).

Museum specimens: Type materialis lost.USNPC holotype 71182, Limnodromus scolopaceus, Alaska, designated as A. clavulus; voucher specimens of $A$. retroversa 162349,91870 , Limnodromus griseus, USA, Alaska, Hooper Bay; among the voucher specimens 78881-78891, Limnodromus spp. from USA (Texas) and Mexico.

One paratype A. clavulus in Limnodromus scolopaceus from Alaska under the field numbers 16343 and 19278 (collection of R. Rausch) currently held in Bondarenko' collection.

\section{Aploparaksis (A.) rissae Schiller, 1951}

Subjective synonyms: A. filiformis Spassky, 1963; A. daviesi Deblock et Rausch, 1968.

Unconfirmed records: A. rissae in Hromada and Macko (1995).

Hosts: Rissa tridactyla (L.) (type host), Limnodromus griseus, L. scolopaceus, Arenaria interpres, A. melanocephala, Gallinago gallinago.

Life cycle: intermediate hosts (experimental infection): Lumbriculidae: Styloscolex sokolskajae, Tubificidae: Rhyacodrilus coccineus, Enchytraeidae: Bryodrilus arcticus and Mesenhytraeus sp.; site: coelom; metacestode: ramicercus.

Localities: USA (State of Washington, type locality; Alaska, Montana), Russia (Yakutia, Chukotka, Kamchatka, Vrangel Island).

Diagnostic characters (Figs. 114-117). Rostellar hooks 18-21 in length, blade long and thin, longer than guard; handle feebly demarcated; length of blade 11-12; length of base 1416 ; wide of hooks 10. Cirrus sac 193-362 × 2537 reaches or overlaps aporal osmoregulatory canals; sometimes antiporal region of cirrus sac reaches opposite margin of hermaphroditic proglottis. Cirrus almost cillindrical, 320-413 (151 in type-specimen) long; wide at base 8 ; wide at distal part 6; approximately one-third of cirrus length covered with dense sparsely distributed triangular spines arranged for 4-6 spines per diagonal row on each side of cirrus. Eggs single, with an additional envelope or in packets, each 
containing 2-14 eggs; embryophore slightly knobbed; embryonic hooks 11-12 long.

Remarks. A. rissae is the common parasite of Limnodromus and is rarely a parasite of Arenaria. Originally, this species was described by Schiller (1951b) from Rissa tridactyla. The re-examination of the type-slide (Bondarenko, 1993a) has revealed that, in addition to the specimen of $A$. rissae, it contains a strobili of $A$. brachyphallos. Most likely, the description of $A$. rissae was prepared on the basis of mixed samples of $A$. rissae and A. brachyphallos. As a result, a hermaphroditic proglottis of $A$. rissae was described by Schiller (1951b) but a proglottis of A. brachyphallos was, in fact, pictured. For details of the morphology and the life cycle, see Bondarenko (1993a).

Museum specimens: USNCP holotype 47086, Rissa tridactyla, USA, St. Lawrence Is- land, 19279, Limnodromus scolopaceus, USA, St. Lawrence Island, designated as Aploparaksis daviesi, among the voucher speciments 7888178891, Limnodromus spp. from USA (Texas) and Mexico; MHNG 19336, Limnodromus griseus, Russia, Chukotka.

\section{Aploparaksis (A.) sachalinensis Krotov, 1952}

Unconfirmed records: $A$. sachalinensis in Mamaev (1959) in part, Gubanov and Mamaev (1964), Huan (1962), Oschmarin (1963), Ryzhikov et al. (1974), Spassky (1963), Spasskaya (1966).

Host: Gallinago solitaria Hodgson.

Localities: Russia (Sachalin Island, type locality), Kolyma River basin), Tadzhikistan.

Diagnostic characters (Figs. 118-120). Rostellar hook 20-24 in length; blade long and thin,

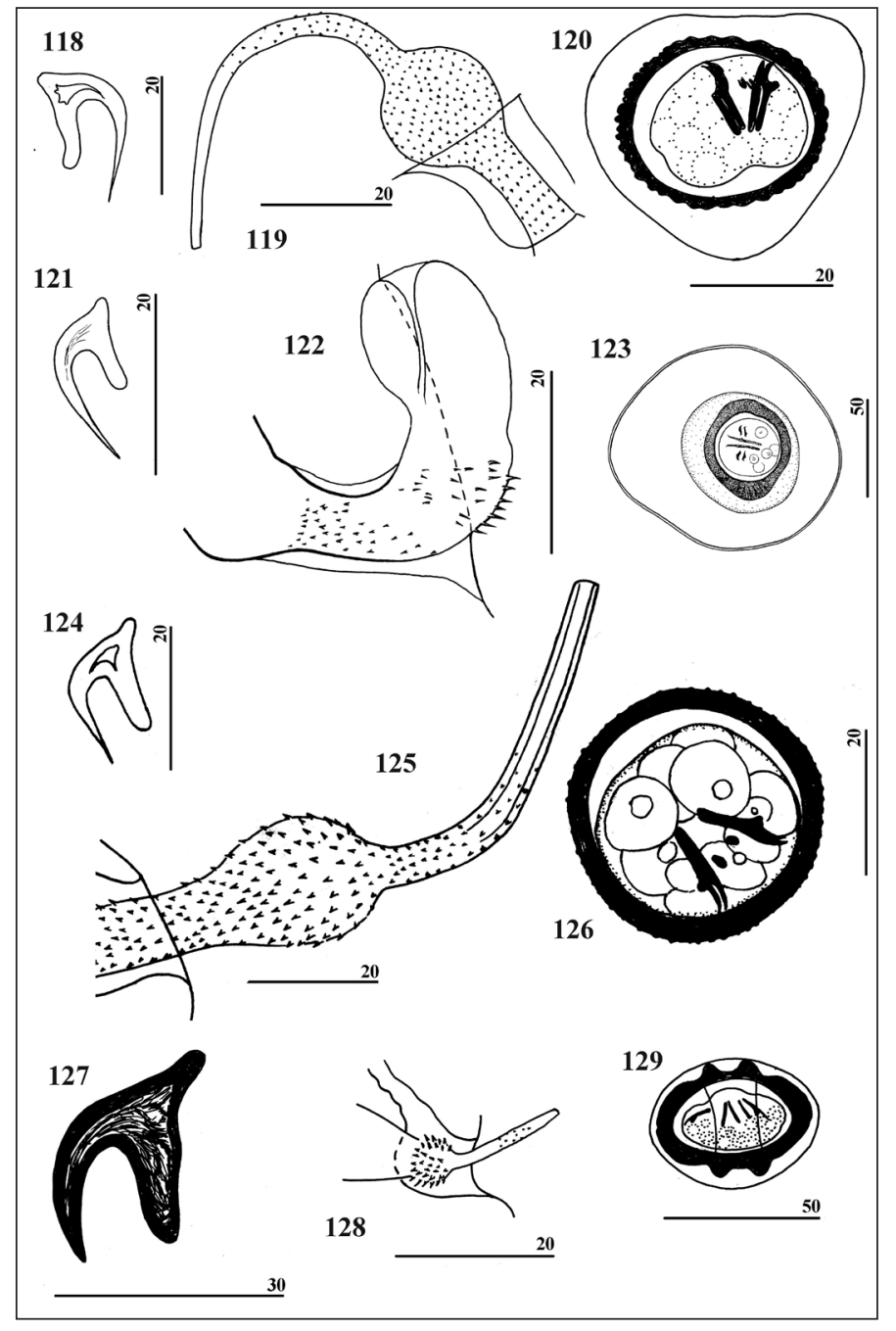

Figs. 118-120. Aploparaksis sachalinensis: 118 - hook, 119 - cirrus, 120 - egg. Figs. 121-123. Aploparaksis sanjuanensis: 121 - hook, 122 - cirrus, 123 - egg. Figs. 124-126. Aploparaksis schilleri: 124 - hook, 125 - cirrus, 126 - egg. Figs. 127-129. Aploparaksis scolopacis: 127 - hook, 129 - cirrus, 129 - egg 
longer than guard, 13-15 in length; handle feebly demarcated; length of base with guard 13-14; length of guard 7-8; width of hook 11.5-12. Cirrus sac $270-350 \times 40-60$, with thick muscular walls. Cirrus with parabasal swelling, up to 120 long; cylindrical base of cirrus, $24-36 \times 8-12$; parabasal swelling about round, 25-29 $\times 25-33$; distal part up to 66 long with diameter on base 5-6 and 3-4 on distal end. Basal part, swelling and half of the length of the distal part of cirrus covered with very small spines. Eggs single; walls of embryophore can be slightly tuberous; embryonic hooks 14 long.

Remarks. Re-examination of the specimen from the type series of $A$. sachalinensis revealed that the cirrus of this species significantly differs from the cirri of other species with bulbous swellings. A. sachalinensis is restricted to the solitary snipe. Borgarenko (1981) recorded this species in Tadzhikistan on the basis of the morphology of rostellar hooks of young specimens only and occurrence in this host species. This identification, however, is considered to be reliable.

Museum specimen: The K. I. Skrjabin Institute of Helminthology (VIGIS, Moscow) syntype 383, Gallinago solitaria, Russia, Sakhalin Island.

\section{Aploparaksis (A.) sanjuanensis Tubangui et Masilungan, 1937}

Subjective synonyms: $A$. pseudofilum sensu Mamaev (1959) in part, sensu Hromada and Macko (1993).

Unconfirmed records: A. sanjuanensis in Mamaev (1959) in part, Ryzhikov et al. (1974) in part, Spasskaya $(1964,1966)$ in part, Spasskaya and Spassky (1971) in part.

Hosts: Gallinago megala (type host), G. gallinago.

Life cycle: intermediate host (natural infection): Lumbriculidae: Lamprodrilus issosimovi Morev; site: coelom; metacestode: typical diplocyst.

Localities: The Philippines (type locality), Russia (the lower reaches of the Ob' River, Yakutia, Chukotka), Slovak Republic.

Diagnostic characters (Figs. 121-123). Rostellar hooks 16-18 in length; blade long and thin, falciform, twice as long as guard, length of blade
11-14; length of base with guard 10-13; length of guard 6-8; handle reduced, 2-2.5 long. Cirrus sac 92-250 × 13-30 crosses poral osmoregulatory canals or reaches mid-line of proglottis. Cirrus foliaceous, 47-83 long and 12-15 maximum wide at proximal part, often may bend; when this happens, distal half of cirrus is directed anteriorly; usually distal part invaginated. Basal part of cirrus cylindrical, $10-21 \times 5-8$, covered with very fine spines arranged in 9-10 transverse rows; gradual increases to 13-15 in diameter in midpart, than graduate narrow to 4 in distal part; base of mid-part covered with needle-shaped spines, 2-3 long. Eggs single, with external two-circuit envelope; embryophore with smooth polar swellings and smooth or tuberous surface in middle region; embryonic hooks $16-18$ long.

Remarks. Morphologically, A. sanjuanensis is notably similar to both $A$. australis and A. pseudofilum, differing from the former in the position of the oncosphere inside the embryophore and from the latter in the length of the rostellar hooks and structure of the embryophore wall. This species was discovered by us among the specimens of $A$. pseudofilum from the Carpathian region of the Slovak Republic (see Hromada and Macko, 1995). Because the typematerial did not survive and the brief original description of Tubangui and Masilungan (1937) lacks reliable information for the identification of this species, the validity of $A$. sanjuanensis requires additional study based on specimens from the type locality. The identification of the single metacestode A. sanjuanensis from Chukotka was based of the length and shape of hooks (Bondarenko and Kontrimavichus, 2006a).

Museum specimens: voucher specimens are in the collection of Bondarenko.

\section{Aploparaksis (A.) schilleri Webster, 1955}

Hosts: Calidris alpina pacifica (type host), C. mauri, C. melanotos, Arenaria interpres, Gallinago gallinago.

Life cycle: intermediate hosts (experimental infection): Lumbriculidae: Stiloscolex sokolskajae, Lamprodrilus chaunense Morev, Enchytraeidae: Mesenchytraeus penicillus (?); site: coelom; metacestode: caudate diplocyst. 
Localities: USA (Alaska, type locality), Russia (Chukotka).

Diagnostic characters (Figs. 124-126). Rostellar hooks 19-20 in length; blade thin, almost the same length as guard, 11-12 long; base with guard 14 long; handle reduced. Cirrus sac reaches only mid-line of proglottis, $260 \times 37$. Cirrus with parabasal swelling, 90-95 long; basal part, 22-24 × 10 smoothly turns into parabasal swelling $21 \times 17$; distal part 45-52 long and 5 wide in base decreases to 3 in diameter. Basal part of cirrus, parabasal swelling and distal part (c. onefifth of length) covered with small spines. Eggs single, surface of embryophore tuberous; embryonic hooks 12-14 long.

Remarks. The re-study of the holotype A. schilleri showed (Bondarenko, 1975a) that only the scolex armament with aploparaksoid hooks and two fragments of young strobila, the morphology of which could not be defined, are found on the slide. The scolex obviously belongs to Wardium amphitricha (Rudolphi), and only its hook was illustrated by Webster (1955) in the description of $A$. schilleri. Therefore, there are strong grounds to regard $A$. schilleri as a synonym of $W$. amphitricha. The original description and figure of the proglottis, however, prevent this solution from being considered true. Deblock and Rausch (1968) considered A. schilleri to be a synonym of A. brachyphallos. Bondarenko (1975a) pointed out strong similarities of $A$. schilleri with both A. brachyphallos and A. clavata but supposed that differences in the sizes of the hooks and cirrus gave a basis for considering A. schilleri to be a valid species. The life cycle was studied experimentally (Bondarenko et al., 2006a).

Museum specimens: USNPC holotype 49424, Calidris alpina pacifica, USA, Alaska; MHNG voucher specimen 19342, Calidris melanotos, Russia, Chukotka.

\section{Aploparaksis (A.) scolopacis Yamaguti, 1935}

Subjective synonyms: $A$. crassirostris sen$s u$ Lopez Neyra (1944) in part, sensu Spassky (1963) in part, sensu Spasskaya (1966) in part.

Unconfirmed record: Aploparaksis scolopacis in Kornyushin (1975 in part).
Host: Scolopax rusticola.

Life cycle: intermediate host (experimental infection): Lumbricidae: Eisenia foetida, Dendrobaena octaedra; site: chlorogogenous tissue of the intestine, rarely in cluster of celomic cells; metacestode: ovoid diplocyst.

Localities: Japan (type locality), England, Lithuania, Russia (Kareliya, Primorskiy Kray), Ukraine.

Diagnostic characters (Figs. 127-129). Rostellar hooks 28-37 in length; blade wide and blunt, 15-23 in length; base with guard 23-28 in length; width of hooks 18; handle well-expressed. Cirrus sac 147-252 × 22-33 in male proglottis extends to aporal osmoregulatory canals. Cirrus miniature with basal swelling, distal part mainly evaginated; total length of cirrus varies depending on the degree of evagination from 28 to 49 ; swelling $5 \times 7$, covered with relatively large spines arranged in four transverse rows; very fine sparsely distributed spines visible at base of distal part of cirrus after small unarmed region, rest of surface smooth. Eggs single; embryophore $43-53 \times 39-46$, thick-walled with polar swellings and two large lateral projections; embryonic hooks 12-14 long.

Remarks. A. scolopacis was originally described by Yamaguti (1935) from Japan. Kornyushin (1975) recorded and described A. scolopacis in S. rusticola on the Ukrainian coast of the Black Sea. Bondarenko (1993a) re-examined Kornyushin's specimens and recognized that the description was based on heterogeneous material containing both $A$. scolopacis and a specimen that later was described as the new species A. kornyushini (Bondarenko and Kontrimavichus, 2006c). This species is restricted to $S$. rusticola. The life cycle of A. scolopacis was studied under experimental condition in Lithuania (Bondarenko, 1993a).

Museum specimens: IZU voucher specimens 181-3, Scolopax rusticola, Ukraine; numerous voucher specimens are in the collection of Bondarenko.

\section{Aploparaksis (A.) shigini Bondarenko et Kontrimavichus, 2006}

Subjective synonyms: $A$. cirrosa sensu Clerc (1903), Dubinina (1953), Spasskaya (1957) in 
part, A. larina sensu Shigin (1961), Spassky (1963) in part, Spasskaya (1966) in part.

Hosts: Larus ridibundus L. (type host), L. canus, L. delawarensis Ord, Sterna hirundo L., Larus sp.

Localities: Russia (Yaroslavskaya oblast', type locality; Yakutia, the Ob' River, the Kolyma River, Primorskiy Kray), USA (Wisconsin)).

Diagnostic characters (Figs. 130-132). Rostellar hooks 23-25.6 in length, blade long and thin, significantly longer than guard, handle rudimentary; length of blade 16-17; length of base with guard 14-17. Cirrus sac cylindrical, $170-250 \times 32-45$, crosses median line or reaches antiporal osmoregulatory canals. Evaginated cirrus up to 104 long, with parabasal swelling 11-16 × 12-16; basal part of cirrus 25-33 $\times 6-8$, cylindrical and distal part 50 long with diameter at base 3 . Basal part and parabasal swelling armed with spines differ in size; smaller spines cover base of cirrus, and largest cover surface of swelling where they become triangular-shaped (c. 5-7 spines per diagonal row on each side of cirrus); several very small spines visible at base of distal part of cirrus, rest of surface smooth. Eggs enclosed in large, single packet in center of uterus; embryophore smooth-walled; embryonic hooks 12.

Remarks. For a long time, A. shigini was reported under different names (for details, see Bondarenko and Kontrimavichus, 2006b). This species is restricted to Laridae.

Museum specimens: CPAR holotype 903, paratypes 904 and 905, Larus ridibundus, Russia, the Rybinsk Reservoir; BMNH paratypes 2004.7.28.3-5, L. ridibundus, Russia, Ob' and Kolyma rivers; USNPC paratypes 94901, 94902 Rybinsk and the Kolyma River, 94903, L. delawarensis, USA, Wisconsin.

43. Aploparaksis (A.) sinensis Tseng Shen, 1933

Subjective synonyms: $A$. filum (Goeze) sensu Clerc (1910) in part, Oshmarin (1963) in part; A. parafilum Gasowska (1931) sensu Kornyushin (1967) in part; A. sachalinensis Krotov, 1952 sensu Mamaev (1959) in part, Demshin (1985).

Unconfirmed record: A. sinensis in Huan (1962).

Host: Scolopax rusticola.
Life cycle: intermediate host (experimental infection): Lumbricidae: Nicodrilus roseus, Eisenia foetida, Eiseniella tetraedra, Dendrobaena octaedra, Octolasium lacteum; site: coelom; metacestode: caudate diplocyst.

Localities: China (type locality), Elba, Lithuania, Ukraine, Russia (Karelia, Urals, Primorskiy and Khabarovskiy Kray).

Diagnostic characters (Figs. 133-135). Rostellar hooks 21-27 in length, blade long and thin; length of blade 13-17; length of base with guard $15-21$. Cirrus sac $123-295 \times 24-60$, with powerful muscular walls, crosses median line or reaches antiporal osmoregulatory canals in some of male proglottids. Cirrus miniature, 22-31 long with small parabasal swelling $8 \times 5-7$; basal part of cirrus 4-5 in diameter at base; basal part and parabasal swelling armed with very fine spines; distal pipette-like part unarmed. Eggs single with an additional outer envelope, sometimes enclosed in small packets containing up to 11 eggs; embryophore smooth-walled, sometimes slightly tuberous with polar swellings 8-12 thick; embryonic hooks 12-16 long.

Remarks. This species is a common parasite of S. rusticola. Re-examination of the type specimens of Tseng Shen (1933) revealed that the original description was based on heterogeneous material containing both $A$. sinensis and A. scolopacis. For details of the morphology of the lectotype and paralectotype, taxonomic comments and life cycle, see Bondarenko et al. (2002).

Museum specimens: MHNG syntypes 29/1-29/10 Scolopax rusticola, China; CPAR 64, 974 designed as A. sachalinensis; ZIN 3738 designated as A. filum.

\section{Aploparaksis (A.) spasskii Bondarenko, 1966}

Subjective syn: $A$. shiraishii Sawada et Kifune, 1974 in part; A. sanjuanensis Tubangui et Masilungan sensu Spasskaya $(1964,1966)$ in part, Spasskaya and Spassky (1971) in part; A. filum sensu Spasskaya $(1964,1966)$ in part, Spasskaya and Spassky (1971) in part).

Hosts: Gallinago stenura (type host), G. media, G. megala.

Localities: Russia (Lake Keta, central part of Siberia, type locality), Tuva, Yakutia. 


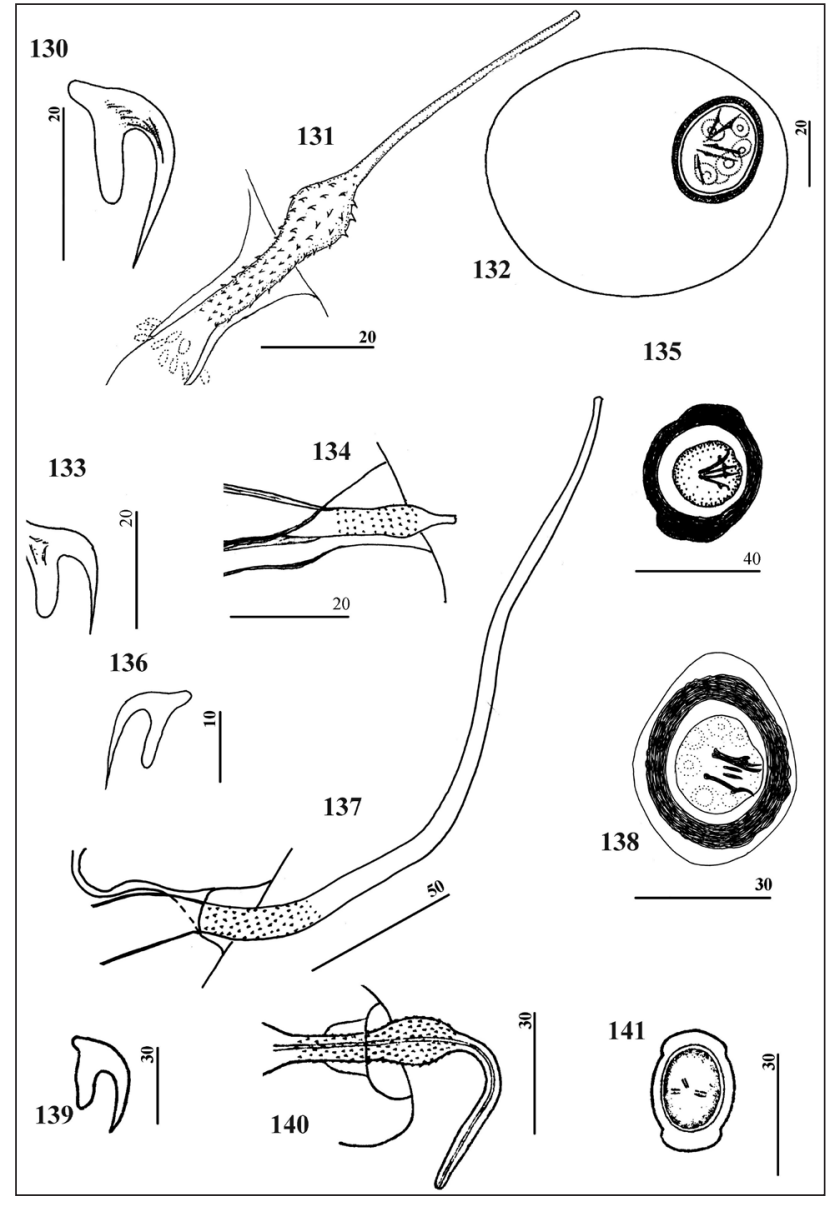

Figs. 130-132. Aploparaksis shigini: 130 - hook, 131 - cirrus, 132 - egg. Figs. 133-135. Aploparaksis sinensis: 133 - hook, 134 - cirrus, 135 - egg. Figs. 136-138. Aploparaksis spasskii: 136 - hook, 137 - cirrus, 138- egg. Figs. 139-141. Aploparaksis sphaerophora: 139 - hook, 140 - cirrus, 141 - egg
Diagnostic characters (Figs. 136-138). Rostellar hooks 16-20 in length, blade thin, significantly longer than guard. Testes appear as 3 small primordia close together, which later unite to become 1 in mature male proglottis. Cirrus sac long, 255-448 $\times 23-33$ reaches or overlaps aporal osmoregulatory canals in male proglottids. Evaginated cirrus conical, 130-209 long and wide $9-12$ at base, gradually decreases to $3-4$ at distal part; proximal part of cirrus about 40 in length, covered with fine spines arranged in 6-7 transverse rows. Eggs single; embryophore thick-walled, wall 4-8 thick; surface of mature slightly tuberous; embryonic hooks 12 long.

Remarks. A. spasskii was originally described by Bondarenko (1966a) in G. stenura on the basis of a single hermaphrodite and several juvenile specimens; therefore there was no information on the morphology of fullyevaginated cirrus or eggs. During the re-study of voucher specimens of aploparaksids from the collection of CPAR, we discovered one whole specimen and a strobila fragment, both with fully mature gravid proglottids that allow the filling of a gap in the morphology of the species.

Museum specimen: CPAR holotype 108, Gallinago stenura, Russia, Norilsk Lakes; voucher specimens 3545 , G. stenura (designated as A. filum) and 595, G. media (designated as A. sanjuanensis), Russia, Tuva.

\section{Aploparaksis (A.) sphaerophora (Rudol- phi, 1810) Fuhrmann, 1906}

Objective synonyms: Taenia sphaerophora Rudolphi, 1810; Hymenolepis sphaerophora (Rudolphi, 1810) Fuhrmann, 1906.

Subjective synonyms: Aploparaksis numenii Kulachkova, 1969, A. brachyphallos sensu Dubinina (1953) in part; Aploparaksis sp. sensu Mamaev (1959).

Hosts: Numenius arquata (L.) (type host), N. minutus Gould, N. tenuirostris Vieillot, Scolopax rusticola (?). 
Localities: Germany (type locality), Scotland, Russia (White Sea coast, Novosibirskaya oblast', Baikal Lake, Yakutia).

Diagnostic characters (Figs. 139-141). Rostellar hooks 31-32 (34-35 when with epiphysis) long; blade wide and blunt. Cirrus sac cylindrical, nearly reaches mid-line, 112-118 × 14-17. Cirrus with parabasal swelling; maximum cirrus length $65-72$; cylindrical basal part $17-$ $20 \times 6$; parabasal swelling 16-18 $\times 9-11$; distal part 32-34 long and 4 wide at base. Basal part and parabasal swelling covered with small spines. Embryophore smooth-walled with polar swellings 9 thick; embryonic hooks 9 long.

Remarks. A. sphaerophora is a specific parasite of curlews. The history of the species is rather confused because it was known only from its original description (Rudolphi, 1810) as a member of Taenia, which contained no information about the rostellar hooks, morphology of the proglottids, or armament of the cirrus. Under those circumstances, the species was included within different genera or even considered to be a species inquirenda (Fuhrmann, 1906). Joyeux and Baer (1936), despite considering A. sphaeropho$r a$ to be an "especes insuffisammer connues", recorded it not only in Numenius spp. but also in Scolopax rusticola. Re-examination of the specimens designated as "Type" T. sphaerophora in MHNG shows their identity with A. numenii, which was described by Kulachkova (1969) in N. arquata from the coast of the White Sea. Therefore, we regard A. numenii to be a junior synonym of $A$. sphaerophora.

Museum specimens: MHNG (slides from the Museum Viene 284, MHNG 52/52-57 and 1925 Museum of Berlin), N. arquata; BMNH 1972.12.13.1-4.; 52/52-57, N. arquatus, Scotland; ZIN type-specimens of $\mathrm{A}$. numenii, $\mathrm{Nu}$ menius arquata, the coast of the White Sea.

\section{Aploparaksis (A.) spinosus (Bondarenko, 1966) Belopolskaja et Kulachkova, 1968}

Objective synonyms: Globarilepis spinosus Bondarenko, 1966; Aploparaksis (Globarilepis) spinosus Belopolskaya et Kulachkova, 1968.

Subjective synonyms: Aploparaksis shiraishii Sawada et Kifune, 1974 in part; A. brachyphal- los sensu Dubinina (1953) in part, Kornyushin (1967) in part, Hromada and Macko (1995); A. filum sensu Dubinina (1953) in part; A. crassirostris sensu Dubinina (1953) in part; A. sachalinensis sensu Mamaev (1959) in part; Aploparaksis sp. sensu Kornyushin (1967).

Hosts: Gallinago gallinago (type host), G. solitaria, G. stenura, Heteroscelus incanus, Numenius arquata (?), Tringa ochropus.

Localities: Russia (Taimyr, type locality), the coast of the Baltic Sea, Karelia, Novosibirskaya oblast', Yakutia, Primorskiy Kray), Slovak Republic, Ukraine, Japan.

Diagnostic characters (Figs. 142-144). Rostellar hooks $18-18.4$ in length, blade long and thin, longer than guard; length of blade 11.5-13; length of base with guard 10-13; length of guard 7 . Cirrus sac $287-379 \times 37-$ 64 , with powerful muscular walls $8-13$ thick, usually crosses midline or reaches antiporal osmoregulatory canals in germaphrodite proglottids. Cirrus 70-126 long, with parabasal swelling 24-29 long and 18-21 wide taking into account length of spines covering it, and 15-17 wide without spines. Basal part of cirrus cylindrical, 27-36 $\times 8-12$; distal part 1463 long with diameter at base 4 . Basal part and parabasal swelling covered with spines. Spines differ in size, smaller needle-shaped spines cover base of cirrus, and largest triangular spines to 2.3 in length cover surface of swelling (c. 7-8 spines per diagonal row on each side of cirrus). Eggs enclosed in few egg-packets; embryophore smooth-walled; embryonic hooks 11 long.

Remarks. A. spinosus was described by Bondarenko (1966b) as the type species of a new genus, Globarilepisis. It is particularly similar to A. shigini, which parasitizes gulls (Bondarenko and Kontrimavichus, 2006b). Schmidt (1986) reported this species as a member of Globarilepis, which was recorded in snipes from North America, but gave no reference to where the specimens were found.

Museum specimens: CPAR holotype 227, Gallinago gallinago, Russia, Norilsk Lakes; paratypes 234, 235, Heteroscelus incanus, Russia, Yakutia. 


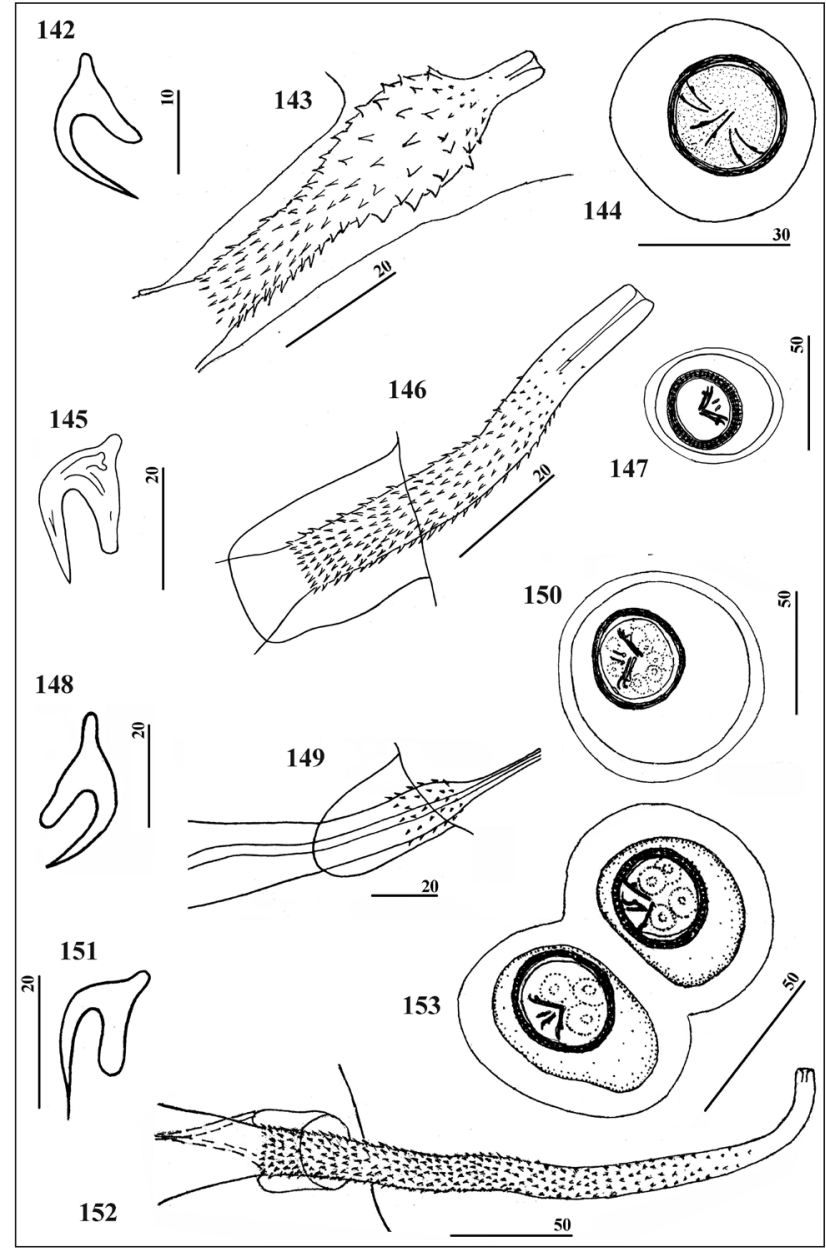

Figs. 142-144. Aploparaksis spinosus: 142 hook, 143 - cirrus, 144 - egg. Figs. 145-147. Aploparaksis stricta: 145 - hook, 146 - cirrus, 147 - egg. Figs. 148-150. Aploparaksis taimyrensis: 148 - hook, 149 - cirrus, 150 - egg. Figs. 151-153. Aploparaksis thomasi: 151 - hook, 152 - cirrus, 153 - eggs

\section{Aploparaksis (A.) stricta Spassky, 1963}

Objective synonyms: Aploparaksis rauschi stricta Spassky, 1961, nomen nudum; Aploparaksis raushi stricta Spassky, 1963;

Subjective synonyms: A. brachyphallos sensu Huan (1962); A. crassirostris sensu Huan (1962) in part, Spassky (1963, 1965), Bondarenko (1966a, 1975a), Belopolskaya (1969) in part, Belopolskaya and Kulachkova (1970) in part, Pelgunov (1987), Maksimova (1989) in part; A. filum sensu Huan (1962) in part; A. moensis Oshmarin, 1963; A. rauschi sensu Spassky (1965) in part; A. secessivus sensu Huan (1962) in part; A. sinensis sensu Huan (1962) in part.

Unconfirmed record: $A$. stricta in Deblock and Rausch (1968) in part.

Hosts: Calidris alpina (type-host), C. ferruginea, C. maritima, C. melanotos, C. minuta, C. temminckii, Limicola falcinellus.
Life cycle: intermediate hosts (experimental infection): Tubificidae: Rhyacodrilus coccineus, Enchytraeidae: Mesenchytraeus penicillus, Mesenchytraeus sp.; site: coelom; metacestode: caudate diplocyst.

Localities: Russia (Kamchatka, type locality), the White Sea coast, the lower reaches of the Ob' River, Khabarovskiy Kray, Yakutia, Chukotka, Commander Islands), Poland, Kazkhstan (the Aral Sea), USA (Alaska).

Diagnostic characters (Figs. 145-147). Rostellar hooks with wide and blunt blade, slightly longer than guard; handle reduced. Total length of hook 28-31; length of blade 16-20.7; length of base with guard 20-23; wide of hook 17. Testis large, $164-211 \times 80-140$, in young proglottids slightly lobed or with constrictions, occupies entire width of middle field of proglottis. Cirrus sac relatively short, $150-200 \times 24-29$, reaches but does not cross midline in relaxed proglottids; 
however, in compressed strobila it does not cross even poral osmoregulatory canals anteriorly directed to anterior margin of proglottis. Cirrus conical, reaches 75-105 in length, maximum width in base 8-12 taking into account length of spines covering it (to 13-17 in specimen mounted in polyvinyl alcohol after staining), diameter evenly decreases toward distal region to 5-7. Proximal part of cirrus (sometimes two-thirds of its length) covered with distinct evenly distributed spines decreasing in length towards distal end (c. 7-9 spines per diagonal row on each side of cirrus). Eggs single with additional envelope; embryophore evenly thickened, tuberous; embryonic hooks 12 long.

Remarks. A. stricta was first described by Spassky (1963) as the Asian subspecies of A. rauschi stricta. Spasskaya (1966), however, elevated this subspecies to the species level. Our study of the collection of Spassky allows us to conclude that the same species was described twice under two names: $A$. rauschi stricta in C. alpina from Kamchatka and A. crassirostris in C. ferruginea and C. minuta from the coast of the Aral Sea. This circumstance gave grounds for many authors to identify A. stricta as A. crassirostris. Bondarenko et al. (2002) revised A. crassirostris and re-described this species on the basis of the scolex of the type-specimen and entire specimens from their own material. The postembryonal development of $A$. stricta was investigated at a temperature of $10^{\circ} \mathrm{C}$ and $20^{\circ} \mathrm{C}$ (Bondarenko and Kontrimavichus, 2006a).

Museum specimens: CPAR 106 holotype and paratypes, Philomachus pugnax, Russia, Lake Keta; MNHG 19333 Ph. pugnax, Russia, Chukotka.

\section{Aploparaksis (A.) taimyrensis Bondaren- ko, 1966}

Subjective synonym: A. pseudofilum in Ginetsinskaja \& Naumov (1958).

Hosts: Philomachus pugnax (type host), Calidris alpina, Tringa ochropus.

Life cycle: intermediate host (experimental and natural infection): Lumbriculidae: Lumbriculus variegatus; site: coelom; metacestode: typical diplocyst.
Localities: Russia (the lower reaches of the Yenisey (type locality), Ob' and Lena rivers), the coasts of the White and the Baltic seas, Ukraine.

Diagnostic characters (Figs. 148-150). Rostellar hooks with thin and long blade; total length of hook 32-33; length of blade 19; length of base with guard 22-23; length of handle 5; wide of hook 17. Cirrus sac cylindrical, 281-361 × 23, reaches median line. Cirrus miniature, 31 long; parabasal swelling slightly expressed or almost imperceptible, with diameter 9; distal part pipette-like, 2 wide; spines covered middle part of cirrus distributed in 3-6 transverse rows of 5 spines in each. Eggs single, with additional external envelope; embryophore smooth-walled without polar swellings; embryonic hooks 16 long.

Remarks. This species is a specific parasite of $P h$. pugnax and is rarely recorded in other shorebirds. It is very similar to A. bulbocirrus and A. xemae but differs from it both by the shape of the rostellar hooks and the armament of the cirrus. Belopolskaya and Kulachkova (1970) also recorded Limosa lapponica and Limicola falcinellus as hosts of A. taimyrensis, but we cannot confirm these data because the cirrus in all of their specimens was invaginated. For details of the morphology and the life cycle of this species, see Bondarenko (1975a), Bondarenko and Kontrimavichus (2006a).

Museum specimens: CPAR 106 holotype and paratypes, Philomachus pugnax, Russia, Norilsk Lakes; MNHG 19333, Ph. pugnax, Russia, Chukotka.

\section{Aploparaksis (A.) thomasi Bondarenko, 1990}

Subjective synonyms: $A$. shiraishii Sawada et Kifune (1974) in part; A. filum sensu Davies (1940), Spassky (1963), Spasskaya (1966), Deblock and Rausch (1968), Spassky and Yurpalova (1969), Bondarenko (1969, 1975a), Belopolskaya (1969), Belopolskaya and Kulachkova (1970); A. clerci sensu Schmidt (1964).

Host: Gallinago gallinago.

Site: ceca.

Life cycle: intermediate hosts (experimental infection): Lumbriculidae: Styloscolex sokolska- 
jae, Tubificidae: Rhyacodrilus coccineus, Enchytraeidae: Mesenchytraeus sp.; site: coelom; metacestode: caudate diplocyst.

Localities: England (type locality), USA (Colorado), Ukraine, Russia (Chukotka, Kamchatka).

Diagnostic characters (Figs. 151-153). Rostellar hooks 17-25 in length, blade thin and long, longer than guard; length of blade 13-16; length of base with guard 12-17. Cirrus sac 140$200 \times 18$ reaches or crosses midline. Cirrus cylindrical to conical, 220-230 in length, with diameter at base 17-20, in middle part 12, in distal part 7; covered with distinct spines 2 in length arranged in transverse rows at 10-11 spines in each on the visible side; distal part unarmed. Eggs single; embryophore knobbed; embryonic hooks 12-13 long.

Remarks. A. thomasi is one of the most widespread obligate parasites of the snipe and is localised exclusively in the ceca. This species was first described by Davies (1940) and later by Spassky (1963) as A. filum. Bondarenko (1990a) revised $A$. filum and concluded that specimens described under this name by both these authors and A. filum sensu Clerc (1903) were not identical. Bondarenko (1990a) proposed a new species name, A. thomasi, for the cestodes described by Davies (1940) and Spassky (1963). Notably, there is a significant difference in the occurrence of infection between male and female snipes as can be observed among more than 100 samples of snipes (mainly in Siberia); predominantly females were infected with $A$. thomasi, whereas among males, only a few young birds were found to be infected. For details of the life cycle, see Bondarenko and Kontrimavichus (2006a).

Museum specimens: CPAR holotype 665, Gallinago gallinago, England (specimen from collection of Dr. Thomas Davies); MNHG 19335, Philomachus pugnax, Russia, Chukotka.

\section{Aploparaksis (A.) xemae Schiller, 1951}

Subjective synonyms: $A$. andrei sensu Belopolskaya (1969); A. filum sensu Dubinina (1953) in part; A. hirsuta sensu Bondarenko (1966a) in part, Belopolskaya (1969) in part; A. orientalis sensu Tolkacheva (1975) in part; Aploparaksis sp. sensu Bondarenko (1975a).
Unconfirmed records: $A$. xemae in Bondarenko (1975a, 1976), Krasnoschchekov and Bondarenko (1975, 1976), Bondarenko and Kontrimavichus (1976), Krasnoschchekov and Nikishin (1979).

Hosts: Xema sabini (type host), Calidris alpina, C. ferruginea, C. melanotos, C. minutus, C. temminckii, Phalaropus fulicarius, Gallinago gallinago, Limnodromus griseus, Arenaria interpres, Tringa erythropus.

Life cycle: intermediate hosts (experimental infection): Lumbriculidae: Stylodrilus sp., Styloscolex sokolskajae; site: coelom; metacestode: typical diplocyst.

Localities: USA (Alaska, type locality), Russia (Chany Lake, the lower reaches of the Ob', Yenisey, and Lena rivers, Chukotka).

Diagnostic characters (Figs. 154-156). Rostellar hooks 25-33 in length; length of blade 14-19; length of base with guard 16-23. Testis often slightly antiporal, however, in some proglottids or even in whole strobila located in centre of proglottis. Cirrus sac in male proglottis reaches aporal osmoregulatory canals or crosses middle line in hermaphroditic one. Cirrus 45-50 in length, with basal swelling $12 \times 12-16$, covered with hamiform spines arranged in 4-5 transverse rows, spines about 2 in length; distal part pipette-like, 28-33 in length; basal and distal parts of cirrus unarmed. Eggs single or enclosed in small packets with 2-15 eggs in each; embryophore tuberous, without polar swelling; embryonic hooks 15-16 long.

Remarks. For a long time, A. xemae was known only from its original description (Schiller, 1951a). Re-studying the type material from the USNPC, Bondarenko (1979) did not confirm the topography of female glands described by Schiller. Erroneous information caused Spassky and Yurpalova (1968) to include A. xemae within the subgenus Tanureria. It was determined that the female glands of $A$. xemae were deposited ordinarily (as in the type subgenus), with the vitellarium being located under the anatomical centre of the ovarium. Simultaneously, the misidentification by Bondarenko (1975a) of the tapeworms and metacestodes of A. (Tanureria) diagonalis as A. xemae was 


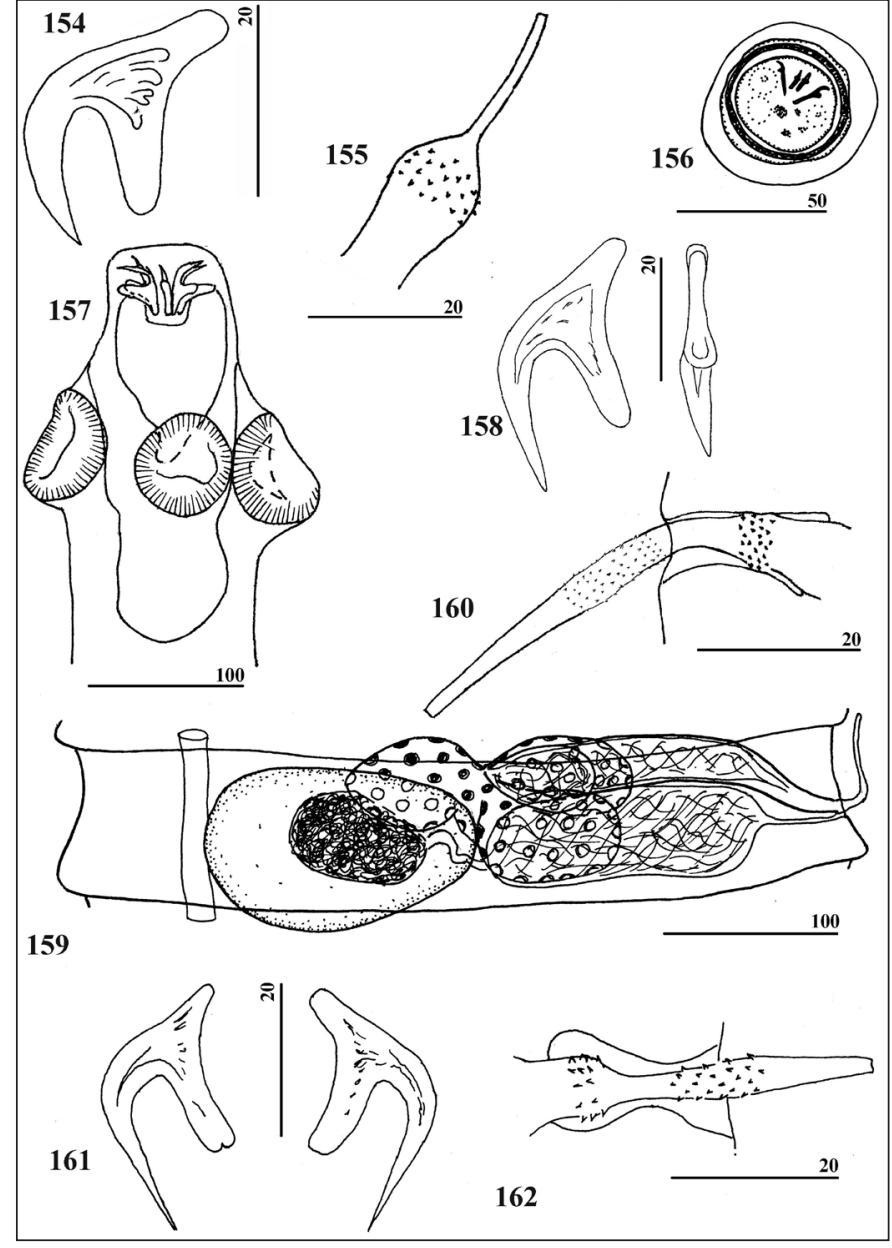

Figs. 154-156. Aploparaksis xemae: 154 hook, 155 - cirrus, 156 - egg. Figs. 157162. Aploparaksis secessivus in different hosts: 157 - scolex, 158 - hooks, 159 - hermaphroditic proglottis, 160 - cirrus specimen of T. glareola; 161 - hook, 162 - cirrus specimen of C. ruficollis established; the tapeworms therein described as Aploparaksis sp. were actually A. xemae. The host range of $A$. xemae includes obligatory Calidris and Phalaropus and, rarely, other shorebirds.

Museum specimens: USNPC holotype 47346, Xema sabini, USA, Alaska; voucher specimens under the field numbers B-68-36, B-6837 and B-68-76, Calidris alpina, all from Barrow, Alaska (collection of Robert Rausch, currently held in the collection of Bondarenko); MNHG 19345, Tringa erythropus, Russua, Chukotka.

\section{Subgenus Aploparaksis (Tanureria) Spassky et Jurpalova, 1968}

Diagnosis (according to: Spassky and Yurpalova (1968), with supplements). Strobila of moderate or large size. Rostellar hooks aploparaksoid or close to aploparaksoid, 10 in number. Single testis displaced aporally from middle line. Female gonads disposed in transverse row in median field of proglottid, compact vitellarium antiporal to lobate ovarium or diagonally against its central axis and ventral to testis. Eggs single, embryophore without polar swellings. In all other respects, the morphology as in nominotypical subgenus. Parasitic in Charadriiformes, rarely in Galliformes and Passeriformes; intermediate hosts Oligochaeta (Enchytraeidae); morphological modification of cysticercoid is autotomicercus.

Type species: $A$. (Tanureria) secessivus $\mathrm{Gu}$ banov et Mamaev in Spassky, 1963 (“1960”).

\section{Key to the species of subgenus Aploparaksis (Tanureria)}

1a. Cirrus almost cylindrical, with poorly developed basal and parabasal swellings, 45-80 in length (Figures 157-162). Rostellar hooks 36-44 in length. Parasite of Tringinae... A. secessivus Gubanov et Mamaev in Spassky, 1963 ("1960")

1b. Length of rostellar hooks smaller... 2 
2a. Length of rostellar hooks 29-33, blade of hook longer than guard, handle of hook well developed. Cirrus 62-70 in length. Parasite of Calidris, rarely of Arenaria (Figures 178-180)... A. regelae Bondarenko et Kontrimavichus, 2006

2b. Length of rostellar hooks smaller, cirrus longer... 3

3a. Rostellar hooks 26-29 in length. Evaginated cirrus 100-139 in length. Parasite of Calidritinae, rarely of other shorebirds and nestling gulls (Figures 166-168)... A. diagonalis Spassky et Bobova, 1961

3b. Length of rostellar hooks smaller... 4

4a. Rostellar hooks 21-22 in length, blade and base of hook equal in length. Cirrus 49-74 in length. Specific parasite of Phalaropus, rarely of Philomachus (Figures 175-177)... A. pseudosecessivus Belopolskaja, 1969

4b. Cirrus longer than $100 \ldots 5$

5a. Rostellar hooks 19-25 in length, blade 14 . Evaginated cirrus 105-112 in length. Parasite of Charadriidae. (Figures 172-174)... A. lateralis Spassky et Yurpalova, 1968

5b. Cirrus another shape... 6

6a Cirrus foliaceous (Figure 182). Evaginated cirrus 130 in length, partly evaginated 80-100 in length, distal part of cirrus enlarged up to 25-32.5 in diameter; covered with heteromorphic spines. Rostellar hooks $21-25$ in length. Parasite of Vanellus... A. vanelli Kornyushin, Bondarenko et Greben, 2006

6 b. Cirrus another shape, shorter than $100 \ldots 7$

7a. Cirrus almost cylindrical at base, distal end tapered, 45-86 in length. Rostellar hooks 22-26 in length. Parasite of Passeriformes, reported also from Laridae (Stercorarius)... A. borealis Bondarenko et Rausch, 1977

7b. Cirrus another shape, longer than $100 \ldots 8$

8. Cirrus cylindrical to conical, up to 246 in length. Rostellar hooks 12-14 in length. Parasite of Galliformes... A. galli Rausch, 1951

\section{Aploparaksis (T.) secessivus Gubanov et Mamaev in Spassky, 1963 ("1960")}

Subjective synonyms: $A$. brachyphallos sensu Mamaev (1959) in part, A. hirsuta sensu Mamaev (1959) in part.
Unconfirmed records: A. secessivus in Huan (1962) in part, Bondarenko (1975a), Deblock and Rausch (1968) in part, Spassky and Yurpalova (1969) in part, Pelgunov (1987).

Hosts: Tringa glareola and T. ochropus (type hosts), T. hypoleucos, T. nebularia, Heteroscelus brevipes, $H$. incanus.

Life cycle: intermediate host (natural infection): Enchytraeidae: Mesenchytraeus sp.; site: coelom; metacestode: autotomicercus.

Localities: Russia (Yakutia, type locality; Baikal, Buryatia, Magadanskaya oblast', Kamchatka).

Diagnostic characters (Figs. 157-162). Rostellar hooks with wide blunt blade and relatively short handle; total length of hooks 32-41; length of blade 17-22; length of base with guard 25-28; length of guard 16; wide of hook 20-23. Cirrus sac reaches mid-line, $200-330 \times 25-36$. Cirrus 45-80 long, with poorly developed basal and parabasal swellings; basal swelling and proximal part of parabasal swelling armed; spines on basal swellings slightly larger, arranged in 3-4 transverse rows; distal part of cirrus unarmed. Female glands disposed in transverse row in median fields of proglottis, vittelarium antiporal or diagonal to trilobed ovarium and ventral to testis. Eggs single, embryophore thick-walled, embryonic hooks 12 long.

Remarks. The original description of $A$. secessivus was based on the specimens in eight species of shorebirds from Siberia and first published in a monograph by Spassky (1963). The re-examination of the type-material (syntypes) in the museum of CPAR revealed that neither the type specimen nor the type host of A. secessivus were designated and that it is a composite species. We restricted the hostrange of this species only to Tringa and Heteroscellus spp. Erroneous definitions of tapeworms have also been discovered in other collections, which increased the host-range and the geographical distribution of the species without a good reason. Data on the life cycle of $A$. secessivus was based only on the discovery of a single naturally infected Enchytraeidae near Magadan (Bondarenko and Kontrimavichus, 2006a). The metacestode occurred in a naturally infected Lumbriculus variegatus from Chukotka 
and was identified by Bondarenko (1975a) to be $A$. secessivus on the basis of the hook morphology only; in fact, it belongs to A. penetrans.

Museum specimens: CPAR syntypes 295, 307, Tringa ochropus and 306, 308, Tringa glareola, all from Russia, Yakutia.

\section{Aploparaksis (T.) borealis Bondarenko et} Rausch, 1977

Hosts: Stercorarius longicaudus (type host), Anthus cervinus (Pallas), Calcarius lapponicus (L.), Emberisa sp.

Life cycle: intermediate host (experimental infection) Enchytraeidae: Mesenchytraeus sp. II (penicillus?); site: coelom; metacestode: autotomicercus.

Localities: USA (Alaska, type locality), Russia (Chukotka).
Diagnostic characters (Figs. 163-165). Rostellar hooks 18-26 long, with very short handle; base with guard 17-22 long; blade 12-14 long; wide of hooks 14 . The number of hooks on the rostellum amounts to 11 in one case. Cirrus sac elongate, $140-220 \times 25-45$, directed anteromediad with proximal end near anterior margin of proglottis and mostly anterior to anterior margin of ovary; crosses poral osmoregulator canals extending mediad across about $1 / 3$ of mature proglottis. Cirrus 45-86 long, cylindrical at base, distal end attenuated; maximum diameter 8-14 in the middle of length and 3 to 5 at distal end. Surface of cirrus covered with small spines arranged in 16-20 transverse rows of 8-10 spines visible on each side of cirrus. Embryophore with smooth walls, embryonic hooks 12-13 long.

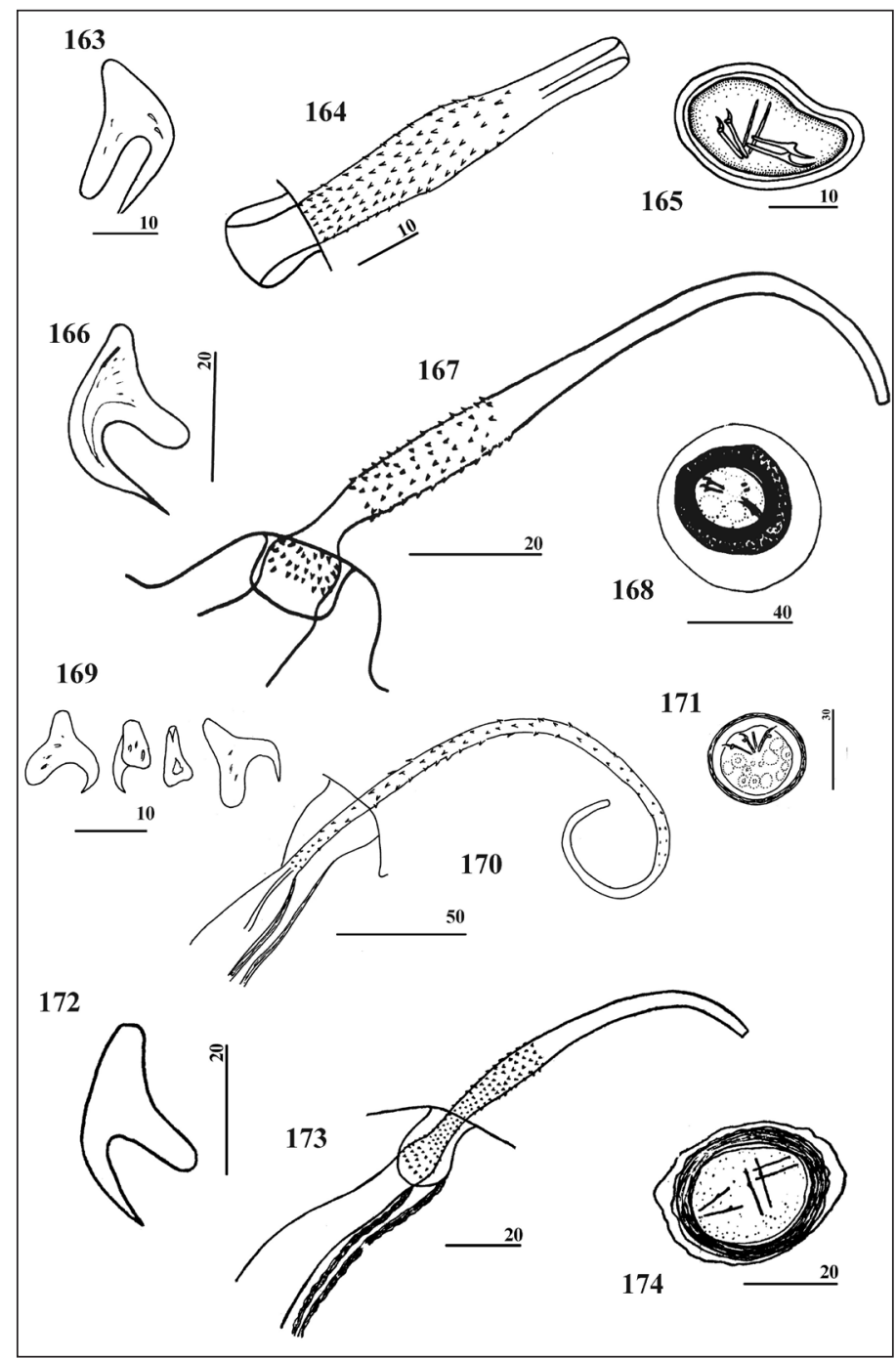

Figs. 163-165. Aploparaksis borealis: 163 - hook, 164 - cirrus, 165 - egg. Figs. 166-168. Aploparaksis diagonalis: 166 - hook, 167 - cirrus, 168 - egg. Figs. 169-171. Aploparaksis galli: 169 hooks, 170 - cirrus, 171 - egg. Figs. 172174. Aploparaksis lateralis: 172 - hook, 173 - cirrus, 174 - egg 
Remarks. This species was described on the basis of material collected by R. L. Rausch in Alaska and by Bondarenko in Chukotka (Bondarenko \& Rausch, 1977). Despite the topography of the genital organs, which is characteristic of the subgenus Tanureria, the species was allocated within Aploparaksis s. l. because R. L. Rausch did not share our view of the existence of subgeneric taxa. Subsequent numerous records of $A$. borealis in passerine birds in $\mathrm{Chu}$ kotka gave us a good reason to treat this species as a specific parasite of passeriform birds because it was discovered only once in S. longicaudus in Alaska. For data on its life cycle, see Bondarenko and Kontrimavichus (2006a).

Museum specimens: CPAR 460 holotype, Stercorarius longicaudus, USA, Alaska; USNPC paratype 74085, Calcarius lapponicus, Russia, Chukotka.

\section{Aploparaksis (T.) diagonalis Spassky et Bobova, 1961}

Subjective synonyms: $A$. xemae sensu Bondarenko (1973, 1975a), Bondarenko and Kontrimavichus (1976), Krasnoschchekov and Bondarenko (1975, 1976), Krasnoschchekov and Nikishin (1979).

Unconfirmed record: A. diagonalis in Belopolskaya (1969), Bondarenko (1966a), Deblock and Rausch, (1968) in part, Spassky and Bobova (1961), Spasskaya and Spassky (1971).

Hosts: Tringa incana (type host), Tringa erythropus Calidris alpina, C. maritima, C. minuta, C. temminckii, Crocethia alba, Arenaria interpres, Pluvialis squatarola, Phalaropus lobatus, Ph. tricolor Vieillot, Limnodromus griseus, Larus argentatus Pontoppidan (nestlings); Xema sabini (Sabine), experimentally.

Life cycle: intermediate hosts: Enchaetraeidae: Mesenchytraeus sp. I (M. obscurus Eisen?) (natural infection), Mesenchytraeus sp. II (M. penicillus?) (experimental infection); site: coelom; metacestode: autotomicercus.

Localities: Russia (Kamchatka, type locality; the lower reaches of the Ob' and Lena rivers, Norilsk lakes, Chukotka, Komandorskiye Islands).

Diagnostic characters (Figs. 166-168). Rostellar hooks 26-29 in length; length of blade
14-21; length of base with guard 17-21; wide of hooks 14-17. Cirrus sac 260-330 × 21-34 reaches or crosses midline, rarely reaches antiporal osmoregulator canals in relaxed proglottis. Evaginated cirrus 100-139 long, with poorly developed basal and parabasal swellings; basal swelling $8-13 \times 11$, wholly places in genital atrium; parabasal swelling 7-10 in diameter; distal part gradually decreases up to 2-3; both basal swelling and proximal part of parabasal swelling covered with small spines; narrow spot dislocated between of swellings and distal part of cirrus unarmed. Mature embryophore slightly knobbed; embryonic hooks 12-13 long.

Remarks. This species was first described as a member of Aploparaksis in shorebirds of Kamchatka (Spassky and Bobova, 1961), and Spassky and Yurpalova (1968) subsequently transferred it to the subgenus Aploparaksis (Tanureria). Having discovered cestodes with an antiporal position of the vitellarium in the gull $L$. argentatus from Chukotka, Bondarenko (1975a) at first wrongly identified them as A. xemae. For a detailed description and its life cycle, see Bondarenko and Kontrimavichus (1979). Of particular interest is the source of $L$. argentatus infection with $A$. diagonalis, which we discovered on a small island of a tundra lake in Chukotka. Nestlings, but not adults from the colony studied, were frequently found infected with this parasite. High intensity infections by the metacestodes of $A$. diagonalis were found in large numbers of enchytraeids living in the litter of nests and in the vegetation on the surface of the soil. During the breeding season, oligochaetes were the prey of nestling L. argentatus. This obstacle explains how $A$. diagonalis can be widespread in nestling gull cestode communities. This is the only known case of gull infection by $A$. diagonalis. Borgarenko (1981) recorded this species in Tringa totanus in Tadzhikistan, presenting only a picture of a scolex, hook, and egg.

Museum specimen: CPAR syntype 238, Heteroscelus incanus, Russia, Kamchatka.

\section{Aploparaksis (T.) galli Rausch, 1951}

Hosts: Lagopus lagopus L. (type host), L. mutus (Montin). 
Localities: USA (Alaska, type locality), Russia (Middle Siberia, Yakutia, Chukotka).

Diagnostic characters (Figs. 169-171). Length of gravid specimen from $13 \mathrm{~cm}$ up to $28.3 \mathrm{~cm}$, maximum width accordingly $1.5 \mathrm{~mm}$ and $2.16 \mathrm{~cm}$. Surface of scolex and anterior part of neck covered with crowded large microtriches. Rostellar hooks small, 12-14 long, with short hamiform blade and wide base. Cirrus sac from $256 \times 25$ (in Siberian specimens) to 457-613 $\times 41-52$ (in Chukotka specimens); reaches or crosses mid-line of proglottis. Cirrus cylindrical to conical, 164-246 long, with wide of base 6-7 and at the distal end 4-5; covered with relatively large sparsely staggered spines. Embryonic hooks 13 long.

Remarks. A. galli was described by Rausch (1951) from Alaska. Three specimens of A. galli in two L. lagopus from Chukotka (the Amguema River) were kindly provided for our investigation by Dr. Kira Regel. The size of these cestodes was three times greater than those of the specimens known before. We, however, have no strong argument to regard them as a new species or an infraspecific group. Additional investigations are necessary to resolve the taxonomic status of these cestodes.

Museum specimen: USNPC holotype 47347, Lagopus lagopus, USA, Alaska.

\section{Aploparaksis (T.) lateralis Spassky et Yurpalova, 1968}

Subjective synonyms: $A$. diagonalis sensu Bondarenko (1966a, 1969), Aploparaksis sp. 2 sensu Belopolskaya (1969).

Hosts: Charadrius hiaticula L. (type host), Eudromias morinellus (L.), Pluvialis dominica (Müller).

Localities: Russia (Chukotka, type locality; north of Middle Siberia, the lower reaches of the Lena River).

Diagnostic characters (Figs. 172-174). Rostellar hooks 22-25 in length; base of hooks with massive guard; guard a little shorter then blade. Cirrus sac $248-276 \times 25-30$ reaches or crosses mid-line. Evaginated cirrus 105-112 long, with poorly developed basal and parabasal swellings; basal swelling $10 \times 8$, parabasal swelling 8 in diameter gradually decreases to 3 in diameter in distal part; both basal swelling and proximal part of parabasal swelling covered with small spines, spines on basal swelling slightly larger; narrowed region between both swellings unarmed. Embryophore thick-walled; embryonic hooks 11-13 long.

Remarks. A. lateralis is one of two species of Tanureria recorded in Charadriidae (the second being A vanelli). The report by Spassky and Yurpalova (1968) indicating that the specimens occurred in the ceca is evidently incorrect.

Museum specimen: CPAR syntypes 510, Charadrius hiaticula, Russia, Chukotka.

\section{Aploparaksis (T.) pseudosecessivus Be- lopolskaja, 1969}

Subjective synonyms: A. occidentalis sensu Spassky \& Yurpalova (1968) in part.

Hosts: Phalaropus fulicarius (type host), Philomachus pugnax.

Life cycle: intermediate host (natural infection): Enchytraeidae: Mesenchytraeus sp. II; site: coelom; metacestode: autotomicercus.

Localities: Russia (the lower reaches of the Lena River, type locality; Chukotka).

Diagnostic characters (Figs. 175-177). Rostellar hooks 21-22 in length (in three specimens from Ph. fulicarius from Chukotka 27-30), with short handle and wide guard; blade falciform 13-14 long, at the same length as guard; base with guard 16-17 long; wide of hook 14. Cirrus sac 215-259 × 27-35, does not reach mid-line in germaphrodite proglottids. Cirrus 49-74 long with poorly developed basal and parabasal swellings; basal swelling 9-11 $\times 10$, parabasal swelling 17 long and 5 in diameter, gradually decreases to 3 in diameter in distal part; basal swelling and proximal part of parabasal swelling covered with small spines; narrowed region between both swellings $5 \times 3$, and distal part to 27 long, unarmed. Surface of embryophore slightly knobbed; embryonic hooks 11 long.

Remarks. A single metacestode in naturally infected Enchytraeida from Chukotka was identified as belonging to $A$. pseudosecessivus on the basis of the morphology of the hooks (Bondarenko and Kontrimavichus, 2006a). 


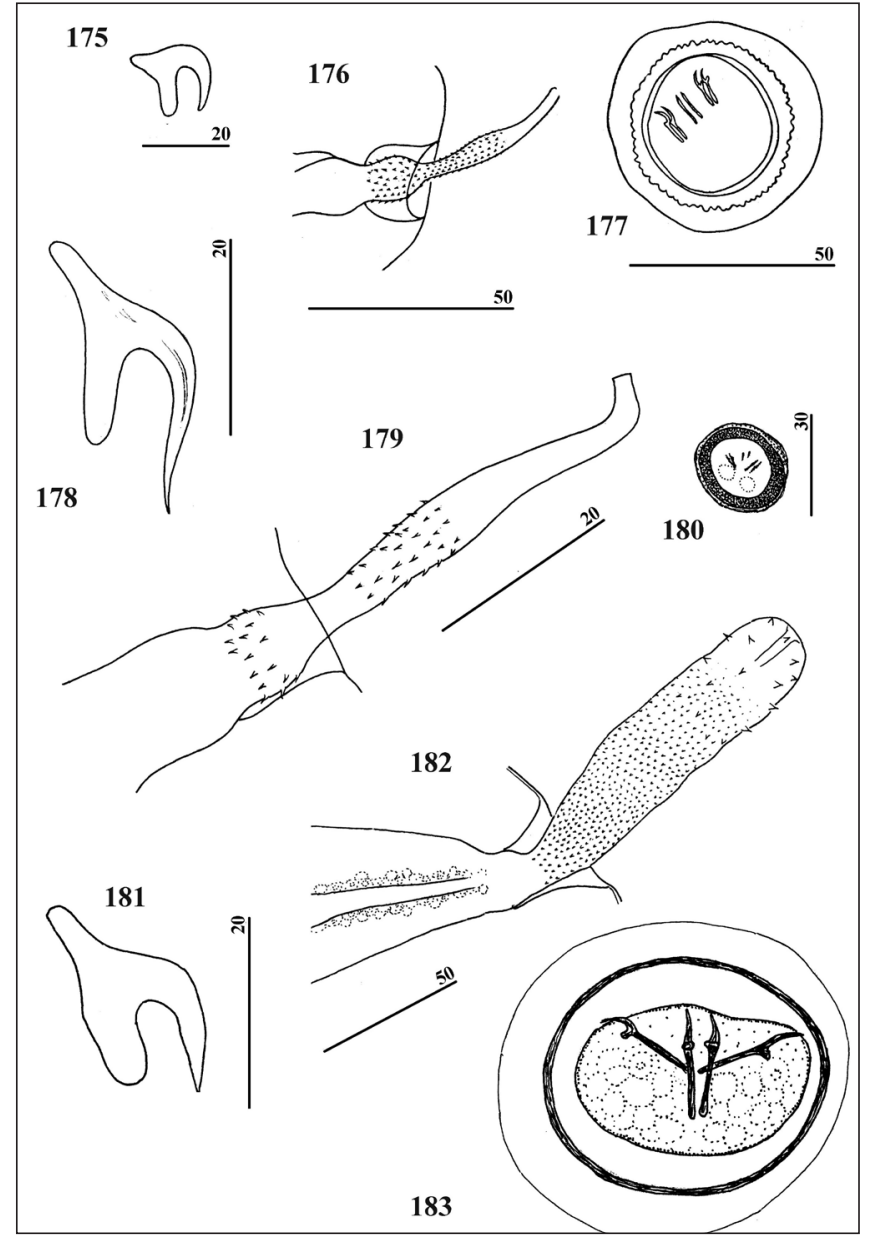

Figs. 175-177. Aploparaksis pseudosecessivus: 175 - hook, 176 - cirrus, 177 - egg. Figs. 178180. Aploparaksis regelae: 178 - hook, 179 - cirrus, 180 - egg. Figs. 181-183. Aploparaksis vanelli: 181 - hook, 182 - cirrus, 183 - egg
Museum specimens: CPAR holotype 477 and paratypes $478,479,826$, Phalaropus fulicarius, Russia, Yakutia.

\section{Aploparaksis (T.) regelae Bondarenko et Kontrimavichus, 2006}

Hosts: Calidris alpina (type host), C. bairdi, Arenaria interpres.

Localities: Russia (Chukotka, the Amguema River, type locality; Wrangel Island), USA (St. Matthew Island, Alaska).

Diagnostic characters (Figs. 178-180). Rostellar hooks 29-33 in length with elongated handle; length of blade 16-20; length of base with guard 21-25; length of guard 7-12; length of handle 8. Cirrus sac $266-287 \times 37-53$ crosses mid-line. Cirrus 62-70 long with poorly developed basal and parabasal swellings; basal swelling $12 \times 6-10$, parabasal swelling $16 \times 4-6$; narrowed region between both swellings $8 \times 4$, and distal part of cirrus unarmed. Mature em- bryophore thick-walled, slightly knobbed; embryonic hooks 12 long.

Remarks. For a detailed description and morphological variability, see Bondarenko and Kontrimavichus (2006a).

Museum specimens: CPAR 942 holotype, Calidris alpina, Russia, Chukotka; 943 paratype, Arenaria interpres, Russia, Chukotka; USNPC 71183, C. bairdi, USA, Alaska.

\section{Aploparaksis (T.) vanelli Kornyushin, Bondarenko et Greben, 2006}

Host: Vanellus vanellus (L.)

Locality: Ukraine (Volyn' Region).

Diagnostic characters (Figs. 181-183). Rostellar hooks with wide and blunt blade, wide guard and well developed handle. Total length of hook 21-25; length of blade 10-15; length of base with guard 18-23; length of guard 7.5-12; length of handle 2.5-7.5; wide of hook 10-15. Cirrus sac pear-shaped or sigar-shaped, $150-230 \times 35-60$, 
crosses mid-line only in hermaphroditic proglottis. Cirrus foliaceous, slightly narrowed at the base; Fully-evaginated cirrus 130 in length, partly-evaginated 80-100 in length; distal part of cirrus enlarged up to 25-32.5 in diameter; covered with heteromorphic spines: very small microtrichial-type spines covered most part of cirrus, whereas large triangular spines $2.5-12$ in length sparsely distributed on distal part. The armament of invaginate cirrus indistinguishable. Embryophore smooth-walled, embryonic hooks 12 long.

Remarks. A. vanelli is the second species of the subgenus Tanureria, a parasite of Charadriidae (the first being $A$. lateralis) and the first recorded in the Western Palearctic region. For a detailed description, see Kornyushin et al. (2006).

Museum specimens: IZU holotype 5212a, paratypes 52-12 b-g, Vanellus vanellus, Ukraine, Volyn' region.

Our investigation and analysis of the literature show or corroborate that 44 species have been wrongly identified as members of Aploparaksis. Comments on each of these species are provided below.

\section{List of invalid species of Aploparaksis}

1. Aploparaksis acanthocirrus Deblock et Rausch, 1968 in Heteroscelus incanus from Alaska was considered by Bondarenko and Kontrimavichus (2006a) to be a synonym of $A$. andrei.

2. Aploparaksis baeri Schiller, 1951 is a new name for the form described by Joyeux and Baer (1928) in Larus argentatus from Europe as $\mathrm{Ha}$ ploparaksis fusus (=Taenia fusus Krabbe, 1869). After the re-examination of Krabbe's material, Baer (1956) confirmed that they belonged to the genus Hymenolepis and considered A. baeri to be a synonym of Hymenolepis fusus.

3. Aploparaksis bulgarica Kamburov, 1969 was described in Scolopax rusticola from Bulgaria. The analysis of the description of Kamburov (1969) gave us the basis to consider it a composite and most likely based on the specimens of A. filum, A. australis and A. pseudofilum. Because the type material is lost, Bondarenko and Kontrimavichus (2006a) considered A. bulgarica to be species inquerenda.
4. Aploparaksis caballeroi Flores-Baroetta, 1953 was described in Larus pipixcan Wargler from Panama. Spassky (1963) placed the species within the genus Retinometra Spassky, 1955.

5. Aploparaksis chikugoensis Sawada et Kifune, 1974 was described as Haploparaksis chikugoensis in Podiceps ruficollis paggei from Japan. A study of the type specimens from Nara University of Education has confirmed (Bondarenko and Kontrimavichus 2006a) the assumption of Tolkacheva (1975) that the species belongs to genus Confluaria Ablasov in Spasskaya, 1966.

6. Aploparaksis cirrosa (Krabbe, 1869) Clerc, 1903 in Holarctic gulls and terns of the genera Larus (L.) and Sterna was described by Krabbe (1869) as a member of Taenia and was later wrongly included in Aploparaksis by Clerc (1903). Fuhrmann (1906) established the presence of three testes in T. cirrosa, and now it is treated as a species of Wardium Mayhew, 1925. We had the opportunity to re-examine the specimens recorded by Clerc (1903) as A. cirrosa in Larus sp. from Ural (ZIN, No. 312) and consider them to belong to $A$. shigini.

7. Aploparaksis clavulus Deblock et Rausch, 1968 in sandpipers from Alaska was considered by Bondarenko and Kontrimavichus (2006a) to be a synonym of $A$. retroversa.

8. Aploparaksis clerci Yamaguti, 1935 was described in Scolopax rusticola from Japan. LopezNeyra (1944) and Spassky (1963) considered this species to be a synonym of $A$. pseudofilum.

9. Aploparaksis daviesi Deblock et Rausch, 1968 in Arenaria melanocephala (Vigors) and L. scolopaceus from Alaska was considered by Bondarenko (1993b) to be a synonym of A. rissae.

10. Aploparaksis diminuens Linstow, 1905 in Phaloropus fulicarius from the Taimyr Peninsula (Russia) was considered by Bondarenko (1980) to be a synonym of A. brachyphallos.

11. Aploparaksis dujardini (Krabbe, 1869) Clerc, 1903 was described by Krabbe (1869) in Turdus spp. within the genus Taenia from the Palearctic Region. It was selected by Oschmarin (1963) as a type-species of the genus Monorcholepis Oshmarin, 1963. 
12. Aploparaksis dujardini neoarcticus Webster, 1955 in Ixoreus naevius naevius (Gmelin) from Douglas Island, USA, after the re-examination of the type material by Bondarenko and Komisarovas (2007), was regarded as synonym of Monorcholepis dujardini.

13. Aploparaksis echinovatum Deblock et Rausch, 1968 in Gallinago gallinago from Iran was considered by Bondarenko et al. (2002) to be a synonym of $A$. crassirostris.

14. Aploparaksis elisae Skrjabin, 1914 in $N y$ roca ferina from Kazakhstan was placed by Spassky and Freze (1961) in the genus Diorchis Clerc, 1903.

15. Aploparaksis endacantha Dubinina, 1953 in Anas acuta from Russia (Chany Lake) was placed by Spassky (1961) in the genus Diorchis Clerc, 1903.

16. Aploparaksis filiformis Spassky, 1963 in Arenaria interpres from Kamchatka Bondarenko (1993a) was considered to be a synonym of $A$. rissae.

17. Aploparaksis fringillarum (Rudolphi, 1810) Linstow, 1904 in Passeriformes from Germany was considered by Spassky and Spasskaja (1954) to be a synonym of Passerilepis passeris (Gmelin, 1790) Yamaguti, 1959.

18. Aploparaksis fuliginosa sensu Fuhrman, 1932 is the name that appeared as an error in the spelling of A. fuligulosa Solowiow, 1911. Spassky (1963) believed it should be excluded from use.

19. Aploparaksis fuligulosa Solowiow, 1911 is a poorly described tapeworm in Nyroca fuligula from Poland. Spassky (1963) believed this name should be excluded from use. Doubts concerning this species belonging to the genus Aploparaksis were earlier stated by Skryabin and Mathevosian (1945).

20. Aploparaksis fusus (Krabbe, 1869) Joyeux et Baer, 1928 was recorded as a parasite of gulls from Europe. The name originated as a result of an incorrect transfer of the species from Hymenolepis, where it was placed by Fuhrmann (1906), to Aploparaksis by Joyeux and Baer (1928). The re-examination of Krabbe's original material by Baer (1956) confirmed the attribution of this species to Hymenolepis. For the new data concerning H. fusus, see Bondarenko and Kontrimavichus (2004).

21. Aploparaksis kamayuta Johri, 1935 was poorly described in Capella stenura from India. The type material is lost. Because it is difficult to differentiate A. kamayuta from the closely related A. sanjuanensis and A. pseudofilum, Bondarenko and Kontrimavichus (2006a) regard it as species inquirenda.

22. Aploparaksis larina Fuhrmann, 1921 in Antarctic Larus dominicanus was regarded by us to be a synonym of $A$. brachyphallos (for details, see Bondarenko and Kontrimavichus, 2006b).

23. Aploparaksis lymnocrypti Bondarenko, 1966 in Lymnocryptes minimus from Siberia, Deblock and Rausch (1968) was considered to be a synonym of $A$. hirsuta, a decision with which we agree.

24. Aploparaksis linstowi Kintner, 1938 in Passeriformes from Germany was considered by Spasskaya (1966) to be a synonym of Passerilepis passeris (Gmelin, 1790) Yamaguti, 1959.

25. Aploparaksis moensis Oschmarin, 1963 in Calidris tenuirostris from Primorskiy Kray was considered by Bondarenko and Kontrimavichus (2006a) to be a synonym of $A$. stricta.

26. Aploparaksis moldavica Spasskaya et Shumilo, 1971 was described in Gallinago gallinago from Moldova. The type material is lost. Bondarenko et al. (2002) consider it to belong to A. crassirostris.

27. Aploparaksis murmanica Baylis, 1919 was described in Somateria mollissima from the Kola Peninsula of Russia. This species was characterised by diorchoid hooks, and therefore Baer (1956) and Spassky (1963) considered that $A$. murmanica does not belong to the genus Aploparaksis.

28. Aploparaksis numenii Kulachkova, 1969 was described in Numenius arquatus on the coast of the White Sea. We considered this species (Bondarenko and Kontrimavichus, 2006a) to be a synonym of $A$. sphaerophora (see discussion above).

29. Aploparaksis passerellae Webster, 1952 in Passeriformes from Alaska was transferred by Spassky (1961) to Monorcholepis passerellae (Webster, 1952). 
30. Aploparaksis porzana (Fuhrmann, 1924) was poorly described in Porsana porsana (L.) from Europe as a member of genus Hymenolepis. On the basis of the shape of rostellar hooks of a single specimen in $P$. pusilla from Western Siberia, Dubinina (1953) assumed that the species could be allocated within Aploparaksis. Bondarenko and Kontrimavichus (2006a) consider it to be species inquerenda.

31. Aploparaksis primus Szidat, 1964 was poorly described in Larus dominicanus from Argentina. This species is known only from a single record (Szidat, 1964). Bondarenko and Kontrimavichus (2006a) prefer to regard it as species inquirenda.

32 Aploparaksis pseudofurcigera Mathevosian in Skrjabin and Mathevosian (1945) in Anas platyrhynchos from the Leningrad Region was considered by Bondarenko and Kontrimavichus (2006a) to be a synonym of $A$. furcigera.

33. Aploparaksis pubescens (Krabbe, 1882) in Lymnocryptes minima arose through a clerical error in the original description of T. hirsuta by Krabbe (1882). Clerc $(1903,1910)$ corrected the error and transferred the species to the genus Aploparaksis under the name A. hirsuta.

34. Aploparaksis rhomboidea (Dujardin, 1845) in Anseriformes was considered by Fuhrmann (1932) to be a synonym of $A$. furcigera.

35. Aploparaksis shiraishii Sawada et Kifune 1974 in Gallinago megala from Japan was considered by Bondarenko and Kontrimavichus (2006a) to belong to A. spinosus.

36. Aploparaksis skrjabini Spassky, 1945 was described in Garrulus glandularius from the Smolensk region of Russia. This species is inadequately described and known only from a single record; the type material was not deposited in a collection. Bondarenko and Kontrimavichus (2006a) considered it to be species inquirenda.

37. Aploparaksis skrjabinissima Spasskaya, 1950 was described in Tringa glareola from Western Siberia, Russia. The type specimen is lost. Bondarenko and Kontrimavichus (2006a) considered this species to be species inquirenda.

38. Aploparaksis sobolevi Oschmarin et Morosov, 1948 in Gallinago gallinago from the mid- dle part of the Volga basin was considered by Spassky (1963) to belong to A. penetrans.

39. Aploparaksis sovieticus Deblock, Capron et Rose, 1960 was a new name for A. cirrosa (Krabbe, 1869) Clerc, 1903 in Spasskaya (1957) in gulls of Yakutia, which was proposed by Deblock et al. (1960) based on cestodes characterized by a single testis and an unusual shape of the eggs. Bondarenko and Kontrimavichus (2006a) re-examined the material of Spasskaya and revealed that the description of $A$. cirrosa by Spasskaya (1957) was a composite based on specimens of different genera; therefore, they considered the name A. sovieticus to be invalid.

40. Aploparaksis stefanski Czaplinski 1955 was described in Anas platyrhynchos dom. from Poland. Spassky and Freze (1961) attributed the species as a synonym of Diorchis elisae (Skrjabin, 1914) Spassky et Freze, 1961.

41. Aploparaksis tandani Singh, 1952 was scantily described in Tringa hypoleucos from India; this description does not allow it to be differentiated from other species of the genus. The type material was not found, and Bondarenko and Kontrimavichus (2006a) considered this species to be species inquirenda.

42. Aploparaksis tinamoui Olsen, 1970 was described in Nothoprocta perdicaria from the Chilean Andes. Studying the type specimens has shown the presence of three testes in the proglottids, which allowed Bondarenko and Kontrimavichus (2006a) to transfer this species to the genus Wardium.

43. Aploparaksis uelcal Spassky et Jurpalova, 1969 in Phalaropus fulicarius from Chukotka, Bondarenko and Kontrimavichus (2006a) was considered to be a synonym of $A$. brachyphallos.

44. Aploparaksis veitschi Baylis, 1934 was poorly described in Anas gibberifrons Müller from Australia. Spassky and Freze (1961) excluded this species from Aploparaksis as being inapplicable to the generic diagnosis and assumed that the species could be allocated within the group of Hymenolepididae, which includes the genera Diorchis and Microsomocanthus.

A re-examination of the collections allows us to identify the following Aploparaksis spp. 
that were formerly unidentified at the species level. These are the following:

Aploparaksis sp. Bondarenko, $1975=$ A. xemae Schiller, 1951;

Aploparaksis sp. 2 Belopolskaya, $1969=$ A. lat eralis Spassky et Yurpalova, 1968;

Aploparaksis sp. II Belopolskaya et Kulachkova, $1970=$ A. crassipenis Deblock et Rausch, 1968;

Aploparaksis sp. Hromada et Macko, $1995=$ A. mackoi Bondarenko et Hromada, 2004;

Aploparaksis sp. Spassky, 1963 ex parte $=$ A. andrei Spassky, 1965 .

\section{DISCUSSION}

Until recently, the genus Aploparaksis, together with two other related genera, Monorcholepis Oshmarin, 1963 and Wardium Mayhew, 1925, were recognised by the majority of authors as members of the family Hymenolepididae Ariola, 1899, although in order to accommodate hymenolepidids, which had a single testis, Mayhew (1925) created the new subfamily, Aploparaksinae Mayhew, 1925 for only one genus, Aploparaksis. Simultaneously, Mayhew (1925) erected the genus Wardium within the subfamily Hymenolepidinae Perrier, 1879, which was characterized by three testes that were variable in position in the different proglottids of the strobila. Inter alia, Spassky and Spasskaya (1954) and Spassky (1963, 1975) considered that Wardium belongs to the subfamily Aploparaksinae. Next, Spassky (1992) raised the status of Aploparaksinae to the level of a full family. Nevertheless, certain subsequent authors have not accepted Aploparaksidae, and according to the key of Czaplinski and Vaucher (1994), Aploparaksis and Wardium are recognised as members of the subfamily Hymenolepidinae. Analysis of the results of our investigation supported the validity of the family Aploparaksidae, but in contrast to Spassky (1975, 1992), we limited the composition of the family to three genera, namely, Aploparaksis, Wardium, and Monorcholepis. Furthermore, the composition of the genus Wardium was revised by Bondarenko and Kontrimavichus
(2004, 2006a). We should mention that we concluded that Spassky (1992) was mistaken by including the subfamily Nematoparataeniinae Poche, 1926 within Aploparaksidae because they are neither morphologically nor ontogenetically compatible.

All taxa within the family Aploparaksidae are notably similar morphologically, differing slightly in details. Thus, both Aploparaksis and Wardium are characterized by the presence of ten rostellar hooks and in other respects are distinguished only by the number of testes per proglottid. In contrast, the number of rostellar hooks in the species of the genus Monorcholepis always exceeds ten (up to twice as many or more), but the rest of their morphology is identical to Aploparaksis (Tanureria) spp.; both genera are characterized by the presence of a single testis and the antiporal position of the vitellarium relative to the ovary. When the genus Monorcholepis was erected by Oshmarin (1963) for the species originally described as Aploparaksis dujardini (Krabbe, 1869) in passeriform birds, other species with the same topography of the gonads were unknown among Aploparaksis spp. Spassky and Jurpalova (1968) established the subgenus Aploparaksis (Tanureria) when describing $A$. (Tanureria) diagonalis. At present, eight species correspond to the diagnosis of this subgenus.

The combination of morphological characters for adults, the morphogenesis and the structure of a mature metacestode, the range of intermediate and definitive hosts, and the site of its location within both hosts were employed to diagnose each of these species. This revision enabled us to restrict the species composition of the genus, and as a result, the validity of 58 of 102 described or recorded species of Aploparaksis was recognized. Annelids were exclusively determined to be the intermediate hosts for all studied species and were often demonstrated to be highly host-species specific. The patterns of development and the morphology of mature metacestodes (Bondarenko, 1973, 1978, 1989, 1990a, b, 1993a, b, Bondarenko and Kontrimavichus 1976a, b, 1979, 2005, 2006a, c, and others), indicated the presence of six morphological 
modifications of a cysticercoid (four were first established by us): autotomicercus, ramicercus, floricercus, caudate diplocyst, ovoid diplocyst, and typical diplocyst. The modifications of the cysticercoid form a compatible series that demonstrates a sequential transformation of the tail into an additional protective structure, which is referred to as an exocyst. The results of this study allow us to subscribe to the concept promoted by a number of authors (Burt and Jarecka 1982, Demshin 1984b, Freeman, 1973, 1982, Jarecka, 1975, Stunkard 1967, 1975) that invertebrate intermediate hosts are the primary hosts in the evolutionary history of the life cycles of cestodes (for details, see Bondarenko and Kontrimavichus, 2004), and therefore there is a reason to suppose that the distinguishing features of the Aploparaksidae are not only the morphological peculiarities of the adult stages and their postembryonic morphogenesis, but also the exclusive use of annelids (not arthropods as Hymenolepididae) in their life cycles. We consider the latter factor especially important because it illustrates the ancient phylogenetic isolation of the group.

The greatest species diversity of Aploparaksis occurs in Scolopacinae. We studied the life cycles of eight of the 13 species recorded in the common snipe, Gallinago gallinago. Their metacestodes turned out to belong to the three different modifications of cysticercoid. A "typical diplocyst" was determined for A. filum, A. parafilum, A. pseudofilum and A. sanjuanensis; a "caudate diplocyst" for A. gallinagii and A. thomasi, and a "ramicercus" for A. orientalis and $A$.penetrans. A similar situation was noticed among the seven species of Aploparaksis, which are parasites of the woodcock Scolopax rusticola. Three species - A. australis, A. filum, and A. pseudofilum - have a "typical diplocyst", three other species - A. demshini, A. kornjuschini, and A. scolopaceus - have an "ovoid diplocyst", and A. sinensis has a "caudate diplocyst". It is reasonable that, given the insignificant morphological differences in adults, the differences in the morphology of metacestodes in a number of cases turned out to be the conclusive argument in favour of the validity of these species.
Because we assume that interrelations between ancestral aploparaksids and annelids may be more ancient, the range of intermediate hosts can serve as an additional criterion for the differentiation of closely related species, for example, A. clangulae and both A. furcigera and A. polystictae, or A. brachyphallos and A. gallinagii.

The data on the site of the metacestode within the intermediate host were also useful in certain cases. Thus, metacestodes of both A. australis and A. filum developed in the connective tissue of the ventral nerve cord of earthworms, whereas metacestodes of the morphologically close species A. parafilum and A. pseudofilum developed in the coelom of earthworms, and $A$. demshini and A. kornjuschini under the chloragogenous tissue of the intestines of earthworms.

The locality of the strobilate worm within the intestine was found in a number of cases to be strictly species-specific. A. penetrans, for example, was found exclusively in the duodenum, whereas A. thomasi, A. hirsuta, A. octacantha, $A$. rauschi, and $A$. retroversa were observed mainly in the caecum. We considered the accidental recovery of specimens of these species in the small intestine of birds to be post-mortem.

The results of morphological and ontogenetic investigations, which we applied to the examination of the taxonomic structure of the family Aploparaksidae and genus Aploparaksis, cannot, however, resolve all the problems. First, determining the taxonomic status of several polyhostal forms from the number of species parasitising charadriiformes is difficult, e.g., A. (A.) brachyphallos, A. (A.) xemae, $A$. (T.) diagonalis, and certain others. The samples of these species frequently occurred in different groups of definitive hosts, which provided grounds for supposing that either we were dealing with a species complex or with a notably complicated intraspecific structure of these taxa. Second, the problem of the relationships between the species of the subgenus Aploparaksis (Tanureria) and genus Monorcholepis can hardly be said to be entirely solved. Spassky and Spasskaya (1972) mentioned the intermediate morphological position for species of the subgenus Tanureria relative to those of 
Aploparaksis and Monorcholepis. They questioned the validity of Monorcholepis and discussed its possible position as a subgenus within Aploparaksis. Bondarenko and Kontrimavichus (2002a, 2006a) returned to this question when discussing certain intricate taxonomic problems of Aploparaksidae. These researchers mentioned that the data on the morphological characteristics, the life cycle, and development in the definitive host were not currently sufficient for proposing an explicit hypothesis concerning the phylogenetic relationship between the species with an antiporal position of the vitellarium and the other Aploparaksis spp. with the usual arrangement of gonads. We take it into account that additional criteria are needed to answer that question. A molecular analysis is likely to contribute to the answer.

\section{ACKNOWLEDGEMENTS}

Our sincere appreciation goes to the entire staff of the Laboratory of Ecology of Helminths and Ornithology at the Institute of Biological Problems of the North (IBPN) of the Russian Academy of Sciences (Magadan), with special thanks to Gennady Atrashkevich, Liubov Kondratyeva, Aleksander Kondratyev, Olga Orlovskaya, and Kira Regel for their constant assistance in collecting materials and carrying out experimental research. We are also grateful to the curators of various parasitological collections for the loan of specimens to study: INPA (Larisa Filimonova), ZIN (Aleksander Galkin, Marie Dubinina, Valentina Kulachkova), former USNPC held in the Biosystematics Parasitology Unit, USDA, Agricultural Research Service (Ralph Lichtenfels, Eric Hoberg and Patricia Pillit), NHMG (Claude Vaucher, Alain de Chambrier and Jean Mariaux), BMNH (David Gibson, Rodney Bray and Eileen Harris), HWML (Scott Gardner and M. Sterner), CLAB (Todor Genov, Boyko Georgiev), and those from other museums that contributed to our work. We owe a huge debt to Marie Belopolskaya for presenting her large collection of Aploparaksis, which was collected in different parts of Russia. Robert L. Rausch and Virginia R. Rausch provided access to the collections of cestodes from North America, many of which are now held in the Parasitology Division of the MSB at the University of New Mexico (Sara Brant). We are grateful to Aleksey Spassky for discussing Aploparaksidae with us and for the loan of slides of Aploparaksis from the Republic of Tuva identified by him and Lidiya Spasskaya. In particular, we need to thank Eric Hoberg for all-round assistance in preparation of this manuscript over a number of years, as well as Boyko Georgiev, the Editor, and two anonymous referes for providing some useful comments and for assistance with the language. We also thank Leonas Kontrimavičius for his valuable assistance with the preparation of illustrations for this publication.

Investigations into Aploparaksis were started when the present authors worked at the Helminthological Laboratory of the Academy of Sciences USSR (Moscow) and were in progress at the IBPN and the Institute of Ecology of the Nature Research Centre (Lithuania). This work was completed with the financial support of the International Science Foundation (grant LE 3000) and the Lithuanian State Research and Studies Foundation.

Received 27 September 2017 Accepted 4 October 2017

\section{References}

1. Ablasov NA. Helminth fauna of domestic and wild waterfowl of Kirgizia. PhD thesis. Moscow: K. I. Skrjabin Institute of Helminthology; 1953. 198 p. Russian.

2. Baer JG. Parasitic helminths collected in West Greenland. Meddelelser om Grønland. 1956;124: 5-55.

3. Baer JG. The Zoology of Iceland. Vol. 2, part 12. Cestoda. Ejnar Munksgaard, Copenhagen and Reykjavik; $1962.63 \mathrm{p}$.

4. Baylis HA. A collection of Entozoa, chiefly from Birds, from the Murman Coast. Annals and Magazine of Natural History. 1919; 3, Ser. 9: 501-515. 
5. Baylis HA. Some parasitic worms from Australia. Parasitology. 1934; 26: 129-32.

6. Bailys HA. Records of some parasitic worms from British vertebrates. Annals and magazine of natural history. 1939; Ser. 11 4(23): 473-88.

7. Bayanov MG. Helminths of shorebirds in South Urals. In: Bol'shakov NV, editor. Materialy po faune i ekologii zhivotnyh. Sverdlovsk: Institute of Ecology of the Academy of Sciences USSR; 1977. pp. 39-51. Russian.

8. Belopolskaya MM. Cestodes of the genus Aploparaksis Clerc, 1903 (Hymenolepididae) from shorebirds. Parazitologicheskiy sbornik. 1969; 24: 44-50. Russian.

9. Belopolskaya MM, Kulachkova VG. Pseudocapsules of cestodes of the genus Aploparaksis Clerc, 1903 subgenus Globarilepis Bondarenko, 1966. Parazitologiya. 1968; 2: 502-6. Russian.

10. Belopolskaya MM, Kulachkova VG. Cestodes of the genus Aploparaksis, parasites of ducks (Anatida) and shorebirds (Charadriidae) from the White Sea. Trudy Kandalashkogo zapovednika. 1970; 8: 313-55. Russian.

11. Bondarenko SK. Cestodes of the genus Aploparaksis Clerc, 1903 (Hymenolepididae) from the shorebirds in lowland of the Yenisey River and Norilsk Lakes. Trudy Helmintologicheskoy Laboratorii AN SSSR. 1966a; 17: 19-34. Russian.

12. Bondarenko SK. New trematodes and cestodes from shorebirds in Arctic regions of Asiatic part of USSR. In: Ershov VS, editor. Materialy k nauchnoj konferentsii Vsesoyuznogo obshchestva gel'mintologov. Moscow: Vsesoyuznoe obshshestvo gel'mintologov; 1966b. pp. 50-60. Russian.

13. Bondarenko SK. Helminth fauna of shorebirds in North of the Middle Siberia. Trudy Helmintologicheskoy Laboratorii AN SSSR. 1969; 20: 35-45. Russian.

14. Bondarenko SK. Modifications of larvae of the genus Aploparaksis (Hymenolepididae). In: Bezubik B, Czaplinski B, editors. Materials of the International Conference of the Hy- menolepididae. Warszawa: Polish Academy of Sciences; 1973. p. 8-10.

15. Bondarenko SK. Cestodes of the genus Aploparaksis Clerc, 1903 (Hymenolepididae) from charadriiform birds in Chaun lowland (fauna, morphology and life cycles). In: Kontrimavichus VL, editor. Paraziticheskie Organizmy Severo-Vostoka Azii. Vladivostok: Academy of Sciences of USSR, Far-East Science Centre; 1975a. pp. 44-77. Russian.

16. Bondarenko SK. Cestodes of the Genus Aploparaksis Clerc, 1903 (Hymenolepididae) from ducks (Anatidae) and their life cycles. In: Kontrimavichus VL, editor. Paraziticheskie Organizmy Severo-Vostoka Azii. Vladivostok: Academy of Sciences of USSR, Far-East Science Centre; 1975b. p. 78-96. Russian.

17. Bondarenko SK. Postembryonal development of cestodes of the genus Aploparaksis Clerc, 1903 (Hymenolepididae) with a cystercercoid of the diplocyst type. Parazitologiya. 1978; 12: 345-8. Russian.

18. Bondarenko SK. Systematic position and life cycle of two species of cestode of the genus Aploparaksis from shorebirds (Charaddriiformes) of Chukotka. Trudy Gelminyhologicheskoy Laboratorii Akademii Nauk SSSR. 1979; 29: 16-21. Russian.

19. Bondarenko SK. Changes of the systematic status of cestodes Aploparaksis diminuens Linstow, 1905 and A. acanthocirrus Deblock et Rausch, 1968. In: Markevich AP, editor. Tezisy IX Konferentsii Ukrainskogo Parazitologicheskogo Obschestva, 5. Kiev: Naukova Dumka; 1980. p. 13-14. Russian.

20. Bondarenko SK. Aploparaksis kulachkovae sp. n. (Cestoda, Hymenolepididae), a new parasite of Anatidae. Parasitologya. 1987; 21(2): 121-6. Russian.

21. Bondarenko SK. Aploparaksis belopolskajae sp. n., a new species of hymenolepidids of birds. Parasitologya. 1988; 22(2): 86-9. Russian.

22. Bondarenko SK. Aploparaksis australis Johnston, 1911, and its life-cycle. Acta Parasitologica Lituanica. 1989; 23: 99-114. Russian. 
23. Bondarenko SK. Type species of the genus Aploparaksis (Cestoda: Hymenolepididae) A. filum and its life cycle. Parazitologiya. 1990a; 24: 37989. Russian.

24. Bondarenko SK. Aploparaksis pseudofilum (Clerc, 1903) non Gasowska, 1931, and its postembryonal development. Parazitologiya. 1990b; 24: 509-17. Russian.

25. Bondarenko SK. Aploparaksis scolopacis Yamaguti, 1935 and its ecology. Parazitologya. 1993a; 27(3): 251-9. Russian.

26. Bondarenko SK. A ramicerc in the life-cycles of three species of the genus Aploparaksis (Cestoda) - parasites of waders. Parazitologiya. 1993b; 27: 375-84. Russian.

27. Bondarenko S, Hromada M. Aploparaksis mackoi n. sp. (Cestoda: Hymenolepididae), a parasite of the common snipe Gallinago gallinago (L.) from the Slovak Republic. Systematic Parasitology. 2004; 58: 63-7.

28. Bondarenko S, Komisarovas Y. Redescription of Monorcholepis dujardini (Krabbe, 1869) and M. passerellae (Webster, 1952) (Cestoda: Cyclophyllidea: Aploparaksidae) in passerine birds from the Holarctic Region. Folia Parasitologica. 2007; 54: 68-80.

29. Bondarenko SK, Kondratyeva LF. On the cestode fauna of the genus Aploparaksis Clerc, 1903 (Hymenolepididae) of birds of the family Anatidae. Acta Parasitologica Lituanica. 1985; 21: 507-17. Russian.

30. Bondarenko SK, Kontrimavichus VL. Polymorphism of larvae of the genus Aploparaksis Clerc, 1903 (Hymenolepididae). Folia Parasitologica. 1976a; 23, 39-44.

31. Bondarenko SK, Kontrimavichus VL. Differentiation of intermediate hosts and polymorphism of larvae of cestodes of the genus Wardium Mayhew, 1925. Doklady Akademii nauk SSSR. 1976b; 230: 489-91 Russian.

32. Bondarenko SK, Kontrimavichus VL. The life cycle and post-embryonic development of Aploparaksis (Tanureria) diagonalis Spasski et Bobova, 1961, a parasite of Charadriiformes.
In: Sonin MD, editor. Ekologiya i morfologiya gelmintov pozvonochnykh Chukotki. Moscow: Nauka; 1979. p. 38-45. Russian.

33. Bondarenko SK, Kontrimavichus VL. The helminth fauna of Charadriiformes in Alaska: zoogeographical features and origin. Russian Journal of Zoology. 1999; 2(2): 250-9. Russian.

34. Bondarenko SK, Kontrimavichus VL. Aploparaksis americanensis sp. nov. and A. paraspinosus sp. nov., two new species of cestodes (Hymenolepididae) from snipe in America. Zoologicheskiy Zhurnal. 2001; 80(3): 269-77. Russian.

35. Bondarenko SK, Kontrimavichus VL. Cestodes of the genus Aploparaksis Clerc, 1903 (Hymenolepididae): results of research and unsolved issues. In: Alimov AF, editor. The problems of Cestodology 2. St. Petersburg: Zoological Institute of RAS; 2002a. p. 47-63. Russian.

36. Bondarenko SK, Kontrimavichus VL. Aploparaksis parafilum Gasowska, 1931 (Cestoda: Hymenolepididae) and its life cycle. In: Alimov AF, editor. The problems of Cestodology 2. St. Petersburg: Zoological Institute of RAS; 2002b. p. 34-46. Russian.

37. Bondarenko S, Kontrimavichus V. On Branchiopodataenia n. g., parasites in gulls, and its type-species, B. anaticapicirra n. sp. (Cestoda: Hymenolepididae). Systematic Parasitology. 2004; 57: 119-33.

38. Bondarenko S, Kontrimavichus V. Aploparaksis demshini n. sp. (Cestoda: Hymenolepididae), a parasite of the woodcock Scolopax rusticola (L.), and its life-cycle. Systematic Parasitology. 2005; 61: 53-63.

39. Bondarenko SK, Kontrimavichus VL. Aploparaksidae of wild and domesticated birds. Fundamentals of Cestodology 14. Moscow: Nauka; 2006a. 434 p. Russian.

40. Bondarenko S, Kontrimavichus V. Cestodes of genus Aploparaksis reported from gulls, with the description of new species. Journal of Natural History. 2006b; 40: 2589-610. 
41. Bondarenko S, Kontrimavichus V. Aploparaksis kornyushini n. sp. (Cestoda: Hymenolepididae), a parasite of the woodcock Scolopax rusticola (L.) and its life-cycle. Systematic Parasitology. 2006c; 63: 45-50.

42. Bondarenko SK, Kontrimavichus VL, Vaucher C. A revision of Aploparaksis crassirostris and A. sinensis (Cestoda: Hymenolepididae). Parazitologiya. 2002; 36: 119-31. Russian.

43. Bondarenko SK, Krasnoshchekov GP. Postembryonal development of the cestode Aploaraksis birulai (Hymenolepididae). Zoologicheskiy Zhurnal. 1978; 57: 485-94. Russian.

44. Bondarenko SK, Rausch RL. Aploparaksis borealis sp. n. (Cestoda: Hymenolepididae) from passeriform and charadriiform birds in Chukotka and Alaska. Journal of Parasitology. 1977; 63(1): 96-8.

45. Borgarenko LF. Helminths of birds in Tadzhikistan. Book I. Cestodes. In: Spassky AA, Editor. Dushanbe: Donish; 1981. 327 p. Russian.

46. Burt MDB, Jarecka L. Phylogenetic host specificity of cestodes. Mémoires du Muséum natural d'histoire naturelle, Nouvelle série. 1982; 123: $47-52$.

47. Czaplinski B. Aploparaksis stefanskii sp. n. - nowy gatunek tasiemca zrodziny Hymenolepididae Fuhrmann, 1907 u kaczki domowej (Anas platyrhynchos dom.). Acta parasitologica Polonica. 1955; 2(15): 303-18. Polish.

48. Czaplinski B, Vaucher C. Family Hymenolepididae Ariola, 1899. In: Khalil LF, Jones A, Bray R, editors. Keys to the cestode parasites of vertebrates. Wallingford: CAB International; 1994. p. 595-663.

49. Canaris AG. Ortiz R, Canaris GJ. A predictable suite of helminth parasites in the longbilled dowitcher, Limnodromus scolopaceus, from the Chihuahua Desert in Texas and Mexico. Journal of Parasitology. 2010; 96(6): 1060-5.

50. Clerc W. Contribution à l'etude de la faune helminthologique de l'Oural. Pt. 1, 2. Zoologischer Anzeiger. 1902; 25: 569-75, 650-64. French.
51. Clerc W. Contribution a l'etude de la faune helminthologique de l'Oural. Revue Suisse de Zoologie. 1903; 11: 241-368. French.

52. Clerc W. Systematic list of intestinal parasites of birds in Midle and South Urals. Zapiski Ural'skogo obshchestva lubitelej estestvoznanya. 1910; 30: 99-113. Russian.

53. Davies TJ. Three closely related species of Aploparaksis Clerc, 1903. Parasitology. 1940; 32: 198-207.

54. Deblock S, Biguet J, Capron A. Contribution a letude des cestodes de Lari des cotes de France. 1. Le genre Hymenolepis. Annales de Parasitologie Humaine et Comparée. 1960; 35(4): 538-74. French.

55. Deblock S, Capron A, Rose F. Redescription d'Hymenolepis (nec Aploparaksis) cirrosa (Krabbe, 1869) (Cestoda, Hymenolepididae). Bulletin of the Zoological Society of France. 1960; 85(1): 58-67. French.

56. Deblock S, Raush R. Dix Aploparaksis (Cestoda) de Charadriiformes d'Alaska et quelques autres d'ailleurs. Annales de Parasitologie Humaine et Comparée. 1968; 43(4): 429-48. French.

57. Demshin NI. Postembryonal development of the cestode Aploparaksis filum (Goeze, 1782) (Hymenolepididae). In: Oshmarin PG, editor. Ekologiya gel'mintov: mezhvuzovskii tematicheskii sbornik. Yaroslavl': Yaroslavskiy Gosudarstvenniy Universitet; 1981a. p. 18-23. Russian.

58. Demshin NI. On the fauna of the larval cestodes in oligochaetes from the Primorskiy Kray. In: Mamaev YL, Demshin NI, editors. Biologia i systematika gel'mintov zhivotnyh Primorskogo Kraya. Vladivostok: Dal'nevostochnyi Nauchnyi Centr AN SSSR; 1981b. p. 28-34. Russian.

59. Demshin NI. Postembryonal development of the cestode Aploparaksis crassirostris (Hymenolepididae). Parazitologiya. 1984a; 18: 40-6. Russian.

60. Demshin NI. Evolution of host-parasite relationships between oligochaetes and larvae of 
helminths. In: Oshmarin PG, editor. Voprosy ecologicheskoy Gelmintologii. Yaroslavl': Yaroslavskiy Gosudarstvenniy Universitet; 1984b. p. 16-26. Russian.

61. Demshin NI. Postembryonal development of two species of cestodes of the genus Aploparaksis (Cyclophyllidea, Hymenolepididae). Zoologicheskiy Zhurnal. 1985; 64: 16-23. Russian.

62. Dubinina MN. Tapeworms of birds nesting in the Western Siberia. Parazitologicheskiy Sbornik. 1953; 15: 117-234. Russian.

63. Dujardin F. Histoire naturelle des helminthes ou vers intestinaux. Paris: Libraiie Encyclopédique de Roret; 1845. 684 p. French.

64. Floress-Barroeta L. Cestodes de vertebratos II (i). Revista ibérica de parasitología. 1953; 15(2): 115-34.

65. Furhmann O. Die Hymenolepisarten der Vogel. Centralblatt für Bacterologie, Abteilung Originale. 1906. 42(8): 730-55. German.

66. Fuhrmann O. Die Cestoden der Vögel. Zoologische Jahrbücher Suppl. 1908; 10: 232. German.

67. Fuhrmann O. Die Cestoden des Deutschen Südpolar Expedition: 1901-1903. Deutsche Südpolarexpedition 1901-1903. Bd. 16. Zoologie. 1921; 8: 469-524. German.

68. Fuhrmann O. Les Ténias des Oiseaux. Mèmoires de l'Universitè de Neuchatel. 1932; 8: 1-383. French.

69. Freeman RS. Ontogeny of cestodes and its bearing on their phylogeny and systematics. Advances in Parasitology. 1973; 11: 481-557.

70. Freeman RS. How did tapeworms get that way? Bulletin Canadian Society of Zoologists. 1982; 13: 5-8.

71. Gasowska M. Die Vögelcestoden aus der Umgebung von Kiew (Ukraine). Bulletin de'l Academie Polonaise des Sciences. Serie des sciences biologiques. 1931; 11: 599-627. German.

72. Ginetsinskaya TA, Naumov DV. Helminth fauna of some species of shorebirds of White Sea. In: Ershov VS, editor. Raboty po gel'minthologii k 80-letiyu akademika K. I. Skryabina. Moscow: Izdatel'stvo AN SSSR; 1958. p. 99-108. Russian.

73. Goeze JAE. Versuch einer Naturgeschichte der Eingeweidewürmer-tierischer Körper. Blankenburg; 1782. 471 p. German.

74. Gomez MPI. Helminthos parasitos de las aves de la provincial Granada. Maracena-Granada: Copartgraf; 1977. 210 pp.

75. Gubanov NM, Mamaev YuL. On the fauna of helminths from birds in the Yana River basin. In: Popov MV. (Ed.), Vertebrate animals of Yakutya. Yakutsk: Yakutknigoizdat; 1964. p. 11328. Russian.

76. Hanzelová V, Ryšavý B, Šnabel V. Synopsis of cestodes in Slovakia III. Cyclophyllidea: Amabiliidae, Acoleidae, Catenotaeniidae, Davaineidae and Hymenolepididae (in part). Helminthologia. 1995; 32: 67-73.

77. Hromada M, Macko JK. On the morphology and taxonomy of Aploparaksis pseudofilum (Hymenolepididae, Cestoda) from Gallinago gallinago L. and Scolopax rusticola L. (Charadriiformes) in Slovakia. Helminthologia. 1993; 30: 71-7.

78. Hromada M, Macko JK. Species composition and taxonomy of tapeworms of the family Hymenolepididae (Cestoda) from the host Gallinago gallinago (Charadriiformes) in the Carpathian Region of central Europe. Helminthologia. 1995; 32: 53-65.

79. Huan ShI. Helminth fauna of game birds in the lowland of the Amur River. Trudy Hel'mintologocheskoy Laboratorii Akademii Nauk SSSR. 1962; 12: 284-300. Russian.

80. Jarecka L. Ontogeny and evolution of cestodes. Acta Parasitologica Polonica. 1975; 23: 93-114.

81. Johnston H. Cestoda and Acanthocephala. Report of Australian Institute of Tropical Medicine for 1911-1913. 1913; p. 75-96.

82. Johri LN. On Cestodes from Burma. Parasitology. 1935; 27(1-4): 476-9.

83. Joyeux Ch, Baer JG. Note sur quelques helminthes recoltès en Macedonie. Bulletin de la 
Societe Pathologie Exotique. 1928; 21: 214-20. French.

84. Joyeux C, Baer JG. Faune de France 30. Cestodes. Paris: Paul Lechevalier; 1936. 613 p.

85. Kamburov P. Two new species of cestodes, Choanotaenia thracinensis and Aploparaksis bulgarica from woodcock (Scolopax rusticola). Izvestya na Centralnata Helmintologichna Laboratorya. 1969; 13: 185-90. Bulgarian.

86. Kinsella JM, Didyk AS, Canaris AG. Helminth parasites of dowitchers, Limnodromus griseus from Alaska, and Limnodromus scolopaceus from Montana, U.S.A. Comparative Parasitology. 2008; 75(2): 329-32.

87. Kintner KE. Notes on the cestode parasites of English sparrows in Indiana. Parasitology. 1938; 30(3): 347-57.

88. Kornyushin VV. Faunistical review of cestodes of birds from the coast of Black Sea. In: Markevich AP, editor. Fortieth anniversary of Black Sea Reserve. Kiev: Ukrainian Academy of Sciences; 1967. p. 55-9. Russian.

89. Kornyushin VV. Redescription of Aploparaksis scolopacis Yamaguti, 1935 (Cestoda, Hymenolepididae) from Scolopax rusticola L. in Ukraine. Acta Parasitologica Polonica. 1975; 23(14): 207-12.

90. Kornyushin VV, Bondarenko SK, Greben OB. Aploparaksis (Tanureria) vanelli sp. n. (Cestoda, Hymenolepididae) the parasite of lapwing (Vanellus vanellus L.) in Volyn. Vestnik Zoologii. 2006; 40: 131-5. Russian.

91. Kornyushin VV, Genov T, Yanchev Y, Vasilev I. Cestode fauna of wild birds in Bulgaria. In: Vasilev I, editor. Fauna, taksonomiya, ekologiya na helminti po ptici. Sofia: Bulgarian Academy of Sciences: 1984. p. 149-71. Bulgarian.

92. Kornyushin VV, Greben OB. A new species of hymenolepidid (Cestoda, Cyclophyllidea) of ducks in the fauna of Ukraine. Vestnik Zoologii. 2000; 14: 3-8. Russian.

93. Krabbe H. Bidrag til Kundskab om Fuglenes Baendelorme. Videnskabers Selskab Skrifter Naturvidenskabelige og Mathematiske Af- handlinger. Kjøbenhavn: 1869; 8: 249-363. Danish.

94. Krabbe H. Nye Bidrag til Kundskab om Fuglenes Baendelorme. Videnskabers Selskab Skrifter Naturvidenskabelige og Mathematiske Afhandlinger. Kjøbenhavn: 1882; 17: 350-66. Danish.

95. Krasnoshchekov GP, Bondarenko SK. Morphology of cysticercoids of cestodes of the genus Aploparaksis (Hymenolepididae). In: Kontrimavichus VL, editor. Paraziticheskye Organizmy Severo-Vostoka Azii. Vladivostok: Akademy of Sciences USSR, Far-East Science Centre; 1975. p. 217-223. Russian.

96. Krasnoshchekov GP, Bondarenko SK. Histochemical study of cysticercoids of cestodes of the genus Aploparaksis Clerc, 1903 (Hymenolepididae). Parazitologiya. 1976; 10: 25-9. Russian.

97. Krasnoschchekov GP, Nikishin VP. Ultrstructure of the protective membranes of the larval cestodes. In: Sonin MD, editor. Ecology and Morphology of Helminths of Vertebrates of Chukotka. Moscow: Nauka; 1979. p. 116-32. Russian.

98. Krotov AI. New cestodes (Hymenolepididae and Paruterinidae) from birds. Trudy Hel'mintologocheskoy Laboratorii Akademii Nauk SSSR. 1952; 4: 259-72. Russian.

99. Kulachkova VG. New species of cestodes of the genus Aploparaksis Clerc, 1903 from Numenius torquata $\mathrm{L}$. on the White Sea coast. In: Ershov VS, editor. Materialy Vsesoyuznogo Obshchestva Gel'mintologov, part 1. Moscow: Akademia Nauk SSSR; 1969. p. 138-42. Russian.

100. Leonov VA, Belogurov OI, Zueva LS. Hymenolepidids (Cestoda: Hymenolepididae) from waterfowls of Wrangel Island. Uchennye zapiski Dal'nevostochnogo gosudarstvennogo universiteta. 1970; 16: 37-45. Russian.

101. Leyva T, Canaris AG, Bristol JR. Helminths and ectoparasites of the common snipe (Gallinago gallinago) from Southwest Texas and Monte Vista National Wildlife Refuge, Colorado. Journal of Wildlife Diseases. 1980; 16: 549-57. 
102. Linstow OFB. Beobachtungen an Nematoden und Cestoden. Archiv für Naturgeschichte. Bd. 1904; 1: 305-307. German.

103. Linstow OFB. Helminthen der Russischen Polarexpedition 1900-1903. Mémoire de'l Academie des Sciences de St. Petersburg Cl. Phys.-Math. 1905; 18: 1-17. German.

104. Lopez-Neyra CR. Revisión del género Hymenolepis Weinland (s.l.) en otros mas naturales. Part 3. Revista Iberica Parasitologica. 1942; 2(2): 113-256. Spanish.

105. Lopez-Neyra CR. Conpendio de Helmintologia Iberica (continuacion). Parte 2, cap. 3. Family Hymenolepididae. Revista Iberica Parasitologica. 1942; 4(4): 403-91. Spanish.

106. Mahon J. On a collection of avian cestodes from Canada. Canadian Journal of Zoology. 1956; 34: 104-19.

107. Maksimova AP. Hymenolepidid cestodes of the waterfowl of Kazhastan. Alma-Ata: Nauka of Kazakh SSR; 1989. 224 p. Russian.

108. Mamaev JL. Fauna of helminths of gallinaceous and shorebirds in East Siberia. Trudy Hel'mintologocheskoy Laboratorii Akademii Nauk SSSR. 1959; 9: 160-74. Russian.

109. Mayhew RL. Studies on the avian species of the Cestode family Hymenolepididae. In: Forbes SA, Trelease W, Ward HB, editors. Illinois Biological Monographs. Vol. 10(1). The University of Illinois: Urbana, Illinois; 1925. $125 \mathrm{p}$.

110. Neslobinsky N. Zur Kenntnis der Vogeltänien Mittelrusslands. Centalblatt fur Bacteriologie, Parasitenkunde und Infektionskrankheiten. Abteilung Originale. 1911; 57: 436-42. German.

111. Olsen OW. Aploparaksis tinamoui n. sp. Cestode (Hymenolepididae) from the Chilean tinamou Notoprocta perdicaria (Kittlitz, 1830), Tinamiformes. Revista Iberica Parasitologica. 1970; 30(4): 701-18.

112. Oshmarin PG. Parasitic worms of mammals and birds in Primorskiy Kray. Moscow: Nauka; 1963. 323 p. Russian.
113. Oshmain PG, Morosov FI. Substitution of fixing function at cestode Aploparaksis sobole$v i$ nov. sp. Doklady Akademii nauk SSSR. 1948; 59(8): 1509-11.

114. Parona C. Catalogo di elminti raccolti in vertebrati dell' isola d'Elba dal Dott. Giacomo Damiani. Atti della Societa Ligustrica di Scienze naturalie geografiche Genova. 1899; 10: 85-100. Italian.

115. Parona C. Catalogo di elminti raccolti in vertebrati dell' isola d'Elba. Bollettino dei Musei di Zoologia e Anatomia Comparata Genova. 1902; 113: 1-20. Italian.

116. Pelgunov AN. Cestodes of shorebirds of the genus Calidris from Ob' Bay. Communication 1. Trudy Helmintologicheskoy Laboratorii Akademii Nauk SSSR. 1987; 35: 95-107. Russian.

117. Petrova K. Investigation of fauna of helminths of wild birds in Trakiya. III. Cestodes. Helminthologia. 1978; 5: 69-78. Bulgarian.

118. Prudhoe S, Manger BR. Three species of hymenolepidid cestodes from a charadriiform bird in North America. Annals and Magazine of Natural History. 1966; 13(9): 539-49.

119. Railliet A. Traité de zoologie médicale et agricole. 2nd ed. Paris; 1893. 736 p. French.

120. Railliet A. Sur le Cestodes blaireau. Bulletin de la Société zoologique de France. 1899; 17: 115-7. French.

121. Rausch R. Studien under Helminthenfauna von Alaska. IV. Haploparaksis galli n. sp. ein Cestode aus dem Schneehuhn, Lagopus rupestris (Gmelin). Zeitschrift für Parasitenkunde. 1951; 15: 1-3. German.

122. Rudolphi CA. Entozoorum Sive Vermium Intestinalium Historia Naturalis. 1810; 2(2): 386 p.

123. Ryšavý B, Farkaš J. The occurrence of tapeworms in snipe in Slovakia. Folia Venatoria. 1982; 12: 261-8.

124. Ryšavý B, Sonin MD. Cysticercoids of the cestode Aploparaksis diminuens (Linstow, 1905) (Cestoidea: Hymenolepididae). Folia Parasitologica. 1977; 24: 139-40. 
125. Ryzhikov KM. On the helminth fauna of King Eider. Trudy Helmintologicheskoy Laboratorii Akademii Nauk SSSR. 1960; 10: 173-87. Russian.

126. Ryzhikov KM, Gubanov NM, Tolkacheva LM, Khokhlova IG, Zinovyeva EN, Sergeeva TP. Helminths of birds in Yakutiya and contiguous territories. Cestodes and Trematodes. Moscow: Nauka: 1974. 340 p. Russian.

127. Sawada I, Kifune T. Studies on the Helminth Fauna of Kyushi. Part 2. Four new cestodes from wild birds in Fukuoka Prefecture. Bulletin of Nara University of Education. 1974; 23(2): 15-29.

128. Schiller EL. Studies on the helminth fauna of Alaska. 1. Two new cestodes from Sabine's gull (Xema sabini). Journal of Parasitology. 1951a; 37: 266-72.

129. Schiller EL. Studies of the helminth fauna of Alaska. VIII. Some cestode parasites of the Pacific kittwake (Rissa tridactyla Ridgway) with the description of Haploparaxis rissae sp. $\mathrm{n}$. Proceeding of the Helminthological Society of Washington. 1951b; 20: 122-5.

130. Schiller EL. Studies of the helminth fauna of Alaska. 13. Some cestode parasites of eider duck. Journal of Parasitology. 1955; 41: 79-88.

131. Schmidt GD. Parasites from the common snipe, Capella gallinago in Northern Colorado. American Midland Naturalist Journal. 1964; 71: 501 .

132. Schmidt GD. CRC handbook of tapeworm identification. Boca Raton, FL: CRC Press, Inc.; 1986.675 pp.

133. Schmidt GD, Neiland KA. Hymenolepis (Hym.) deblocki sp. n. and records of other helminths of charadriiform birds. Canadian Journal of Zoology. 1968; 46: 1037-40.

134. Shigin AA. 1961. The helminth fauna of lariform birds in the Rybinsk water reservoir. Trudy Darvinskogo Gosudarstvennogo Zapovednika. 1961; 7: 309-62. Russian.

135. Singh KS. Cestode parasites of birds. Indian Journal Helminthology. 1952; 4: 1-72.
136. Skryabin KI. Vogelcestoden aus Russisch Turkestan. Zoologische Jahrbuecher Abteilung für Systematik Oekologie und Geographie der Tiere. 1914; 37: 411-92. German.

137. Skrjabin KI, Mathevosian EM. Hymenolepidid tapeworms of domesticated and game birds. Moscow: Sel'hozgiz; 1945. 487 p. Russian.

138. Solowiow P. Helminthologische Beobachtungen Cestoden avium. Centralblatt für Bakteriologie, Parasitenkunde und Infektionskrankheiten. 1911; 60: 93-132. German.

139. Spasskaya LP. New hymenolepidids from waders in Chany Lake. Trudy Helmintologicheskoy Laboratorii Akademii Nauk SSSR. 1950; 3: 199-205. Russian.

140. Spasskaya LP. Cestode fauna of birds in Yakutia. 1. Acta Veterinaria Academiae Scientiarum Hungaricae. 1956; 6: 287-313. Russian.

141. Spasskaya LP. Cestode fauna of birds in Yakutia. 2. Acta Veterinaria Academiae Scientiarum Hungaricae. 1957; 7. 101-128. Russian.

142. Spasskaya LP. Cestodes from birds in Tuva. 7. Hymenolepididae. Acta Veterinaria Academiaae Scientiarum Hungaricae. 1964; 14: 19-34. Russian.

143. Spasskaya LP. Cestodes of birds of the USSR. Hymenolepididae. Moscow: Nauka; 1966. 698 p. Russian.

144. Spasskaya LP, Shumilo RP. Tree new species of cestodes in shorebirds from Moldova. Izvestya Akademii nauk Moldavii, Seriya biologicheskikh i chimicheskikh nauk. 1971; 1: 56-64. Russian.

145. Spasskaya LP, Spassky AA. Cestodes of birds in Tuva. Shtiintsa Kishinev; 1971. 252 p. Russian.

146. Spassky AA. To knowledge on the cestode fauna of the bird of USSR. Gel'mintologicheskiy Sbornik Posvyashchennyi Akademiku KI. Skryabinu. Moscow: Akademia Nauk SSSR; 1946. p. 252-62. Russian.

147. Spassky AA. Specification of the species composition of some hymenolepididean genera. Trudy Helmintologicheskoy Laboratorii Akademii Nauk SSSR. 1956; 8: 214-25. Russian. 
148. Spassky AA. Key to the species of Aploparaksis Clerc (Hymenolepididae). Helminthologia. 1961; 3: 358-63.

149. Spassky AA. Hymenolepidids-helminths of wild and domestic birds. Part 1. Fundamentals of Cestodology, 2. Moscow: Akademya Nauk SSSR; 1963.418 p. Russian.

150. Spassky AA. Cestodes of the genus Aploparaksis from birds of Kamchatka. In: Oshmarin PG, editor. Paraziticheskie chervil domashnikh i dikikh zhivotnykh. Vladivostok: Dal'nevostochnyi Filial SO AN SSSR; 1965. p. 303-12. Russian.

151. Spassky AA. On the species composition of the genera Oligorchis and Wardium and observation on systematics of hymenolepidids of Charadriiformes. Parazity Zhivotnykh i Rasteniy. Shtiintsa Kishinev. 1975; 11:3-26. Russian.

152. Spassky AA. Two new tribes and the structure of superfamily Hymenolepidea (Cestoda: Cyclophyllidea). Helminthologia. 1992; 29: 167-70.

153. Spassky AA, Bobova LP. Three new species of cestodes of the genus Aploparaksis (Hymenolepididae). Helminthologia. 1961; 3: 34657. Russian.

154. Spassky AA, Freze VI. Revision of the genus Aploparaksis. In: Petrov AM, editor. Tezisy dokladov Vsesoyuznogo obshchestva gel'mintologov. Moscow: Vsesoyuznoe obshchestvo gel'mintologov; 1958. p. 136-44. Russian.

155. Spassky AA, Freze VI. Review of genus Aploparaksis Clerc, 1903 (Cestoda: Hymenolepididae). Československe parasitologie. 1961; 7: 385-9. Russian.

156. Spassky AA, Spasskaya LP. Systematics of the Hymenolepididae parasitising birds. Trudy Helmintologicheskoy Laboratorii Akademii Nauk SSSR. 1954; 7: 55-119. Russian.

157. Spassky AA, Spasskaya LP. 1972. Genera Monorcholepis Oshmarin, 1961, Chimaerolepis gen. n., and subfamily Aploparaksinae (Cestoda: Hymenolepididae). Parazity Zhivotnyh i Rasteniy Shtiintsa, Kishinev. 1972; 8: 69-75. Russian.
158. Spassky AA, Yurpalova NM. Cestodes of Anseriformes in Anadyr Lowland. Trudy Helmintologicheskoy Laboratorii Akademii Nauk SSSR. 1966; 17: 183-210. Russian.

159. Spassky AA, Yurpalova NM. Aploparaksis lateralis $\mathrm{n}$. sp. (Cestoda: Hymenolepididae), a new species from shorebirds, and substantiation a subgenus Tanureria, n. subgen. In: Goryachenko F. (Ed.), Parazity zhivotnykh i rasteniy. 1968; 3: 30-7. Russian.

160. Spassky AA, Yurpalova NM. Cestodes of the genus Aploparaksis from shorebirds of Chukotka and their brief zoogeographical analysis. In: Spassky AA, editor. Parazity Pozvonochnyh Zhivotnyk. Kishinev: KartyaMoldovenyaske; 1969. p. 46-73. Russian.

161. Stunkard HW. Platyheminthic parasites of invertebrates. Journal of Parasitology. 1967; 53: 673-82.

162. Stunkard HW. Life-histories and systematics of parasitic flatworms. Systematic Zoology. 1975; 24: 378-85.

163. Szidat L. Vergleichende helminthologische untersuchungen an den Argentinischen crossmowen Larus marinus dominicanus Lichtenstein und Larus ridibundus maculipennis Lichtenstein nebst neuen beobachtungen über die artbildung bei parasiten. Zeitschrift für Parasitenkunde. 1964; 24: 351-414. German.

164. Tolkacheva LM. Cestodes of water birds in Karasukskiye Lakes. In: Ryjikov KM, Folitarek SS, editors. Parasites in ecosystems of North Kulunda. Novosibirsk: Nauka; 1975. p. 100-13. Russian.

165. Tseng Shen. Studies on avian cestodes from China. Part II. Cestodes from Charadriiformes birds. Parasitology. 1933; 24: 500-11.

166. Tubangui M, Masilungan V. Tapeworm parasites of Philippine birds. Philippine Journal of Science. 1937; 62(4): 409-38.

167. Webster JD. A new hymenolepidid tapeworm from the Fox Sparrow. Proceeding Indiana Academy of Science. 1952; 61: 305-7. 
168. Webster JD. Three new forms of Aploparaksis (Cestoda: Hymenolepididae). Transactions of the American Microscopical Society. 1955; 74: 45-50.

169. Yamaguti S. Studies on the helminth fauna of Japan. Part 6. Cestodes of Birds. I. Japanese Journal of Zoology. 1935; 6: 183-232.

170. Yamaguti S. Systema helminthum. II. The cestodes of vertebrates. New York - London; 1959. $860 \mathrm{pp}$.

\section{Svetlana Bondarenko, Vytautas Kontrimavičius}

APLOPARAKSIS CLERC, 1903 (CESTODA: CYCLOPHYLLIDEA, APLOPARAKSIDAE) GENTIES REVIZIJA IR RÜŠIŲ IDENTIFIKACINIS RAKTAS

\section{Santrauka}

Šiame darbe pateikiami pagrindiniai plačiai paplitusių paukščų parazitų Aploparaksis Clerc, 1903 (Cestoda: Cyclophyllidea: Aploparaksidae) genties rūšių taksonominès revizijos rezultatai. Aploparaksis genties revizija pagrịsta plačia literatūros šaltinių apžvalga, įskaitant ir užsienio mokslininkams sunkiai pasiekiamus darbus rusų kalba, taip pat naujausią autorių monografiją (Bondarenko, Kontrimavichus, 2006a). Darbe panaudoti lauko tyrimų metu Palearktikoje (Lietuvoje, europineje ir azijinejje Rusijos dalyse) ir Nearktikoje (Aliaskoje) surinkti individai. Buvo pakartotinai išanalizuota tipinė medžiaga, sukaupta ịvairiuose muziejuose ir institucijose Rusijoje, Europoje, JAV, bei asmeninès kelių mokslininkų kolekcijos. Taksonominès revizijos išvados apèmé suaugusių cestodų morfologinius požymius, metacestodų ontogenezę ir 36 Aploparaksis rūšių gyvenimo ciklus. Iš 102 aprašytų Aploparaksis rūšių buvo patvirtintas 58 rūšių validiškumas. Kiekviena validinès rūšies aprašymo santrauka apima taksonominius sinonimus, galutinių ir tarpinių šeimininkų (jeigu žinomi) sąrašą, geografini paplitimą, cisticerkoido morfologines modifikacijas ir trumpą rūšies diagnozę su pagrindinių charakteristiku iliustracijomis. Pateikiami kiekvienos rūšies muziejuose deponuotų egzempliorių numeriai. Genties viduje nustatytos dvi filogenetinès linijos pagal moteriškų gonadų topografijos skirtumus: nominotipinè pogentė Aploparaksis (Aploparaksis) Clerc, 1903 su išilgai proglotidų ašies išdèstytomis moteriškomis gonadomis ir pogente Aploparaksis (Tanureria) Spassky et Yurpalova, 1968 su moteriškomis gonadomis, išdesstytomis eilute skersai proglotido viduryje. Pateikta pogenčių diagnozè ir joms priskiriamų rūšių identifikacinis raktas, nepatvirtintų (invalidinių) rūšiu sąrašas su trumpais komentarais apie kiekvieną jų. Darbe aptariama taksonominè ontogenezinių požymių vertè ir su Aploparaksis apibūdinimu susijusios problemos.

Raktažodžiai: Aploparaksis (Aploparaksis), Aploparaksis (Tanureria), sinonimai, diagnoze, galutinis šeimininkas, tarpinis šeimininkas, metacestodų modifikacijos 